\title{
QINTA SECCION,
}

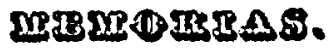

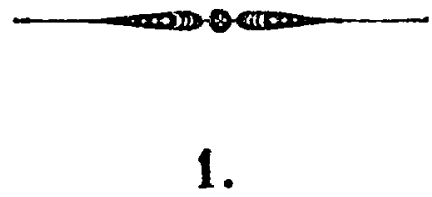

HEMORIA

Whe ortografia americana lelda a la Facultad do Umaniduder el dia 15 de octubre de 1813 por cl Ilcenclado Domingo F. Baxmiento, niembro de la Univerildad de chlle, birector de la Eos enela Normal, del Llceo, ete.

El autor de esta memoria, consagrado largo tiempo a la ensenanza primaria, a tenido ocasion de estudiar prolijamente las irregularidades de la ortografía actual i conocer la insuficiencia de las reglas a qe está sujeta. La dificultad qe tienen los jóvenes de los colejios i escuelas para aprenderla, i los errores qe en este ramo comete el comun de las jentes, con desdoro de su educacion i principios, le an dado en rostro, i se a propuesto desbaratar de un golpe los obstáculos, cimentando la ortografia sobre un principio de qe todos puedan estar al cabo.

Los acendados, los comerciantes, las mujeres no estudian latin, ni pueden andar atisbando años enteros como estan escritas en los libros las palabras: por consiguiente, las reglas de ortografía ge mandan atender al orijen de las voces 1 al uso constante de escribirlas, son para ellos inútiles. No debe aber otra regla qe la pronunciacion.

Mas la pronunciacion del castellano en América no es igual a la de España: i por tanto es preciso establecer una ortografia puramento americana, descartando de nuestro alfabeto las letras qe para 
nosotros no tienen un valor efectivo. Esta es la parte prominente de la memoria.

E aqi su estracto:

(En el siglo XV nuestra ermosa lengua estaba todavia en embrion; era una jerga sin gramática en qe las jentes ilustradas desdeñaban pensar, ablar i escribir; la denominaban idioma del vulgo i creian qe solo el latin era bastante nuble para entrar en sus combinaciones mentales: mas con el trascurso del tiempo, aqel idioma fue echando raices en todas las clases del pueblo español; comenzó a regularizarse, pulirse i ennoblecerse poco a poco, asta ge llegó a ser una lengua independiente i culta. Mientras se 0braba esta revolucion, se principió a escribir libros en castellano aunqe sin ortografía fija, porqe los escritores, a falta de antecedentes, pintaban las palabras a su antojo o segun creian representarlas mejor.

La ortografía empezó a determinarsemas tarde, cuando el mayor número de escritores de nota iba adoptando una manera uniforme de pintar las palabras. Su ejemplo llegó a ser para la jeneralidad una lei qe era indispensable obedecer; pero como todavia estaban dominados por el influjo del latin, la ortografía se resentia de la de éste, $i$ en todas sus dificultades recurrian al orijen como una nave salvadora. El orijen para los sabios, el uso comun para el vulgo; e aqí una regla qe nos a llenado de embarazos en lugar de proporcionarnos facilidades para escribir con propiedad.

Mas el castellano abia sido por largo tiempo un idióma bárbaro; abia sufrido infinitas i sustanciales trasformaciones para pos der llegar a su actual estado, i adquirido peculiaridades en el abla qe debian pintarse en la escritura. Era pues necesario consultar tambien la pronunciacion: $i$ tenemos ya tres reglas qe seguir=el uso, el orijen i la pronunciacion; trinidad tiránica qe a perseguido con el dictado de ignorante al qe no se a sometido a sus antojos.

Tales fueron los principios qe sirvieron de fundamento a la ortografía del castellano; principios qe la ubieran mantenido en un estado bárbaro si la falta absoluta qe por espacio de tres siglos ubo de ombres eminentes qe ilustrasen con sus escritos la intelijencia del pueblo español, no ubiera echo olvidar el orijen, romper la unidad del uso i abrir la puerta o toda clase de reformas. En Francia, Inglaterra i Alemania, sobresalientes injenios i multitud de sabios escritores, sucediéndose unos a otros, an trasmitido asta nuestros tiempos la escritura de la lengua primitiva. La pronunciacion a variado casi completamente; pero la escritura antigua en qe está consignado un inmenso tesoro intelectual, a de- 
bido respetarse por mas chocante qe parezca la contradiccion entre el lenguaje escrito i el ablado. No sucedió lo mismo en España, en donde la inqisicion extinguió en sus ogueras el jérmen del saber, no a abido alli encadenomiento literario qe sostenga la ortogrfía, i por coisiguiente esta se a prestado siempre a las modificaciones del idioma.

Mientras la Real Academia Española gozó de algun inliujo, indicó reformas ortográficas de conocida utilidad; mas al presente en qe aqella corporacion nada dice, nada ace, ni conserva autoridad en el mundo literario, cada cual está facultado para proponer $i$ seguir las reformas qe dicta la conveniencia i la razon

Conociendo esto mismo i la necešidad de acabar de arreglar nuestra ortografía, muchos ombres celosos se an apresurado a presentar proyectos mas o ménos fundados en qe buscan la regularidad i la perfeccion sin acordarse del torpe oríjen i de la rutina:

- Bello i Garcia del Rio, distinguidos americanos, publicaron en Londres diversas obras en qe adoptaban reformas qe tenian por objeto facilitar la silabacion i escritura dando a cada letra su valor $i$ aciendo qe representen su propio sonido. Esta tentativa no fue del todo inútil; alguna de las reformas propuestas, venciendo ábitos arraigados i contrarrestando con la innundacion de libros cscritos con la antigua ortografía, fueron adoptadas por una gran porcion de americanos; i aun mayores ventajas ubieran conseguido si no ubieran dado un mal ejemplo abandonando su sistema en las publicaciones qe posteriormente an echo. Aqellos escritores proponian sostituir la $j$ a la $g$ áspera, la $i$ a la $y$ vocal, la $z$ a la $i$ en las dicciones cuya raiz se escribe con la primera de estas letras, i referir la $r$ suave i la $x$ a la vocal precedente en la division de las sílabas.

El Canónigo Puente publicó tambien en Chile un proyecto en qe reproduciendo algunas indicaciones de Bello i García, propone sostituir la $z$ a la $c$ en las dicciones $c e, c i$.

Pero ni unos ni otros an dado un sistema completo de reformas ortográficas, ni an sabido apreciar un echo del qe dependen esencialmente las dificultades de la ortografía actual, i qe constituye una diferencia fundamental entre el idioma en España $i$ en América =la pronunciacion.

"Cuando el Canónigo Puente sostituia la $z$ a la $c$ excepcional ¿qé regla daba para acer con propiedad la sostitucion? ¿qé regla dá para escribır preziso i no presiso; rezibido i no resibido? ¿El uso comun i constante? Pero su objeto es por el contrario destruir ese uso mismo ${ }_{6}$ El oríjen? Pero debemos suponer qंe veinte millones de americanos $i$ diez de españoles ignoran $\mathrm{i}$ deben 
ignorar siempre el orljen de las palabras castellanas iqé regla pues para el uso de la $z$ ? A no ser qe se suponga ge el qe aya de emplear esta letra conoce todos los casos en qe ántes se eseribia con $c$ excepcional, i en tal caso era completamente inútil acer la tal sustitucion ${ }_{6}$ Por ventura abiamos de guiarnos para el propio i acertado uso de la $z$ en lugar de la $c$, por la pronunciacion qe es la única regla razonable i lejítima de buena ortograffa ? Oh 1 Era aql donde los estaba esperando tanto a. el como a los qe escribieron en Lóndres? Ai sonido $z$ en el idioma ablado en América? No, obsolutamente no. Se a perdido desde Méjico asta Chile i esto es, SS, para siempre jamas. Todos los americanos, cualqiera qe sea la seccion a qe pertenezcan, cualqiera ge sea su clase, su educacion, sus luces, pronuncian s en lugar de $z$ : dicen siensia, asaña, rason etc. etc. Aun ai mas, el sonido de la $s$ española, se a adulterado entre nosotros, suavizándola asta tomar un término medio entre $s i z$ española: i qién no conoce a un español por el solo sonido áspero de la s en estremo retumbante en fin de palabra? ¿qién no conoce en el abla a uno de aqellos peninsulares aun de la plebe misma, cada vez qe ocurre una $z$ o $c e c i$ ? Los americanos son conocidos en España por su pronunciacion distinta, por la falta de los sonidos ce ci i de la z."

Cierto autor, respetable para nosotros qe sin duda a observado esta diferencia, a dicho qe este es un vicio pero talvez no abrá recordado ge los idiomas sufren en sus viajes notables alteraciones, i qe el tiempo deja en ellos estampada su uella, [Llamar viciosos a veinte millones de ombres porqe no pronuncian una letra como los españoles!! ${ }_{6}$ El castellano qe ablamos oi es el mismo qe se ablaba aora cuatrocientos años?

Bello tratando en su Ortolojía de la $b$ i de la $v$ dice: uno el vulgo sino toda clase de jentes $i$ aun la de mas educacion $i$ cultura suele a menudo colocar mal estas dos letras pronunciando, pongo por caso, las palabras vano, tuvo, octava; como si se escribiesen bano, tubn. octaba; i por el contrario bala, ribera, lobo, como si se escribiesen con v.n Pero este echo a sido mal apreciado, porqe en América el sonido $v$ no solo se confunde sino qe se a perdidol Para asegurarnos de esta verdad no tenemos mas qe asistir a los colejios $\mathbf{i}$ acer ablar a los jóvenes qe se encuentren en ellos, asistir a las cámaras donde se allan los ombres mas ilustrados de la nacion, a los sermones i pláticas en qe se ostenta la oratoria sagrada, al teatro, a los estrados de las señoritas, i nunca perciblrémos el sonido $v$ i $z$, a no ser la palabra corazon en qe se pronuncia por moda, $i$ no se crea qe el sonido $v$ se a perdido solo entre los americanos porqe en E8- 
paña a sucedido lu mismo. La Real Academia deplora qe sole los Catalanes, Valencianos i Mallorqinos pronuncien esta letra; *i algunos castellanos cultos" Davila i Alvear dicen "en la - conversacion el sonido de de la $b$ i de la $v$ se confunden ya en toda España.»

El idioma castellano va perdiendo de su antigua rudeza. Los sonidos ins, cons, obs, ip, etc. se dulcifican en el abla cambiándose en is, cos, os, $i$, etc. $i$ la Real Academia a reconocido como lejítima estas alteraciones plebeyas. Esto mismo es, SS., lo qé a sucedido entre nosotros con los sonidos ce, ci i la z. ¿ A qé empenarnos pues en mantener dos caracteres para representar us solo sonido? Purqé no imitar a la misma Academia? ¿Porqe no seguir la marcha qe indica la naturaleza de las cosas? \& porqú el prurito de formarse a fuerza de trabajo una pronunciacion facticia, proponiéndose por regla la tradicion en ménos precio de los echos consumados?

Es inútil pensar en restablecer los sonidos perdid:s. Una experiencia de muchos años adqirida en dos secciones americanas, con los niños en las escuelas primarias, con los adultos en la escuela normal de Santiago me a echo adqirir la conviccion de la inutilidad i desacierto de semejante medida. E luchado por sostener la pronunciacion facticia, extranjera de la $z$ i la $v$ i a fuerza de esqisito trabajo e logrado qe algunos ensayeis con tropiezos en la lectura aqel aprandizaje esteril; pero esto solo en la lectura; la pronunciacion nativa, maternal, constante se revela a cada paso i echa por tierra todo el trabajo del maestro.

«I qé dirémos de la $r$ i la rr? Para cxpresar el sonido llamado suave usamos un casacter solo como en estas palabras:

$$
\text { caracter, palabra, expresar; }
$$

cuando es mas redoblado se usan en lo escrito dos como en

$$
\text { arrayan, chorro, parra. }
$$

Fácil es enseñar a los niños a distinguirlos entre si: son dus sonidos como la $l i$ la $l l$. En ora buena; pero cuando el sonido rr está en principio de palabra se usa en lo escrito del caracter qe representa el sonido $r$; $i$ ya tenemos la confusion para el qe aprende a leer, i el trabajo para el qe enseña. Despues de ciertas partículas componentes, se toma segun nuestra actual ortografía, el earacter del sonido $r$ de qiero, i se le da en lo ablado el valor. 
de $r$. Nuevos tropiezos. El niño de cuatro años a de saber qe en

$$
\text { abrogar, subrepcion, prorogar, }
$$

ai particulas componentes, i qe no dice bro ni bre sino rro i rre, esto es qe la $r$ no es $r$ sino $r$.

Luego ocurren los compuestos

$$
\text { malrotar, boqirubio, maniroto, }
$$

qe el niño a de conocer para pronunciar debidamente; $i$ en seguida

$$
\text { onra, Ulricn, Israel. }
$$

Nueva excepcion.

¿No fuera mas lójico, mas obvio, mas natural escribir

$$
\text { rrudo, rriqeza, onrra, Enrriqe, }
$$

como escribieron los autores ge principiaron en el siglo XV a pintar en caracteres los sonidos qe erian sus oidos, sin consultar para ello el latin ni la etimolojía?

Creo escusado detenerme sobre los inconvenientes i dificultades del uso de la $h$ sin sonido, i de su absoluta inutilidad : nada diré del doble $\mathrm{i}$ contradictorio valor de la $y$ qe es consonante $\mathrm{i}$ vocal a la vez: el uso comun no le conserva ya el valor de $i$ sino en el caso de conjuncion, i pronto desaparecerá esta anomalia. Inútil tambien me parece pararme en la importunidad de conservar la $x$ qe puede i debe resolverse en sus sonidos componentes $c$ i s, $6 g$ i s como pretenden los gramáticos.

Se prepara en Chile la organizacion de un sistema completo de enseñanza popular: entre las cosas qe van a enseñarse a la presente jeneracion infantil $i$ aun a las venideras, es a escribir con propiedad lus palabras; esto es la ortografía. Aora pregunto yo a la Facultad de Umanidades, qe está encargada de impulsar i dirijir esta grande obra, ¿cuál es el sistema qe tiene preparado para acer ge la nacion entera escriba con propiedad sus pensamientos? La ortogralia de la heal Academia de la lengua? - Vamos a analizar si ai una sola regla en ella que pueda darse a la juventud americana.

aPara acerlo sentir mejor qiero estractar brevemente las reglas: 
fundamentales qe da aquella corporacion para el acertado uso de las letras cuya eleccion presenta mayores dificultades.

\section{B.}

«Con $b$ se deben escribir todas las voces qe ta TIEאEM EN sU ORIJEN.

"Aun qe algunas voces ayan de escribirse con $v$ SEgUr SU 0nIJEN, a prevalecido el uso de escribirlas con b.

\section{C.}

Las sílabas ce ci en qe se percibe el sonido mas suate, se escribirán con $c$.

La Academia en esta regla se olvida de los orfjeres $i$ del uso comun $i$ constante, apelando a la pronunciacion, al oido español, ge distingue perfectamente en su idioma ablado el sonido suave $c e, c i$. Un americano no tiene este norte: pronuncia $\&$ donde los españoles acen sonar la c. ¿Qé regla le da entonces para guiarse?

\section{H.}

“Se usará de la $h$ en todas las voces qe La TIENEN EN su oriJEN.)

kTambien en las qe ex so onjuer tenian $f$.

S.

Sobre el uso de esta letra en las conbinaciones se, si, qe entre nosotros se confunden con la de ce, ci, la Academia no establece regla ninguna. ¿ Ni para qé? Un español ace sonar tanto el sonido representado por esta letra, qe ni el ombre rudo de la plebe la confunde con ninguno otro.

v.

Se escriben con esta letra las voces qe LA TIENEN EN SU ORLJEN.

$$
\text { Z. }
$$

La $z$ a de usarse antes de las vocales $a, 0, \|$. 
Antes de la e, $i$, no se usará la $z$ excepto en los casos qe id TIENEN BA SU OBLEN.

Un americano entenderia qe segun esta regla podria escribir con z, zuzurro, zalero, zoterrado, etc. Pero la Academia abla con españoles qe tenian en el lenguaje ablado el sonido representado por aqella letra: para ellos está buena la regla; para los americanos no vale.

Qé cosa tan digna de risa seria ver a uno de los miembros de esa famosa Academia tan amiga del orfjen, rejentando una de esas escuelas primarias, donde "preguntado por un alumno 6 cou qe letra se escribe beber? contestase con tono majistral-Consulte el orfjen: sepa $U$. antes como escribieron una palabra'semejante lus romanos.

Con qé letra se escribe azaña.

Consulte el orijen, vea U. con qe letra lo escribieron los romanos i qe otra so usó en su lugar antiguamente.

¿Como escribo obispo? = Estudie latin i sabrá.

Como vivir $?=$ Sabiendo latin fácil es acertar.

Como $c e ́ f$ iro? = Estudie griego.

Como alferez?=Estudie árabe.

No es, SS., burlarse de la razon, el remitir para casi todos lus - asos a la nacion entera a buscar los orljenes de las palabras? Suponen acaso los académicos qe el qe no sepa latin no tiene necesidad de escribir ordenadamente i por tanto para él no se deben dar reglas de ortogralía?

Gon sobrada razon dicen Garcla i Bello "Uno de los mayores - absurdos ge an podido introducirse en el arte de pintar las pa- labras, es la regla qe nos prescribe deslindar su orijen para sa- ber de qe modo se a de trasladar al papel, como si la escritura no " tratase de representar los sonidos que son, o si debiesemos escriw bir como ablaron nuestros abuelos, dejando probablemente a - nuestros nietos la obligacion de escribir como ablamos nosotros. )

I no se crea qe la regla del uso comun $i$ constante es mas racional qe la del orijen; pues qe agella usupone para un niño el estudio constante de todo el idioma palabra por palabra, ś́laba por sflaba, es decir la observacion asldua, i la retencion prolija, para ye en el momento en qe vaya a escribir una carta, tenga presente ge palabras qe principian por vocal, tienen una $h$ antes, donde a de poner $b$ i dunde $z$; donde $c, z, i$ donde $s "$ iI esto SS. no es pretender un absurdo?

No qeda pues mas regla que la pronunciacion; pero la pronunciacion en América no es la misma qe en España : ningun americano ace distincion entre la $c, z, i s ;$ entre la $b$ i la v; todas estas 
letras no suenan en su boca sino como s i $b$. $\varkappa_{i} Q$ é resulta mientras tanto de esta discordancia entre las reglas i la pronunciacion?

Resulta 1.० Qe de cada mil ombres educados, de encumbrada posicion en la sociedad, los noveciéntos noventa i nueve llevan consigo al baldon de ignorantes desde el momento en qe escriben dos palabras en qe aya una $b, 0 v, c, s, z, h, 0 x$.

2.' Qe todas las señoras americanas, cualqiera qe sea su rango, su educacion, lleven el baldon de ignorantes desde qe dirijan una esqela a su amiga.

3. ${ }^{\circ}$ Qe todos los ombres qe tienen necesidad de escribir, pero qe no an tenido tiempo ni medios para darse a la ciencia cabalística de la ortografía española, llevan para siempre el baldon de ignorantes si ponen por escrito una palabra.

4. $Q$ Q no ai un impresor americano qe pueda componer dos renglones sin cometer veinte faltas.

5. Qe no ai medio umano de enseñar a los niños ortografía, a no ser qe los maestros les digan como la Real Academia, escribid $b$ en las palabras qe la tengan en su orijen.

$V$, en las qe la traen en su orijen.

C, en las qe la traen en su oríjen.

$Z$, en las qe la traen en su orijen.

$\mathrm{S}$, en las ge la traen en su orijen.

Si qeremos librarnos de este pesado yugo impuesto por nuestros antiguos amos, si qeremos pintar nuestras palabras como las pronunciamos; si qeremos; lavarnos de la mancha de bárbaros de ignorantes, por no saber el tira i afloja de la $c$ i de la $s$, de la $b$ i de la $v$ qe no representan nada, olvidemos de una vez i para siempre est. s cuatro letras del alfabeto español: $\mathbf{H}, \mathbf{V}, \mathbf{Z}, \mathbf{X}$.

No usemos la $c$ sino unida a las vocales $a, o, u$.

No usemos de la y sino en las sílabas ya, ye, yi, yo, yu; en los demas casos pongamos $i$.

Se me objetará talvez diciendo qe si formamos una ortografía nueva, discordante con la española, vamos a introducir la anarqía, i acer del castellano escrito un idioma inintelijible para los diversos pueblos qe lo ablan.)

Pero tengamos prosente qe aora menos qe nunca puede estarse a la regla del uso comun i constante, porge la ortografía del castellano, como manifesté al principio, está oi abierta a todas las reformas. No solo García i Bello en Lóndres i el canónigo Puente en Chile, an propuesto innovaciones; en la península misma puJulan los proyectos de cambiar la ortografía qe an rota la unidad del uso. Citaré entre otros, a D. Mariano Vallejos qe, maestro de escuela como yo, a presenciado «el tormento en qe la ortografía 
actual pone la naciente razon de los niños: si SS. es preciso tener a su lado a uno de esos peqeñuelos i verle confundido, anonadado con el ce, ci, ge, gi, i con todos los absurdos de la escritura actual para saber lo qe importa librarnos de una patada de todos los obstáculos i contradicciones. Vallejos a propuesto a la Real Academia eliminar del abecedario español la $v$ como inútil; la $x$ como representante de un sonido compuesto, la $c$ como embarazosa por su doble valor, i la $h$ por no representar sonido alguno. No contento con esto a qerido desembarazar la escritura de los caracteres compuestos como la $r r$ i la ch empleando en lugar de la primera la a llamada por los impresores versalita, i la $x$ en lugar de la segunda.»)

"Qiero poner a la vista de la Facultad el órden en qe se an sucedido estos varios sistemas de ortografía.

\section{La Rral Acadrata.}

Voz, voces, ageno, original, texto, excepcion, excusarse, expresion, exacto, muy, hay, hoy, frayle, traydor; ley, buey, ahora, hacia, ciencia.

\section{Bello I García.}

Voz, vozes, ajena, orijinal, terto, excepcion, excusarse, expresion, mui, hoi, fraile, traidor, lei, buei, ciencia.

\section{Purwte.}

Voz, vozes, ajeno, orijinal, texto, exzepzion, excusarse, expresion, mui, hoi, fraile, traidor, lei, buei, ahora, hazia, zoziedad, zienzia,

\section{Vallejos.}

Voz, akzion, Remo, kamo, xanxo, (chancho) muxaxo (muchacho) lektura, komo, manuskritos, oi, azer.

"Cual de estos sistemas de escritura deberemos seguir? El de la Real Acadernia esta en desuso; el de Bello i García es incompleto, el de Puente inaplicable a nuestro idioma ablado, i el de Vallejos chocante por su brusca separacion de todo antecedente, fuera de qe no salva todas las dificultades qe embarazan a un americano para representar las palabras. Aprovechemosnos, pues, de este momento de anarqia, realizemos en nuestro propio bien lo ge el sehtido comun aconseja, lo qe de mucho tiempo atras se abia revelado a Antonio Nebrija qe sentó por principio «qe no debia aber 
3) Letra qe no tuviese su distinto sonido, ni sonido qe no tuviese su $x$ diferente letra.n

Juzguese, pues aora si se nos podrá tachar de anarqistas; i-si ai necesidad de formar decididamente una ortograffa americana $q e$ represente nuestro idioma ablado.

No qeda ya mas qe tratar de la falta qe nos aria la España dado el caso de un cisma ortográfico.

Para resolver esta dificultad tenemos un medio mui facil. =Entremos a cualqier establecimiento de educacion, i preguntemos par los autores qe sirven de texto en todos los ramos de enseñanza, i sacaremos por resultado qe casi todos son extranjeros, uno qe otro americano, pero ninguno español: entremos a las escuelas de primeras letras, i preguntemos asta por qien se enseña en ellas la doctrina cristiana, i nos responderán por un catecismo frances qe a sido traducido al español. Entremos a nuestras mejores librerías i preguntemos a sus dueños cuales son lus libros de mas crédito qe proporcionan una lectura agradable $i$ útil a la juventud, $i$ nos aran una larga enumeracion en qe qizá no encontramos uno solo orijinal español: preguntémosles de donde surten sus almacenes i nos diran de un pais qe no es la España. Preguntemos en fin a nuestros literatos cuales son los escritores de reputacion en filosoffa, en istoria, en gramática. en ciencias naturales i exactas, en física, en medicina, en obrasd e injenios, en todos los ramos del saber, i nos nombrarán un español entre miles de extranjeros.

¿lin donde está, pues, esa famosa literatura española cuya cision se lamenta? \& En donde está? ¿Cual seria el perjuicio efectivo qe sufririamos si adoptasemos una ortngrafia americana?..... \& Los de qe tendriamos algunos cuantos libros de provecho traducidos en España, e impresos con tres o cuatro diferencias entre la ortografía de estos i la de los qe traduzcamos o demos orijinales nosotros?

Pero adviertase qe nuestras prensas se an ensayado imprimiendo obras de algun mérito; i nas las an dado con mas cuenta, i con mayores ventajas tipográficas qe las traidas de España: téngase presente qe las prensas qe nos surten de libros no estan en aqel pais, qe los traductores mismos salen de su patria a establecer sus casas en otra parte para negociar con su trabajo en nuestros mercados. "Digámosles, pues, la manera como necesitamos el efecto, seguros de qe tendremos los libros como los pidamos, por qe en esto no se trata sino.de acer la mercadoría al gusto dela plaza.

Creo aber probado suficientemente:

1.' Qe no tenemos actualmente un sistema de ortograffa castellano; apoyado oni el uso.comun i constante: 
2. Qe la de la Real Academia es inaplicable para la instruccion de la mayoría de los americanus, por cuanto supone qe debe el qe qiera escribir con propiedad una carta estudiar primero el latin.

3. Qe el idioma ablado de los españoles es distinto del nuestro, i por tanto los caracteres qe en el escrito representan los sonidos, deben ser distintos.

4.0 Qe podemos adoptar sin inconveniente una escritura sencilla i perfecta, $i$ al alcance de todo el mundo.

5.० Qe los libros qe nos vienen impresos de Europa la adoptarian por conveniencia de sus editores.

6.0 Qe dado caso qe se obrase un cisma en la ortografía española, ningun inconveniente tendria esto ni para españoles, ni para americanos.

I en efecto, SS., o yo me alucino mucho, o son verdades estas qe se están palpando.

La Facultad sabrá sin embargo apreciarlas en su justo valor.

\title{
PROYECTO DE ORTOGRAFL AMERICANA.
}

\author{
ALFABETO. \\ a, é, i, o, a, \\ $\begin{array}{rrrrrrrrr}m & \mathbf{r} & \mathbf{s} & \mathbf{t} & \mathbf{d} & \mathbf{l} & \mathbf{c h} & \mathbf{b} & \mathbf{p} \\ \mathrm{me} & \text { re } & \text { se } & \text { te } & \text { de } & \text { le } & \text { che } & \text { be } & \text { pe }^{\prime}\end{array}$

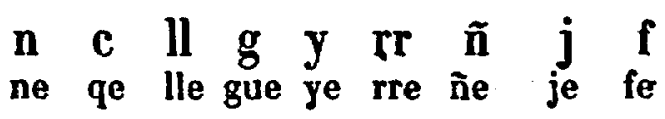

COMBINACIONES،

Todo consonante imprime, sin excepcion, a la rocal qe acompaña, el sonido qe su nombre representa.

Toda consonante colocada entre dos vocales modifica a la vocal subsiguiente; la verdadera division de las silabas; en cuanto - las particulas competentes pertenece al estudio de la gramática. 
Cuando los alumnos de las escuelas primarias ayan aprendido a leer perfectamente el silabario, i primero i segundo libro de lectura, se les enseñará en su leccion separada las

\section{Letras extranjeras}

$$
k, z, v, \mathbf{x}, \mathrm{h}, q u, p h, w:
$$

explicándoles las irregularidades de la ortografía antigua; el uso promiscuo de la $r$ i la $r r$; las aberraciones de la $g$ i la $c$; $i$ el soninido eqivalente a los caracteres conocidos de la $v$ i de la $z$; concluyendo con la explicacion del uso i valores de la $x$ i de la $h$, de todo lo qc se les aran en los tratados de lectura algunas pájinas escritas con la antigua ortografía a fin de qe la conozcan; pero tor do esto despues qe sepan leer perfectamente en los libros escritos con la nuestra.

\section{Para el uso comun de la prensa i manuscritos.}

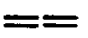

Mientras qe se forman nuevos ábitos de ortografía conviene:

1. No usar jamas la combinaeion ce, ci para expresar nuestro sonido se, si.

2. Mantener el que, qui; pero omitiendo la u muda, i escribiendo solamente $q e, q i$.

3. Qitarde una vez la $u$ muda qe ai en gue, gui; pues no usandose ya en ningun caso ge, gi, poco costará abituar a los adultos a Jeer gerra (guerra) gitarra (guitarra).

No sé si convendria contemporizar todavia con la aberracion de la rr en principio de diccion, cuyo sonido redoblado se expresa con el signo $r$; pero esto se entiende solo en la escritura actual, en manera ninguna en la de los líbros de enseñanza donde cada letra a de tener su valor fijo invariable.

Para los casos en qe la $h$ parece sonar al fin de las esclamaciones, bastaráa acompañar la vocal del signo administrativo, con lo cual qeda suficientemente marcada la aspiracion. 


\section{BXPOSICION}

de 10 trahnjos de lo Uniteraldad de Chlle, desde las primeran reunlones del Conselo 1 de las Facultadew, asta el 23 de setiembre de 1844, ula en qe rué lelda dicha exposicion por el Sceretario Jeneral, en la reunlon en claustro pleno qe, cumpliendo con lo dispnesto por el articulo 28 de la lel orshoica, celebró esta corporacton.

\section{EXMO. SEÑOR.}

\section{SRĨoRES $=$}

El Consejo de la Universidad me a conferido el encargo do cumplir lo dispuesto por el art. 28 de la lei de 19 de noviembre de 1842 qe fundó esta corporacion, dando cuenta de los trabajos qe la an ocupado durante el año transcurrido desde su instalacion solemne. Al desempeñar tan onrrosa comision, solo es de sentir go el cuadro qe va a ofrecerse a nuestros ojos, no abrace una esfera mas vasta de mejoras en los importantes ramos qe estan confiados a los desvelos de la Universidad. justo exijir este reqisito en los trabajos de un cuerpo apénas nacido de ayer, i qe al emprender la.gloriusa carrera a qe está destinado, se encontraba aın sin reglas qe le dirijiesen en su marcha $i$ asegurasen el acierto i regularidad de sus futuras resoluciones? Guando la nueva Universidad celebró sus primeros acuerdos despues de mediado el año próximo pasado, solo existia la lei qe abia delineado esta institucion: faltaba aun completar la obra de organizarla, i determinar los medios de extender su saludable influencia por toda la República. A estos objetos debian necesariamente consagrarse sus primeras tareas.

Apénas se ubo reunido el. Consejo, cuando trató de fijar la promesa qe abia de prestarse porlos miembros universitarios, al tieınpo de su incorporacion. No se creyó suficiente la ordinaria en todos los cuerpos de esta clase, de observar fielmente sus estatutos. Penetrado el Consejo de la mision primordial i santa qe por su propio instituto incumbe a la Universidad, consideró necesario qe todos sus individuos : se: comprometiesen formalmente a cooperar, en cuanto estuviese a sus; alcances, a la educacion moral i.relijiosa del pueblo: qiso qe el lisanjero recuerda del acto en qe se 
abia recibido una condecoracion, premio del talento i del estudio, se ofreciese siempre a la imajinacion acompañado del de ese solemne compromiso, i fuese como una garantia de su cumplimiento.

Los primeros acuerdos de las Facultades fueron contraidos a la designacion de los temas para las memorias ge aspirasen a los premios universitarios en el año presente; i ya se abrá advertido en los qe elijieron el deseo sobresaliente de promover trabajos útiles para el progreso del pais en todos sentidos. La obra en qe mejor se desenvolviese $i$ explicase un plan de misiones para la conversion i civilizacion de los Araucanos; aqella en qe con mas filosofía se expusiesen los defectos del actual sistema probatorio de nuestros juicios i las variaciones qe conviniese introducir en él, señalando los medios de reducirlas a práctica; la mejor memoria sobre una de las enfermedades ge anualmente arrancan mayor número de victimas del seno de nuestra sociedad; la qe se aventajase en exponer los medios de perfeccionar con el cultivo de las Matemáticas i Ciencias Físicas el estado actual de nuestra industria; i últimamente, el trabajo qe sobresaliese en explicar el objeto qe la educacion debe proponerse en las diversas clases de la sociedad chilena, i el modo práctico de conseguirlo, fueron declarados los medios de obtener la palma qe las varias Facultades ofrecian, $i$ los puntos ácia los cuales ellas deseaban llamar la competencia de los talentos.-De sentir es qe los deseos de todas ellas no se ayan visto por esta vez plenamente satisfechos; pero debe animarnos la esperanza de qe abrá ménos desaliento o ménos indiferencia en lo futuro.

El art. 14 de la lei de 19 de noviembre de 1842, abia atribuido al Consejo de la Universidad las facultades señaladas a la Superintendencia de educacion pública creada por la Constitucion, i era preciso ante todas cosas determinar los límites asta donde podian ensancharse esas facultades, i los medios de ponerlas en ejercicin dentro de la esfera de su accion. A esta obra importante contrajo desde luego su atencion preferente el Consejo, $i$ en el Reglaınento qe, convertido en lei mediantela sancion del Supremo Gobierno, a visto ya la luz pública, abrán podido examinarse los resultados de la larga discusion qe ocasionó esa materia. Na solo fueron allí fijados con precision los deberes del Consejo i de sus diversos miembros, sino qe tambien se establecieron secciones para la mas pronta i cumplida expedicion de los trabajos qe estan a su cargo.=Señalóse a sus atribuciones la division correspondiente para qe, sin perjuicio de la libertad de la enseñanza, pudiesen ellas extenderse sobre todos los establecimientos tanta públicos como particulares en qe se la suministra. I comprendióse abímismo aqella jurisdiccion qe debe ejercer una majistratura 
de esta especie sobre todos los empleados en la instruccion pública, a fin de asegurar los adelantamientos i la moralidad de la juventud qe les está encomendada.

Fueron designados en el mismo Reglamento los funciomarios por cuya interposicion abia de ponerse en ejercicio la autoridad del Consejo en las provincias i departamentos, cuidándose en lo posible de qe tan delicados cargos recayesen sobre aqellos individuos qe tanto por sus presuntas luces, como por su puesto en la sociedad, ofreciesen mas garantias de un buen desempeño. Diéronseles reglas para el mismo efecto; i reconociéndose la necesidad de tener informes periódicos exactos sobre la marcha de la educacion en toda la República, se creyó dar mayor importancia a las obligaciones de los Directores de colejios i escuelas a este respecto, determinando en el cuerpo mismo del Reglamento del Consejo las épocas i la forma en qe esas noticias debian remitirse.

Una vez echa obligatoria la observancia de este Reglamento, se cuidó de poncrla cuanto ántes en ejecucion. Distribuyóse, confurme a él, entre varias comisiones del Consejo, la inspeccion de las casas de educacion de esta capital, i pidiéronse datos a los Intendentes acerca de las personas qe en sus respectivas provincias considerasen mas aptas para componer las Juntas e Inspecciones. Todos los nombramientos pertenecientes a las provincias de Coqimbo, Valparaiso, Santiago, Colchagua, Talca, Maule i Valdivia, an tenido ya lugar, i si no a sucedido otro tanto respecto de Atacama, A concagua, Concepcion i Chiloé, es por la insuficiencia de los datos qe de ellas se an recibido, motivo qe a echo necesario el solicitar otros nuevos.

A fin de qe no aya paraje qe carezca de los beneficios de la vijilancia, se a dado tambien la facultad de nombrar sustitutos a los Inspectores de aqellos departamentos qe por su demasiała extension u otras circunstancias, no pudiesen ser debida í frecuentemente visitados.

Concluidos estos trabajos, el qe se presentaba con el earácter de mas urjente era la formacion del Reglamento para la concesion de los grados de bachiller i licenciado en la nueva Universidad. Las Facultades abian trabajado desde el principio, cada una de por sí, su proyecto particular para este objeto. Peru llegado et caso de qe el Consejo los revisase, se encontró qe ellas abian discordado en muchos puntos sustanciales, i qe este inconveniente, complicando los reglamentos del Cuerpo Universitario, iba a destruir aqella congruencia tan necesaria para qe todas sus partes compusiesen un conjunto sencillo i armonioso. Fué por lo mismo indispensable pensar en incorporar esos varios proyectos en uno 
solo qe consultase la ventaja enunciada, i así se izo, elijiendo de cada uno de ellos las disposiciones qe parecieron mas oportunas, i dejando solo subsistir aqellas variedades de qe no podia prescindirse. En esa discusion, ademas, tuvo el Consejo siempre en mira la conciliacion de dos importantes fines: el de facilitar a la juventud estudiosa el acceso a las carreras profesionales, desembarazándolo de toda traba supérflua, i el de asegurar la admision de individuos qe se allasen en posesion de los conocimientos necesarios para desempeñarlas con lucimiento.

Subsecuente a esta obra fué la preparacion de cédulas qe sirviesen para el sorteo de los ramos sobre qe abia de recaer el exámen prévio prevenido por la lei orgánica a fin de obtener los grados en cada Facultad. An sido discutidas i aprobadas ya todas las correspondientes a la Facultad de Leyes i a la de Umanidades, i aun parte de las qe pertenecen a la de Matemáticas i Ciencias Físicas; i la redaccion de las demas se alla encargada a los Decanos respectivos. Publicadas estas cédulas, como se a empezado a acerlo, servirán no poco para qe, así los Directores de colejios, como los jóvenes dedicados a las letras, sepan ol órden i direccion qe deben dar a los estudios.

Hui desde el principio llamó tambien la consideracion del Consejo, la necesidad de ge las Facultades tuviesen estatutos para su réjimen interno i método arreglado de sus trabajos. Pero, ocupado en los proyectos de mas urjencia de qe acabo de acer mérito, tuvo qe contentarse por lo pronto con ir dictando acuerdos especiales qe supliesen esa faita, a medida qe se presentaban los casos qe acian mas patente su necesidad. A este número pertenecen los celebrados sobre el modo de computar la tercera parte de miembros qe la lei orgánica exije para formar claustro en las Facultades, providencia qe izo indispensable la suma dificultad qe abia para reunir dicha tercera parte, con motivo de las ausencias, enfermedades u ocupaciones de muchos de sus individuos. Sin contravenir a la lei, se creyó encontrar un arbitrio para acer mas fáciles i frecuentes esas reuniones, disponiéndose qe, prévia una declaracion del Consejo, se escluyesen del cómputo para ese solo objeto, los miembros universitarios qe se allasen física o moralmente imposibilitados para concurrir. Son tambien de esta clase los espedidos sobre supliencias de los Secretarios de las Facultades $i$ de los Decanos mismos, miéntras falten las personas a qienes la lei señala la incumbencia de representar por estos. Así mismo los qe se dirijen a determinar la forma en qe las Facultades an de acer las elecciones para llenar las vacantes qe dejen en ellas los fallecimientos de sus miembros, i el modo como a de efectuarse la recepcion de los elejidos. Mas, como si la 
formacion de los estatutos se dejase encargada al tiempo ia las providencias parciales qe se fuesen dictando, sería ésta una abra larga i sujeta a numerosos inconvenientes, a sido preciso pensar en emprenderla cuanto ántes. I sin embargo de qe al principio se abia qerido oir sobre la materia las propuestas de las varias Facultades, segun se izo con el proyecto para la concesion de grados, abiéndose notado en éste la mucha diverjencia de opiniones qe mas arriba enuncié, el Consejo a creido despues mas conveniente, a fin de evitar el doble trabajo i pérdida de tiempo qe ocasionaria uniformarlas, encargarse por si mismo de componer un proyecto qe con lijeras modificaciones sirva para todas las Facultades.

Aunqe las obras reglamentarias qe van referidas an debido ocupar casi exclusivamente al Consejo durante el primer año de su instalacion, él no a perdido con todo de vista otros asuntos interesantes. Varias son las medidas tomadas por él para el arreglo, conservacion i mejora de los objetos contenidos en el Museo nacional; varias las qe se an propuesto a fin de ge este establecimiento produxca para la ilustracion del pais toda la utilidad de qe es susceptible.=Solo tocaré de paso su empeñosa solicitud, por qe empiezen desde luego a llevarse en esta capital de un modo regular $i$ uniforme las observaeiones físicas $i$ atmosféricas asta aq́i tan descuidadas, i pasaré a ocuparme de algunas disposiciones especiales con qe a empezado a trabajar en beneficio mas directo de la educacion.

Por recomendacion del Supremo Gobierno, se está actualmente preparando un nuevo plan de sueldos i premios para los profesores del lnstituto Nacional. Defectuoso el qe abia estado vijente asta aora, por cuanto no establece la graduacion necesaria en los premios ni la debida diferencia entre los sueldos asignados a los qe dirijen las clases superiores i los de aqellas qe deben considerarse como de un rango inferior, estaba reclamando con urjencia una reforma. El Consejo se ocupará en su discusion, tan luego como esté concluido el proyecto qe por encargo suyo trabaja uno de sus miembros.

El arreglo actual de las clases de Medicina del mismo Instituto abia descubierto el notable defecto de qe en el progreso de cada curso qedaban algunas de ellas acéfalas, por allarse los profesores ocupados en las otras, de manera qe era necesario encargar a algun alumno distinguido la direccion de las primeras, a fin de no variar el método establecido por el llamamiento interino de un profesor estraño. Para remediar este inconveniente, el Consejo a confiado a una comision de su seno la redaccion de un nuevo plan de arreglo de las referidas clases, en qe, bien sea 
creando nuevos profesores, si se estimase necesario, o bjen combinando la distribucion de aqellas de manera qe puedan ser dirijidas siempre por los actuales, se impida qe en lo futuro vuelva a renovarse esa acefalia.

En cuanto a las escuelas de primeras letras, el Consejo a pensado igualmente encargar a una persona intelijente la formacion de un peqeño Reglamento en qe se establezca el réjimen económico qe en todas las públicas a de plantearse, desterrándose asi la falta de uniformidad qe en la actualidad se advierte entre muchas de las del pais, i tijándose el órden qe mas convenga para la comodidad i aprovechamiento de los alumnos. Tambien se a mandado formar una nómina o lista de todas las escuelas qe se encuentren en el Departamento de Santiago, a fin de distribuir su inspeccion entre los miembros del Consejo i los de la Facultad de Umanidades, a qienes la lei recomienda con tanta particularidad este encargo.

Cerraré esta exposicion de las tareas del Consejo anunciando qe él a acabado, ace poco, de discutir un Reglamento para la Aeademia de Ciencias Sagradas qe, segun el art. 12 de la lei orgánica de la Universidad, debe fundarse en esta capital. El Decano de la Facultad de Teolojía, autor de ese proyecto, a demarcado en él con el mejor acierto las bases de un establecimiento, cuya necesidad acia tiempo se dejaba sentir, i qe promete los mayores beneficios a la Iglesia Chilena. Por medio de la extensa instruccion qe a de darse sobre la práctica de la administracion de los Sacramentos, la del Derecho Eclesiástico administrativo, i la de la enseñanza de la divina palabra, él está destinado a formar un gran número de ilustrados inınistros qe den esplendor a la cátedra del Evanjelio.

En cuanto a los trabajos qe an ocupado a las Facultades durante el año trascurrido, abiendo dado ya cuenta de mucha parte de ellos en la relacion de los del Consejo, solo tendré qe añadir algunos en qe la intervencion de esta autoridad no se a verificado, o por no aber tlegado todavia el caso de ello, o por ser dichos asuntos de la incumbencia privativa de las referidas Facultades. La de Teolojía a recibido en su seno, por eleccion propia, a dos nuevos individuos qe an ocupado dignamente las vacantes qe en ella abian dejado los lamentables fallecimientos de dos de sus miembros. Otras tantas elecciones a echo por igual motivo i con no ménos acierto la de Leyes. Prescindiendo de los exámenes qe tanto esta última Facultad, como la de Medicina, an recibido de personas dedicadas a las carreras profesionales, la segunda se a ocupado tambien en varios otros asuntos de conocida utilidad. Ella, recien fué instalada, trabajó i acordó los estatutos provisorios 
para su réjimen interno, qe asta aora la gobiernan. Atenta a promover el buen servicio del público en los ramos qe la están sometidos, i sabedora de qe muchas personas qe ejercen la flebotomia, carecian de los útiles necesarios para desempeñar cumplidamente su profesion, ordenó i a practicado una visita de todos los instrumentos qe usan los sangradores, señalando plazos a los qe no los tenian completos i en buen estado, para proveerse de los qe les faltaban. Movida del mismo celo, ordenó tambien qe todos los farmacéuticos inscribiesen sus nombres i la fecha de sus respectivos títulos, en un rejistro abierto al efecto en su secretaria. Esta disposicion se jzo extensiva a los nombres de todos los alumnos practicantes qe tuviesen dichos farmacéuticos en sus despachos, debiendo expresarse la fecha en qe ubiesen principiado la práctica. 1 fin de socorrer mejor las necesidades urjentes de la crecida poblacion de la capital, se a establecido el turno de tres boticas qe permanezcan semanalmente abiertas durante la media noche, i a mas de todo lo dicho, la Facultad a practicado las visitas de estos establecimientos, qe son de su obligacion.

Pero la mas fecunda en resultados de sus tareas, i la qe por lo mismo a ocupado su atencion desde el principio, es la formacion de la estadística médica de la República. Sin conocer las enfermedades reinantes en los diversos pueblos, i la influencia de los distintos temperamentos sobre su mayor o menor malignidad, sin una noticia exacta de los numerosos accidentes qe en los varios lugares se conjuran para atacar la salud del ombre, ¿qé progresos seguros podia acer la aplicacion práctica al pais de la ciencia de la Medicina? La Facultad supo apreciar debidamente la necesidad de qe precediesen a sus trabajos semejantes indagaciones, $i$ con el fin de obtenerlas, expidió circulares a todos los profesores de Medicina de las provincias, encargándoles qe conforme a ciertas prevenciones $i$ preguntas qe se les icieron, diesen noticia de la salubridad de los respectivos temperamentos. Pero abiéndose reparado la imposibilidad de conseguir tales datos de todas las provincias, por faltar en varias de ellas profesores recibidos, la Facultad propuso al Supremo Gobierno los arbitrios qe consideró oportunos para vencer esas dificultades. Removidas ya felizmente en su mayor parte, ella a emprendido con actividad la obra del cuadro jeneral de la estadística médica del pais.

Al ablar especialmente de lo relativo a la Facultad de Matemáticas i Ciencias Físicas, seguramente no deberá esperarse el desenvolvimiento de un vasto plan de mejoras en los ramos qe la están encomendados. Faltábanla los recursos para ello. Ceñido i limitado asta aora poco a un circulo tan reducido de jóvenes el estudio de las ciencias exactas, i desconocido casi del todo el de 
las ciencias naturales, $;$ qé otros trabajos abian de ocupar con preferencia a esta Facultad, si no eran los qe tendiesen a combatir esa especie de indiferencia con qe por lo jeneral se a mirado en el pais a esos estudios, aciendo ver los ricos veneros, sin explotar todavia, qe ellos ofrecen a la industria chilena? Tal es el principio qe la a guiado en sus tareas, i su deseo de iniciar a la juventud en la justa apreciacion de aqellas ciencias, abrá podido traslucirse desde la eleccion qe izo del tema para las memorias qe aspirasen a su premio del presente año. Llla a confiado despues a un individuo de su seno la traduccion de un curso de mecánica qe esté al alcance de los alumnos qe no ayan estudiado los ramos superiores de matemáticas. A empezado tambien a preparar por medios sencillos el campo para recibir la simiente destinada a producir los mas saludables frutos en lo succesivo, $i$ advirtiendo la falta de un tratado elemental de Butánica i de un curso de Física experimental ge sirvan para la enseñanza en las clases de estas ciencias, reeien creadas en el Instituto, tiene encargada a dos de sus miembros la redaccion de tan necesarios opúsculos. Independientemente de los trabajos enunciados, debe acerse aql justicia al celo con qe el Decano de esta Facultad a atendido a la conservacion i mejora del Museo Nacional, qe está bajo su inmediata direccion.

La lei orgánica de 19 de noviembre de 812 abia encargado a la Facultad de Umanidades, a mas de promover el cultivo de los diferentes ramos de su instituto, una vijilante i especial contraccion al adelantamiento de la educacion primaria; $i$ puede asegurarse qe ella no a descuidado por un momento durante el año transcurrido la promocion de un objeto tan sagrado. Por el contrario, él a absorvido casi exclusivamente sus tareas. En ella se izo advertir desde sus primeras sesiones la falta de un libro a propósito para la lectura jeneral de las escuelas del pais, en muchas de las cuales se ponian en manos de los alumnos obras o papeles de qe su débil intelijencia ningun otro fruto podia reportar, qe el material aprendizaje de la lectura. En esta virtud, encomendó desde luego a una comision de su seno la redaccion de una obra en qe se tuviese en mira el doble fin de ilustrar el entendimiento de los niños con conocimientos adecuados a su capacidad, e imbuir su corazon desde la edad mas tierna en las máximas de una moral pura i relijiosa. Resultado de esta comision fué qe uno de sus miembros se dedicase a traducir del frances una preciosa obrita titulada: "Vida del Salvador», la cual fué acojida desde su presentacion por la Facultad de Umanidades con el aplauso debido a la feliz eleccion de la materia. Creció esta aprobacion cuando se ubo examinado su estilo claro i sencillo qe la pone al alcance de toda 
clase de intelijencias, i ya no vaciló la Facultad en recomendar a Supremo Gobierno, por conducto del Sr. Rector, su adopcion en todas las escuelas de la República. Por medio de su publicazion, encomendada ya a la prensa, se verá en parte remediada la grave necesidad qe acaba de indicarse, i qe seguirá ocupando la atencion de la Facultad.

Otro servicio importante a creido acer ésta a la instruccion primaria, $i$ aun en jeneral a la literatura, simpliticando, en cuanto era por aora posible sin efectuar una cision arriesgada respecto de los otros pueblos qe ablan el castellano, la antigua ortografia de esta lengua. Ella supo acer justicia a la racionalidad del plan completo de reforma qe le fué sometido por uno de sus miembros; pero mesurada $i$ circunspecta en sus acuerdos, no adoptó sino aqellas variaciones tan obvias sencillas, qe contra ellas ninguna otra razon podia oponerse qe el ábito de la rutina; variaciones qe por otra parte, mas tarde o mas temprano, debian necesariamente introducirse, donde qiera qe se escribiese el español. Asl, sin aventurar un solo paso, en qe despues ubiese podido verse aislada, ella a facilitado no poco el aprendizaje de la lectura, i separado tropiezos qe dificultaban en gran manera el buen desempeño del arte gráfica a la jente menos literata.

Por el mismo autor del plan de reforma de qe acabo de acer mencion, a sido leida aora poco tiempo a la Facultad una memoria sobre el modo de simplificar la enseñanza de la gramática castellana; i la Facultad, qe no a cesado de estar dispuesta a prestar la atencion merecida a los trabajos de este escritor, a qien anima un celo laudable por facilitar la propagacion de la educacion del pueblo, se prepara a entrar en la discusion de esa memoria, tan luego como aya concluido otros trabajos de primor. dial interes qe actualmente la ocupan.

Tambien a emitido su opinion, con motivo de aberla consultado el Supremo Gobierno, sobre una gramática de la lengua española, recien publicada en esta capital, i cuya adopcion para la enseñanza en los colejios públicos abia sido solicitada por su autor.

Pero el trabajo qizá de mas trascendencia qe la Facultad de Umanidades tiene emprendido, es la discusion de un Reglamento para la instruccion primaria en Chile, qe la somietió tambien uno de sus individuos, a ocupado gran número de sus últimas sesiones, i está para concluirse en ella. Mediante esta obra, qe las circunstancias del pais reclamaban ya imperiosamente, debe esperarse qe esa educacion tomará un vuelo qe no se la a conocido asta el dia. A mas del mayor ensanche qe en el proyecto se la dá, señalándola diversos grados, la carrera de preceptor primario recibe toda la importancia posible. Concédense a esta carrera e- 
senciones, asignanse estímulos i premios para los qe se muestren sobresalientes en ella, i en fin, se adoptan las medidas opurtunas para alejar de tan delieados cargos a los individuos qe por su mala conducta o falta de capacidad no inspiren la suficiente confianza. La Facultad trabaja asiduamente para la conclusion de este proyecto, deseosa de qe convertido cuanto ántes en lei, mediante la sancion de las supremas autoridades, empiezen a reportarse los beneficios qe promete su adopcion.

Tales an sido, Señores, las ocupaciones de la Universidad en el curso del año de qe acabo de daros cuenta. Mui alto fué sin duda el fin qe el lejislador se propuso al decretar para todos los años el cumplimiento de este deber en una sesion pública i solemne. Los dias en qe se la celebra recuerdan el objeto con qe se fundó la Nueva Universidad, i este acto mismo será siempre un estímulo para sus tareas. Por descarnados i descoloridos qe aparezcan sus primeros ensayos, es do esperar qe cada año se admirar mas en ellos el vigor i la lozanía de una creciente juventud. Tal vez no distará mucho la época, grato es abrigar esta confianza, en qe pueda presentárseos una pintura vasta i extensa de los beneficios qe esta institucion abrá derramado sobre la República.

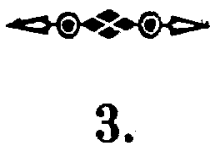

\section{INVBSTIGACIOXES}

sobre la Inmuencla coelal de la conqinta 1 del aintema colontal

le lon enpañoles en chile. Hemorla qe $D . d$. T. Lastarria prewentó a la Uniterafiad en wa aeston jeneral del se de weHembre de 1844 , en cumplimiento del art. 89 de la let de 10 de norlembre de $18 \mathrm{se}$.

INTRODUCCION.

Exmo. Sr. Patrono do la Universidad.

SEÑoRES:

En esta reunion solemne qe la Oniversidad de Chile celebra 
para dar cuenta por primera vez de sus trabajos, ai algo mas qe el simple cumplimiento de una disposicion de sus estatutos: importa ella tambien un verdadero omenaje rendido a la patria en la conmemoracion del gran dia en qe destellaron los primeros lampos de nuestra libertad politica. Destinada a promover el cultiva de la intelijencia i a dirijir el desarrollo de la civilizacion, no puede concurrir de otro modo mas propio a la celebracion del aniversario de la República, qe presentándola un cuadro de sus tareas i proclamando el mérito de los qe consagran sus esfuerzos a tratar las cuestiones de un verdadero interes social qe ella a designado como tema de especulaciones científicas.

Yo e tenido la onrra de ser designado para llenar aora uno de los mas importantes deberes qe la lei impone a esta ilustre corporacion, tal como el de presentar una memoria sobre alguno de los echos notables de la isturia de Chile, apoyandu los pormenores istóricos en documentos auténticos i desenvolviendo su carácter $i$ consecuencias con imparcialidad i verdad (1). Antes de someter, señores, a vuestra consideracion una obra qe está mui léjos de corresponder a mis deseos i de ser digna de vuestra aprobacion, permitidme insinuaros siqiera los principios qe me an guiado al penetrar en el santuario de la ciencia de la umanidad.

La istoria es para los pueblos lo qe es para el ombre su tsperiencia particular: tal como este prosigue su carrera de pefeccion, apelando siempre a sus recuerdos, a las verdades qe le a echo concebir su propia sensibilidad, a las observaciones qe lesujieren los echos qe le rodean desde su infancia, la sociedad cebe igualmente en las diversas épocas de su vida, acudir a la istovia, en qe se alla consignada la experiencia de todo el jénero umano, a ese gran espejo de los tiempos, para iluminarse en sus reflejos. [Cuál seria la suerte de las naciones si se entregaran ciegas n los brazos de la fatalidad, sin curarse de preparar el desarrolo de las leyes morales ge las encaminan irresistiblemente a su verr tura! Su existencia careceria entónces de unidad, no seria otr cosa qe una sucesion de echos aislados, cuyos antecedentes nc entrarian a formar la conciencia de su verdadera posicion ni valdrian para presajiar lo futuro, porqe no se concebiria su enlace natural i necesario; su accion en la carrera de perfeccion se desarrollaria lenta i penosa, al impulso espontáneo de los sucesos, i seria tan varia i tan caprichosa como lo son estos; su educacion estaria encomendada a la ventura i seria necesariamente contradictoria i chocante en sí misma, puesto qe con cada jeneracion desaparecerian para siempre la experiencia i espíritu de las épo-

(1) Art. 28 de la lei de 19 de noviembre de 1342. 
cas, las lecciones qe la umanidad recibe de los echos qe marean el curso de los siglos imprimiéndoles su carácter.

Es cierto qe al contemplar en el inmenso caos de los tiempos un poder superior siempre en accion qe lo regulariza todo, una lei orgánica de la umanidad, siempre constante i demasiado poderosa, a la cual se sujetan los imperios en su prosperidad, en su decadencia $i$ en su ruina; la cual preside a todas las sociedades, sometiéndolas a sus irresistibles preceptos, apresurando el esterminio de las unas i proveyendo a la subsistencia i ventura de las otras; es cierto qe al ver una armonía siempre notable i sabia en esa confusion anárqica qe produce el choqe $i$ dislocacion de los elementos del universo moral, el espíritu se agobia de admiracion i como fatigado abandona el análisis, juzgando no solo excusable sinó tambien lójicanıente necesario creer en la fatalidad, entregarse a ese poder regulador de la creacion, aconfiarse en el b́rden majestuoso de los tiempos i adormecerse arrullado con la esperanza de qe esa potestad qe a sabido pesar $i$ eqilibrar los siglos i los imperios, qe a contado los dias de la vieja Caldea, del Ejipto, de la Fenicia, de Tebas, la da cien puertas, de la eroica Sagunto, de la implacable Roma, sabrá tambien coordinar los pocos instantes qe le an sido reservados al ombre $i$ esos efímeros movimientos qe llenan su duracion (1). Mas el error en qe se funda este raciocinio, al parecer tan lójico, se descubre cuando nos elevamos a contemplar la alteza de la umanidad, cuando nos fijamos en esa libertad de accion de qe la a dotado su creador. La sucesion de causas $\mathrm{i}$ efectos morales qe constituyen el gran código a qe el júnero umano está sometido por su propia naturaleza, no es tan estrictamente fatal, qe se opere sin participacion alguna del ombre; ántes bien la accion de esas causas es enteramente nula si el ombre no la promueve con sus actos. Tiene este una parte tan efectiva en su destino, qe ni su ventura ni su desgracia, son en la mayor parte de los casos otra cosa qe un resultado necesario de sus operaciones, es decir, de su libertad. El ombre piensa con independencia i sus concepciones son siempre el orfjen i fundamento de su voluntad, de manera ge sus actos espontámeos no acen mas qe promover $i$ apresurar el desarrollo de las causas naturales qe an de producir su felicidad i perfeccion o su completa decadencia. El mas sabio i profundo istoriador f lósofo del siglo anterior enseña esta verdad cuando establece qe "la divinidad a impuesto al ombre otros límites qe los qe dependen del tiempo, del lugar i de sus propias facultades. Léjos, di-

(1) Quinet, introduccion a la obra de Herder titulada--Idées sur la philosophie de l'histoire de l'humanité. 
ce, de aber socorrido jamas por medio de prodijios a los qe silfren por sus faltas, ella a dejado siempre desenvolverse el mal en todas sus consecuencias a fin de qe el ombre aprenda a conocerlo.... Tan sencilla es esta lei de la naturaleza, como digna del autor de las cosas i fecunda en consecuencias para la especie umana. Si el ombre debe ser lo qe es i llegar a ser aqello qe puede ser, la espontaneidad es inerente a su naturaleza, i es necesario qe en el centro de acciones libres qe ocupa, no sea turbado en sus obras por ningun accidente estraño. Toda la materia inanimada, todos los seres vivientes qe siguen un instinto ciego, son oi lo qe eran en los primeros dias de la creacion. Dios a establecido al ombre como una divinidad en la tierra, puso en él un principio de actividad personal i por efecto mismo de sus necesidades físicas i morales, le imprimió un movimiento qe no debe terminar jamas. El ombre no podria vivir ni conservarse sino aprendiera a acer uso de su razon; apénas comenzó a servirse de ella, nacieron de todas partes los errores, pero por consecuencia necesaria de sus extravios su razon se ilustró con la experiencia: a medida qe conoció rnejor sus faltas, puso mas empeño en correjirse. Miéntras mas avanzó en su carrera, se desarrolló tambien su umanidad; i es preciso qe la desarrolle todavia, so pena de jemir por muchos siglos bajo el peso de sus errores (1) $)$.

Estas observaciones fundadas rigorosamente en los echos nos prueban demasiado bien qe la umanidad es arto mas noble en su esencia i qe está destinada a fines mas grandiosos qe los qe imajinan aqellos qe la consideran sometida tan estúpidamente como la materia a sus leyes.

Pensar qe las sociedades umanas debieran entregarse pasivas a una lei qe caprichosamente las extingue o engrandece, sin qe ellas puedan influir en manera alguna en su bienestar o en su desgracia, es tan absurdo i peligroso como establecer qe el ombre debe encomendarse a otro poder qe no sea el qe le a dado la naturaleza para labrarse su felicidad, i qe por someterse al $6 r$ den fatal de su destino, debe encadenar en la inercia sus facultades activas.

La sociedad posée pues esa soberanía de juicio i de voluntad qe constituye en el individuo la capacidad de obrar su propio bien i engrandecimiento, miéntras qe no ofenda la justicia. Del mismo modo qe este, ella puede acertar o extraviarse, ora sea apresurando el curso de aquellas causas naturales qe an de traer por

(1) Herder, Idées sur la philosophie de l'histoire de l'humanité, lib. Ir, chap. 1.• 
consecuencia necesaria su perfeccion, ora sea violentando a la misma naturaleza i acarreándose con sus errores la decadencia o una ruina eterna qe no deje mas que el recuerdo de su nombre i de sus vicios.

No puedo negar, con todo, qe la debilidad, la ignorancia u otros accidentes qe no son extraños en la istoria del mundo $i$ qe son difíciles de evitar, suelen obrar las desgracias de los puebles, no obstante qe estos pusieran de su parte todo su esfuerzo en parar el golpe qe los ace sucumbir; pero esta nuisma consideracion nos convence precisamente de la necesidad premiosa qe la sociedad tiene de tomar a su cargo su conservacion i desarrullo, valiéndose no solo de sus propios elementos, sino de las lecciones qe la experiencia le subministre, estudiando a la umanidad en sus virtudes $i$ en sus aberraciones $i$ vicios para sacar de su mismo estudio el preservativo del mal o a lo ménos la manera de neutralizar su accion. il a dónde se alla esa experiencia de las sociedades; en dónde están consignados sus preceptos, sino en la istoria, en ese depósito sagrado de los siglos, en ese tabernáculo qe encierra todo el esplendor de las civilizaciones qe el tiempo a despeñado, toda la sabiduría qe contienen las grandes catástrofes del jénero umano?

La istoria es el oráculo de qe Dios se vale para revelar su sa biduría al mundo; para aconsejar a los pueblos i enseñarlos a procurarse un porvenir venturoso. Si solo la considerais como un simple testimonio de los echos pasados, se comprime el corazon i el excepticismo llega a preocupar la mente, porqe no se divisa entónces mas qe un cuadro de miserias $i$ desastres: la libertad i la justicia mantienen perpetua lucha con el despotismo i la iniqidad i sucumben casi siempre a los redublados golpes de sus adversarios; los imperios mas poderosos i florecientes se conmueven en sus fundamentos $i$ de un instante a otro se ven en el lugar qe ellos ocuparan inmensas ruinas qe asombran a las jeneraciones, atestiguando la debilidad i constante movilidad de las obras del ombre; este vaga por todas partes presıdiendo la destruccion, derramando a torrentes sus lágrimas $i$ su sangre, parece qe corre tras un bien desconocido qe no puede alcanzar sin devorar las entrañas de sus propios ermanos, sin dejar de perecer él mismo bajo el acha exterminadora qe ajita sin cesar contra lo qe le rodea. Empero. cuan de otra manera se nos revela la istoria si la consideramos como la ciencia de los echos; entónces la filosofía nos muestra en medio de esa série interminable de vicisitudes, en qe la umanidad marcha ollando a la umanidad i despeñándose en los abismos qe ella misma zanja con sus manos, una sabiduria profunda qe la experiencia de los siglos a ilustrado; 
ana sabiduria cuyos consejos son infalibles, porqe están apoyados en los sacrosantos preceptos de la lei a qe el omnipotente ajustó la organizacion de ese universo moral. Los pueblos deben penetrar en ese santuario augusto con la antorcha de la filosofía para aprender en él la experiencia qe a de guiarlos; I Uyan ellus $\mathrm{i}$ los ombres qe dirijen sus destinos de esa confianza ciega en el fatalismo, qe los apartaria de la razon. anulando en su oríjen las facultades de qe su naturaleza misma los a dotado para labrarse su dicha!

El jénero umano tiene en su propia esencia la capacidad de su perfeccion, posée los elementos de su ventura i no es dado a otro qe a él la facultad de dirijirse i de promover su desarrollo, porqe las leyes de su organizacion forman una clave qe él solo puede pulsar para acerle producir sonidos armoniosos. A lin de conocer esas leyes $i$ apreciarlas en sus naturales resultados debe abrir el gran libro de su vida en el cual están consignadas con caracteres indelebles: en él verá qe esa constante alternativa de bienes i desgracias en qe a trascurrido los siglos no es ni la obra fatal de un poder ciego qe lo precipita de suceso en suceso, ni la consecuencia inevitable de un capricho, sino un efecto natural de esas leyes, de ese órden de condiciones a qe está sujeto en su naturaleza. Verá tambien qe si en el universo físico se desenvuelven espontáneamente las causas qe le sirven de leyes para producir un resultado necesario, no se opera lo mismo en el universo moral, porqe el ombre tiene el poder de provocar el desarrollo de sus leyes o de evitarlo por medio de la libertad de sus operaciones, segun convenga a su felicidad. i'Tal es la suprema sabiduría de la intelijencia divina! La umanidad no es ni a sido lo qe ella podia rigorosamente ser, atendidas las eircunstancias de lugar i tiempo, sino lo qe a debido ser, atendido el uso qe an echo de esas circunstancias los ombres qe la an dominado i dirijido. Flla tiene una parte activa en la direccion de sus destinos, porqe si asi no fuera, su libertad seria una mentira insultante, su dignidad desapareceria $i$ en el mundo no podria existir idea de la justicia ! (1)

Por esto e dicho, señores, qe la sociedad debe acudir a la istoria a ese precioso depósito de la experiencia, para sacar de ella el preservativo de la desgracia $i$ la luz qe debe guiarla en las tinie-

(1) Talvez podrá calificírseme de osado, porqe me aparto aqí de la base de las brillantes teorias de mas de un jénio de los tiempos modernos, pero pido perdon de esto, si es una falta, i suplico se me per-. mita usar de mi libertad de pensar. Yo no creo en el fatalismo istóri-co, segun lo conciben algunos sabios. 
blas de lo futuro. Solo en ella puede conocer las leyes inmutables de su felicidad o decadencia, en ella solo puede ver los escollos qe tiene qe salvar, las inlluencias del pasado qe pueden detener su progreso, los errores qe deben encaminarla a su ruina, i en fin solo en ella puede estudiar la marcha qe a seguido i el grado i posicion qe ocupa en la escala de las naciones. Los ombres públicos, aqellos a qienes a cabido la dicha de encargarse de la difícil tarea de dirijir un estado, deben por esta razon conocer a fondo la istoria del pueblo cuya ventura se les encomienda. Si la constitucion de una sociedad, en sentir del sabio Sismondi, propiamente ablando no es otra cosa qe su manera de existir, su vida misma, el conjunto de todas sus leyes i de todos sus usos; si tiene por base los antecedentes de la sociedad misma, ¿cómo será posible cunocerla i seguirla en su espiritu sino se conoce filosóficamente la istoria del pueblo? Si el lejislador debe garantir to presente para preparar to qe debe ser $\mathrm{i}$ promover con prudencia las reformas i acelerar el progreso, ¿qién sino la istoria puede guiarle en el espinoso curso qe a de seguir en tan alta empresa? ¿ Cómo descubrir sin esta antorcha de la divinidad cuales son las consecuencias funestas de un antecedente pasado, cuales son las costumbres antisociales qe se perpetuan, cuales las inclinaciones, los vicios qe se arraigan en el corazon del pueblo i qe oponen resistencias insuperables a su perfeccion?

Creo cordialmente qe si los qe aman a su patria $i$ desean de veras su ventura contarán como parte esencial de sus conocimientos en las ciencias sociales el filosófico de la istoria, no cometerian jamas aqellos errores qe detienen la marcha de las sociedades $i$ las acen retroceder muchas veces; porqe o bien son la repeticion de una causa qe en épocas anteriores se a desenvuelto de un modo funesto i lamentable, o bien son propiamente el eco de preocupaciones qe si ubieran sido conocidas en su orijen $i$ naturaleza deberian estar ya aniqiladas $i$ tildadas con la infamia de aqellas qe se consideran como vergonzosas a la umanidad. Tengo arraigada en mi corazon la esperanza de qe el progreso de la civilizacion a de aproximar un tiempo feliz en qe esos errores degradantes no figuren en el catálogo de los actos de ningun pueblo culto, $i$ en qe las leyes ayan llegado a tal grado de períeccion qe castiguen como a verdaderos crıminales a los ombres de mala fé qe se esfuerzen en perpetuarlos. Esta esperanza podrá talvez calificarse de una verdadera utopra, pero a lo ménos no tendrá su fundamento en una de aqellas qinseras engañosas $i$ deslumbrantes qe fascinan la mente i la extravian. IElla es inocente i no tan imposible, como parece, en su realizacion!

Convencido de estas verdades qe la filosofía a elevado a la ca- 
tegoría de dogmas, considero llena de sabia prevision i fecunda en felices consecuencias esa disposicion de los estátutos universitarios qe prescribe a esta ilustre corporacion el deber de presentar periódicamente un estudio sobre la istoria de nuestra patria. Encargado por primera vez este trabajo a un ombre como yo, sin duda el ménos apropósito para realizarlo de una manera onrrosa i satisfactoria, no ofrecerá por cierto ni siqiera en perspectiva el desarrollo qe a de recibir cuando lo ejecuten otros de mis cólegas, mas dignos por sus luces $i$ talentos i con mas tiempo libre, qe el qe yo cuento, para consagrarse a las espinosas investigaciones istóricas i a las serias lucubraciones del filósofo, qe busca la sabiduria al travez de echos remotos e inconexos en la apariencia. No creais, señores, qe al expresarme de esta manera acudo a lo lugares oraturios comunes en qe la vanidad se disfraza muchas veces con las exterioridades de la modestia; no, jesta es la expresion verdadera de lo qe pasa en mi corazon!

Pero olvidemos la persona del qe tiene el onor de dirijiros la palabra en esta ocasion solerune $i$ ocupémonos en el asunto de este discurso.

¿Qé es la istoria de nuestra República? qé provecho puede sacarse de su estudio para la direccion de los negucios en el estado qe actualmente goza? E aquí las cuestiones qe se ofrecen como primurdiales al fijar la consideracion en este asunto de tan vital importancia.

La istoria de Chile es todavía la de un pueblo nuevo qe apenas cuenta tres siglos de una existencia sombría i sin movimiento, es la istoria de una época pasada qe puede el filósofo someter sin gran dificultad a sus investigaciones, i la de una época nueva ge tocamos i nos pertenece porqe es la presente. El órijen e infancia de nuestra sociedad no se escapan a nuestras miradas, no se an perdido todavía en las tinieblas de los tiempos, i para acer su estudio no necesitamos de la crítica qe confronta i rectifica a fin de separar lo falso de lo verdadero, sino de la qe califica i ordena echos conocidos. Dos sun de consiguieute lus puntos culminantes de nuestra istoria, la conqista i la revolucion de la independencia: en estos dos grandes echos pueden refundirse $i$ formularse todos los demas qe an concurrido a consumarlos. La simple narracion de Ios qe forman la istoria del primero de estos sucesos, tal como la an expuesto los escritores, qe, aciendo una crónica descarnada de ellos, an creido escribir la Istoria de Chile, no presenta interes verdadero alguno, a no ser el qe inspira un pueblo bárbaro luchando por defender su independencia de la dominacion de los extranjeros; mas la narracion de la revolucion de la colonia, aunqe echa sin unidad i sin discernimiento flosófico, presenta mayor in- 


\section{$-20 \%-$}

eres, por cuanto en esos echos eroicos, qe tanto alagan nuestro amor nacional, divisamos el fundamento de nuestra libertad politica $\mathrm{i}$ el órijen de una felicidad, qe se a echo sentir tanto mas, cuanto qe está fresca la memoria de los padecimientus causados por el despotismo de qe nos emancipamos: esta es una deduccion filosófica qe todos acemos instintivamente sin qe el istoriador nos encamine.

Sin embargo, los echos qe consumaron la conqista, produciendo por resultado inmediato el establecimiento de la dominacion espanola en Chile, merecen un estudio sério, por cuanto no son tan aislados i tan independientes de nuestra época, qe podamos considerarlos sin influencia alguna en el presente estado de la República. Considerados en su individualidad, tal como lo an echo los istoriadores qe describen la guerra de la conqista, sin atender al enlace necesario qe entre ellos existe, no solo parece qe fueran de una éposa $i$ de una jeneracion independientes $i$ distintas de las nuestras, sino qe tambien es imposible concebir qe su estudio tenga algo de útil i provechoso para la sociedad actual, i es sobre todo difícil mirarlos como datos esperimentales qe envuelvan alguna leccion para lo venidero. Es pues necesario descubrir las relaciones qe ligan tales echos para ver como conspiran todos ellos a la realizacion de un gran acontecimiento de nuestra istoria, la conqista i consiguiente establecimiento del poder español en Chile. Esta manera de considerarlos nos encaminará fácilmente a estudiar ese gran acontecimiento, ese suceso culminante en el cual se compendian i refunden todos los demas particulares qe lo produjeron: entónces podrémos conocer filosóficamente los carácteres de aqella época i su manera de obrar en la sociedad; podrémos apreciar su influencia en el carácter j preocupaciones de esta, i finalmente calcularémos con acierto el poder e intensidad de la reaccion principiada en 810 . Solo así puede sernos útil el estudio de la istoria de la conqista para mirar en su verdadero aspecto nuestra situacion actual $i$ dírijir nuestros negocios públicos de un modo favorable al desarrollo de nuestra felicidad i perfeccion.

Tales son los principios qe me an dirijido en las investigacioues qe tengo el onor de presentaros. E encaminado todos mis esfuerzos a caracterizar la conqista i su inmediato resultado, es decir, el establecimiento del sistema colonial español entre nosotros, para poder desárrollar sus influencias en esta sociedad qe debe su orfjen i su educacion a aqel gran suceso ístórico; pero para esto supongo ya conocida i apreciada la istoria descriptiva de los echos particulares, cuyo encadenamiento forma el cuadro de aqqella época, porqe como dice Sismondí, cántes de inqixir si. 
los echos son ventajosos o perjudiciales, es preciso principiar por reconocerlos.)

Confieso, señores, qe yo abria preferido aceros la descripcion de aqellos sucesos eróicos o episodios brillantes qe nos refiere nuestra istoria, para muver vuestros corazones con el entusiasmo de la gloria o de la admiracion, al ablaros de la cordura de $\mathrm{Co}_{-}$ locolo, de la prudencia i fortaleza de Caupolican, de la pericia i denuedo de Lautaro, de la lijereza i osadia de Painenancu; pero \& qé provecho real abriamos sacado de estos recuerdos alagüeños? iqué utilidad sucial reportariamos de dirijir nuestra atencion a uno de los miembros separados de un gran cuerpo cuyo análisis debe ser completo? Otro tanto i con mas conveniencia, sin duda podria aber efectuado subre cualqiera de los echos importantes de nuestra gloriosa revolucion, pero me a arredrado, os lo confieso, el temor de no ser fiel i completamente imparcial en mis investigaciones. Veo qe, viviendo todavia los érues de aqullas acciones brillantes i los testigos de sus azañas, se contestan i contradicen a cada paso aun los datos mas sencillos qe nos qedan sobre los sucesos influyentes en el densenlace de aqella epopeya sublime; i no me atrevo a pronunciar un fallo qe condene el testimonio de los unus i santifice el de los utros, atizando pasiones qe se allan en sus últimos momentos de existencia. Mi crítica en tal caso seria, sino ofensiva, a lo ménos, pesada e infructuosa, por cuanto no ine creo con la verdadera instruccion i demas circunstancias de dignidad de qe carece un jóven, para elevarse a la altura qe necesita a fin de juzgar echos qe no a visto i qe no a tenido medios de estudiar filosóficamente. Desarrollándose todavia nuestra revolucion, no estamos en el caso de acer su istoria filosófica, sino en el de discutir i acumular datos para trasmitirlus con nuestra opinion $i$ con el resultado de nuestros estudios críticos a otra jeneracíon qe poseerá el verdadero criterio istórico i la necesaria imparcialidad para apreciarlos.

Por estas consideraciones me e determinado a acer mis investigaciones sobre una época de nuestra existencia qe no a sido todavía estudiada, sin embargo de ofrecer un verdadero interes social en. sí misma. No os presento. pues, la narracion de los echos, sino qe me apodero de ellos para trazar la istoria de su influencia en la suciedad a qe pertenecen, cuidando de ser exacto e imparcial en la manera de juzgarlos. Tampoco los encomio ni vitupero ciegamente, si no por lo qe son en su propio caracter $i$ resultados; ni me ciño a descubrir su influjo social, sin permitirme expresar mis opiniones, porqe no pertenezco a aqellos istoriadores qe se limitan a narrar los acontecimientos considerándolos como fatales i absteniéndose de apreciarlos por qe los creen fue- 
ra del alcance de la conciencia umana a causa de su misma fatalidad. En esto sigo el modo de pensar de un autor moderno, qe ablando de los qe escriben la istoria como fatalistas, esclama: "¡Léjos de mi aqel qe qiera materializarla, el qe en las acciones buenas o malas no ve mas qe el reflejo de tal o cual pasado siglo, i qe demasiado consecuente con su sistema envilecedor para la unıanidad, sufoca el grito de su conciencia. Es preciso qe la conciencia se someta a elevados pensamientos morales i filosóficos; es preciso combatir el fanatismo siempre i donde qiera qe se presente, como tambien la sacrílega impiedad, qe es igualmente un fanatismo; es preciso acer la guerra al despotismo, a la iniqidad, a la sedicion, a la indiferencia por la causa pública ! (1)"

Para realizar mi propósito fijo primero el caráctcr de la conqista de Chile i su influencia social; en seguida estudio el sistema colonial español i lo examino en todos sus aspectos para indicar tambien su influjo en la existencia i en todas las rcłaciones de nuestra sociedad. No vereis, señores, en este mal bosqejado cuadro una de aqellas grandes naciones. qe señalan su carrera en el mundo, dejando tras de si una ráfaga luminosa; una de aqellas naciones qe admiran relijiosamente con un orfjen misterioso, una infancia eroica i una virilidad sublime por sus echos; sino un pueblu desgraciado, qe aparece desde sus primeros momentos uncido al carro de un conqistador orgulloso. La ignorancia i la esclavitud protejen su existencia duraute tres siglos, ise esfuerzan en mantenerlo perpetuamente bajo su funesta tutela, inspiráudole preocupaciones i costumbres antisociales qe to preparan desde su infancia a una eterna degradacion. La naturaleza empero, qe no puede soportar por largo tiempo los ultrajes de los ombres, recobra al fin su imperio, ace triunfar la dignidad envilecida $i$ da principio a una era de gloria i de ventura: el pueblo umillado por la esclavitud i la ignorancia vindica sus ollados fueros i se presenta oi en carrera para un porvenir brillante. Tambien suele acontecer qe un matorral descolorido i débil oculta al boldo tierno qe asoma de las entrañas de la tierra, salvándolo con su ramaje de la intemperie i a reces impidiendo su desarrollo con su sombra i su sabia venenosa; pero al fin el árbol jigante se robuştece i se encumbra majestuoso asta ocupar un punto inmenso en el espacio, iergue su altanera cuspide sobre la selva qe le vió crecer $i$ extiende sus ñudosos brazos para protejer los arbulillos qe le circundan. 
caracter de la congista pé Chile i se infuexcia

SOCIAL.

El descubrimiento i conqista del Nuevo Mundo abian robustecido, ácia mediados del siglo XVI, de tal modo en los españoles la conciencia de su valor $i$ de su superiodidad sobre los indíjenas, qe su orgullo i ambicion no reconocian ya límite alguno. El prestijio qe les daba su civilizacion, el poder de sus armas, siempre victoriosas, i el superabundante fruto qe recojian aun de sus masinsignificantes esfuerzos, afianzaban el señorio qe aqellos conqistadores creian aber obtenido de la naturaleza sobre los americanos. Sus uestes se desbordaban en los vastos i risueños campos del continente de Colon i dominaban a sus infelices abitantes, proclamando el derecho funesto de conqista. Los naturales deslumbrados al aspecto de ese pueblo nuevo qe servia a un monarca omniputente i ge se decia propagador de la relijion del Dios del universo, se sentian desfallecidos i se entregaban a poca costa al dominio de tan poderosos señores. Ellos eran tenidos por incapaces de llegar a ser sociables i de comprender los principios de la relijion del salvador, eran conciderados como una especie de ombres marcados por la naturaleza con el sello de la servidumbre (1); i si alguna vez se levantó en el Nuevo Munđo una voz en defensa del pueblo desventurado qe con tanta imprudencia se ultrajaba, el estrépito de las batallas, el brillo de las azañas, las ilusiones de la codicia i del poder aogaron los ecos de esa voz i robustecieron aqel funesto desprecio, aciendo ge el español se considerase como el suberano natural de la América i se gozara en el esplendor de esta realidad, sin temer obstáculos ni contratiempos.

Los conqistadores abian impuesto ya su lei a los vastos i poderosos imperins de Méjico i el Perú i centenares de pueblos amerianos eran víctimas desus depredaciones i de los mentidos derechos qe sobre ellos se arrogaban, cuando, créyendose estrechos en los límites del mundo qe acababan de sojuzgar, qisieron extender su poder a las tribus remotas qe ocupaban los fecundos valles de nuestro Chile. Mas desdesus primeras incursiones en este pais, recibieron un desengaño terribleque irritó i mortificós su orgullo en alto 
grado: encontraron aql ombres de bronce, en cuyos pechos rebotaban las balas de sus cañones, i los cuales miraban con impávida serenidad el tren militar del pueblo osado qe pretendia arrebatarles su libertad; allaron resistencias qe pusieron a raya su conqista i qe demandaban mas valor, mas constancia i mas recursos qe los qe abian necesitado para acerse dueños de todo el continente avasallado. En Chile no existia el indijena envilecido i pusilánime a qien bastaba engañar para vencer, mandar para esclavizar, sino un pueblo altanero i valiente, qe léjos de correr a ocultarse en los bosqes, esperaba a su enemigo en campo abierto, porqe se sonrreiz conla seguridad de vencerle ide acerle sentir todo el peso de su valor.

Esta circunstancia tan notable influyó precisamente para diversificar la conqista d: Chile de la del resto de la América. Los españoles concibieron desde luego la necesidad en qe se allaban de multiplicar sus elementos bélicos i de proceder con mas prudencia i enerjia qe asta entónces, porqe debian combatir con un pueblo valeroso i ostinado, qe contaba numerosos tercios i qe acia la guerra con mas órden i disposicion qe los bárbaros qe acababan de vencer. Desde los primeros encuentros principiaron a irritarse sus ánimos i si asta esa época la crueldad con qe acostumbraban tratar a los vencidos era efecto del desprecio qe les inspiraban, en aidelante lo fué del despecho e indignacion qe ocasionaba la resístencia. Ese desprecio se convirtió insensiblemente en un odio verdadero, el cual subia de punto a medida qe el araucano redoblaba su fiereza en defensa de su independencia; odio qe mui pronto llegó a ser profundo i a đominar en todo las relaciones de ámbos pueblos contendientes.

La guerra de la conqista, sin dejar de ser desigual i sobrado onerosa i desfavorable al pueblo indijena, demandaba a los conqistadores tales costos i tanta contraccion, qe absor vió completamente sus cuidados i llamó con preferencia su atencion. De su éxito dependia la existencia de las colonias qe en el territorio conqistado se fundaban, porqe los ejércitos araucanos, infatigables en su propósito de rechazar a los españoles, llevaban la desvastacion asta el recinto mismo de las poblaciones ent qe se albergaban las fanilias de sus enemigos. Valdivia funda sucesivamente a Santiago, la Serena i Concepcion, i estas ciudades, informes todavía, se ven amenazadas $i$ combatidas, en los primeros dias de su existencia, por millares de indíjenas, qe nada respetan en sil $t$ errible furia : la primera de ellas salva incendiada i demolida en gran parte, a merced de una batalla sangrienta qe se da dentro de sus mismos muros (1); la

(1) Quiroga, en su Compendio Istórico. 
segunda es destruida asta en sus cimientos, a los cinco años de fundada, i Concepcion es arrasada dos veces, sepultando en sus escombros asta la esperanza de su restablecimiento. Los españoles abandonan entóncees la idea de regularizar la administracion de sus pueblos i se apresuran a fortificarse en el territorio qe podian ocupar sus armas: establecen colonais militares, plazas dearmas i bastiones en todos los puntos ventajosos; pero estas prevenciones no acen mas qe redublar el furor de los araucanos, los cuales cada momento mas soberbios con sus triunfos, no perdonan medio de destruccion i aniqilan el poder español en donde qiera qe se les presenta. La guerra se encarniza i se ace interminable, sucédense unas a otras las batallas i en cada una de ellas se destruye de tal manera a la ueste vencida, qe parece terminada para siempre la contienda; pero los ejércitos se suceden a los ejércitos, la sangre qe se prodiga fecunda el valor i multiplica los combatientes; ya no ai medio ilfíito de ataqe, se fomenta el espionaje, no se desprecia estratajema por reprobado ge parezca, se emplean la astucia i la traicion; la lealtad i la jenerosidad uyen de esta lucha sin ejemplu; los prisioneros se esclavizan o se inmolan en expiacion del crímen de sus ermanos, los jenerales mismos se acen morir en un patíbulo, en medio de la algazara sarcástica de los vencedores.

Cortés habia consumado en pocos años la conqista de Méjico, Pizarro asesina alevosamente al Inca del Perú i se ace dueño de sus vastos dominios, sin verter mas sangre que la de los inocentes vasallos de aquel monarca ; pero Valdivia es en Chile la víctima desventurada de la rabia de los araucanos, i los conqistadores qe le suceden, apesar de su admirable denuedo ide sus eroicos esfuerzos, no pueden domar al pueblo infatigable que los rechaza i sucumben tambien bajo la maza poderosa del salvaje. Firme la España en su propósito, reemplaza los guerroros i los anima a qe sostengan sin recompensa $i$ sin esperanzas siqiera una guerra prolongada, la mas cruel $i$ obstinada de que pueden presentar ejemplo los anales del mundo. Mas la desvastacion los fatiga, la resistencia los exaspera $i$ al fin consienten en reconocer la superioridad de los araucanos sobre los demas pueblos de la America, prefieren establecerse en la porcion de terreno qe aqellos les dejan libres i se dedican a la consolidacion de sus colonias, pero sin arrimar las armas, porqe necesitan estar combatiendo $i$ siempre dispuestos a defender ta posesion de este pais, qe les cuesta mas sangre i mas dinero qe el resto de sus conqistas en el Nuevo Nundo (1). 
Acia el año de 1622 propone Felipe III la paz en una carta dirijida al congreso de los nobles de Arauco. Esta era la primera vez qe el orgulloso monarca del mas extenso i potente imperio de la tierra, se umillaba asta dirijirse personalmente a un pueblo de la desventurada América, reconociendo explícitamente su soberania e independencia e inzitándolo a celebrar un tratado, en qe se sellara para siempre la amistad de los dos estados i se puslera término a una guerra desoladora, cuyo estrépito asombrába a la Europa entera. I no era esta una inconsecuencia en el sistema de congrista adoptado por la Espaũa, sino un reconocimiento solemne del estéril resultado de su empeño i un omenaje debi do a la nacion qe abia tenido la superioridad de mantener su independencia, defendiéndola en batallas ordenadas $i$ rechazando con lealtad i valor al conqistador, tal como to ace un pueblo organizado qe sabe apreciar su dignidad. El rei católico qeria la paz, proponiendo qe el Biobio sirviera de barrera al uno $i$ al otro estado, de modo qe a ninguno le fuese lícito traspasarla con ejército; qe ámbos se entregaran recíprocamente los desertores i qe los misioneros españoles tuvieran la libertad de predicar el evanjelio a los infieles. Pero la paz no se realizó, sin embargo de aber sido propuesta sobre tan moderadas condiciones ide aber sido aceptada por los araucanos, porqe muchos de los jefes del ejército conqistador tenian todavía interes en la continuacion de las ostilidades, $i$ abrigando la esperanza de medrar, se aprovecharon para paliar sus perniciosos intentos de las dificultades qe presentó la extradicion qe el Toqi araucano exijia, como condicion previa, de varias de sus mujeres que se abian refujiadn en la colonia española (1). La guerra se encendió nuevamente con redoblado furor i continuó con los mismos desastres i depredaciones qe asta entónces.

Mas este accidente no alteró en nada la necesidad qe la España tenia de procurarse un avenimiento para conservar sus posesiones. El cansancio i aun los temores empezaban a reempla zar el denuedo tenaz desplegado en los primeros años de la conqista, i los colonos deseaban la paz porqe no podian soportar la insegnridad i la perpetua alarma en qe vivian a causa de las ostilidades. Emprendiéronse nuevas negociaciones, con mejor éxito, i despues de algunos contratiempos, se ajustó en $\mathbf{1 6 4 1}$ un pacto de amistad, qe llenaba las aspiraciones i el cual fué celebrado con solemnidades qe testimoniaban el regocijo causado por un acontecimiento de tan señalada importancia.

Empero los araucanos no desmayarun jamas de su furor, sino

(1) Molina, Istoria de Chile. 
por momentos; la guerra interrumpia siempre las treguas qe los españoles obtenian de $\tan$ tenaces enemigos, i la colonia nu se libertaba sino por intervalos mas o ménos prolongados de los desastres i de la destruccion. Los tratados de paz qe se ajustaban, no sin gran dilijencia de parte de los colonos, eran solo verdaderas suspensiones de armas, qe ostensiblemente no tenian otro objeto qe el de recobrarse ámbos belijerantes de sus pérdidas. para volver a atacarse con redoblado encono. De esta manera la guerra era perpetua i siempre demasiado costosa, por cuanto no se respetaba principio alguno ni se adoptaban medios que templaran sus rigores. La España mantenia un ejército avanzado a la frontera $i$ aprovechaba las oportunidades de atacar, i iss araucanos permanecian sobre las armas $i$ practicaban frecuentes incursiones al pais de las colonias, arrazándolo sin piedad i cometiendo todo jénero de depredaciones. Los esfuerzos que alguna vez se icieron para regularizar la guerra fueron vanos, i ántes bien continuaron en progreso la traicion i el vandalaje i subió de grado el odio de ámbas naciones.

Por este lijero bosqejo en qe e tratado de caracterizar la conqista vereis, señores, qe las colonias españolas en Chile se establecieron i se desarrollaron en medio de la alarma i de los con . tratiempos qe ocasionaba una guerra tan obstinada, cruel i dificultosa. La guerra meció la cuna de las primeras jeneracionès de nuestra sociedad i protejió su precaria existencia; la guerra fué el único desvelo de este pueblo desde susprimeros momentos de vida, o diré mejor, fué la expresion única i verdadera de su modo de ser. El perpetuo peligro de qe se allaba amenazado fué endureciendo paulatinamente su carácter, aciéndolo triste i sombrio i asta cierto punto enervando su natural actividad, porqe teniendo siempre al frente un enemigo poderoso, qe acechaba el momento oportuno de aniqilarlo i qe no le dejaba seguridad ni qietud para organizarse, solo cuidó de defender su existencia a fuerza de sangre i de contrastes. A cada paso tenia qe lamentar una desgracia o celebrar un triunfo, qe nuevos acontecimientos venian a convertir en ilusorio i estéril. Las batallas eran el único arbitrio de defensa a qe podia apelar, los incendios, la desolacion de los campos i ciudades i la pérdida de un ejército eran los únicos sucesos qe lo ajitaban i qe venian con frecuencia a patentizarle su desventura i a sufocar en su mente toda ilusion risueña, toda esperanza de un porvenir mas feliz. Las comodidades de la vida doméstica, los beneficios de la industria, los goces de la sociedall le eran desconocidos, o por lo ménos eran bienes de un órden secundario, en cuya pnsesion no pensaba, porqe no tenia tranqilidad. De modo pues qe este pueblo a qa oi pertenecemos, 
ántes de ser industrioso fué guerrero i ántes de saborear placer alguno de los qe constituyen la dicha del ombre social, soportó las angustias de una guerra eterna i funesta. La ciega sumision del soldado i la dura esclavitud de un umillante vasallaje, la desesperacion de las derrotas sangrientas i el terror de un poder doméstico qe sojuzgaba asta las conciencias apagaron i casi estinguieron en su alma los jérmenes de todo sentimiento social $\mathbf{i}$ de toda aspiracion brillante: era un pueblo dormido qe solo despertaba para batallar, un pueblo qe no estaba organizado mas qe para la guerra.

Los españoles se abian risto preeisados a separarse de su sistema, porqe sus fuerzas solas no eran suficientes para resistir a la omnipotencia de los araucanos. Abian comunicado su espfritu militar a sus colonias chilenas i contaban en ellas el refuerzo qe abian menester para defenderlas.

Amediados del siglo pasado las plazas de armas del reino de Chile eran las únicas en toda la América del sur qe tenian la ventaja de poder servirse de las milicias qe formaban los vecinos de las poblaciones i campañas inmediatas, en estado de tomar las armas, porqe era crecido el número de estas milicias i podian juntarse fácilmente por el buen órden de su disciplina (1). En 1777 se dí́ a estos cuerpos mas perfecta organizacion i en 1792, sin contar el copiosísimo número de milicias urbanas, ascendian las provinciales regladas a 15,856 plazas en servicio expedito (2). Por estos datos se deja ver qe los conqistadores, abandonando sus recelos, se consagraron a establecer en Chile cuerpos de milicias mejor reglados $i$ disciplinados qe los qe tenian en su propio pais.

Mas tarde veremos como influye i se desarrolla el espiritu de disciplina militar en los eriollos i de qe manera a contribuido a fijar asta cierto punto uno de sus mas sobresalientes rasgos característicos.

(1) Noticias Secretas de América por D. J. Juan D. A. de Elloa.

(2) Molina, Istoria do Chile, cap. XI, lib. IV. 
II.

IDEA DEL SISTEka COLONIAL RSPÃ̃uL.

No solamente el caráeter de la conqista modificó la existencia de esta nacion; ai todavia otro elemento qe sin duda a ejercido un influju mas poderoso en su jenio e inclinaciones sociales, tak es el sistema colonial adoptado por la España.

Sabido es qe los españoles conqistaron la América, empapando en sangre su suelo, no para colonizarla, sino para apoderarse de los metales preciosos qe tan abundantemente producia. Torrentes de aventureros se desbordaban sobre el Nuevo Mundo predominados por la esperanza de reunir injentes riqezas a poca custa i dirijian a este solo objeto su actividad, sin omitir arbitrio ni viulencia alguna qe les fuese necesario emplear para obtenerlo. Al fin la realidad fué aciendo decaer la ikusion, i convencidos lus conqistadures por su propia experiencia de qe no era tan excesiva, como se ponderaba, la fecundidad de las minas americanas, fueron abandonando sus arrojadas especulaciones i dedicándose paulatinamente a las empresas de agricultura i comercio. Pero este nuevo jiro de sus aspiraciones no dió de sí cuanto podia, atendidas las ventajas qe brinda el suelo amerieano, porqe no tenian gusto ni intelijencia para explutar este nuevo venero de riqeza, i su gobierno, por otra parte, con su absurdo sistema industrial, estancaba en su orijen todos los bienes qe podian prometerse.

Al establecer la España sus colonias en América, trasplantó a ellas todos los vicios de su absurdo sistema de gobierno, vicios qe se multiplicaron infinitamente por causas qe tenian su orijen en el sistema mismo.

Las colonias chilenas fueron divididas en provincias, qe, gobernadas por un jefe subalterno, tenian un cabildo de rejidores perpetuos i de alcaldes, los cuales administraban justicia i eran elejidos por aqellos entre la primera nobleza. Estaban estos cuerpos sujetos a un presidente, gobernador i capitan jeneral del reino, nombrado por la corte de España i dependiente de ella, excepto en los casos de guerra, en qe reconocia la preeminencia del Virrei del Perú asta cierto punto. Aqel alto funcionario de Chile, como representante de su majestad católica, era el supremo administrador de las colonias; como capitan jeneral, era el jefe del ejército $i$ tenia bajo su potestad a los tres grandes oficiales del reino, qe eran el maestre de campo, el sarjento mayor i el comisario, i tambien a los gobernadores militores de las cuatro pla- 
zas maritimas de Valparaiso, Valdivia, Chiloé i Juan Fernandez: como presidente i gobernador tenia el poder jurisdiccional i presidia a la real audiencia i a los tribunales de acienda, de cruzadas, de tierras vacantes i comercio, qe eran los encargados de la administracion de justicia en los diversos ramos a qe estaban destinados. La real audiencia juzgaba en última instancia todas las causas civiles i criminales de alguna importancia i se componia de un rejente, un fiscal o procurador rejio, un protector de indios $i$ de varios oidores, todos nombrados i pagados con gruesos estipendios por el rei. Este tribunal supremo fue establecido en 1567 i encargado del mando político i militar de las colonias; en 1575 fue suprimido, porqe los defectos de su constitucion i de su mandato multiplicaban a eada paso los embarazos en la administracion; i despues de treinta i cuatro años, en 1609, fue restablecido con solo el encargo de administrar justicia en los términos indicados (1).

E aq́ una idea del poder administrativo de las colonias chilenas: todo él estaba reducido a una rigorosa unidad, imperaba de un modo absoluto i dependia únicamente del rei, qe no solo se consideraba soberano, sino tambien dueño de sus vasallos americanos $\mathbf{i}$ de todas las tierras qe abia conqistado en el Nuevo Mundo, cuyo dominio abia sido santificado por una bula del papa.

El monarca español gobernaba las Américas por medio de un consejo supremo, qe llamaba de Indias, donde se consideraba presente su augusta i sacrosanta majestad, i del cual emanaban todas las leyes, todos los reglamentos, todas las medidas, ora fuesen jenerales o locales, qe era necesario dictar para rejir unas colonias qe se allaban a la distancia de millares de leguas i cu. yo carácter $i$ circunstancias no eran ni siqiera remotamente cono. cidos. Lo mas digno de notarse con relacion al gobierno de América es qe a cualqiera resolucion qe se expidiese por el órgano de la corona o por el del consejo de Indias, con tal qe fuese sobre algun asunto americano, se daba todo el vigor de una lei verdadera, aunqe no tuviese los caracteres de tal. El número de estas resoluriones no tenia término, porqe se expedian arbitrariamente i sin concierto, i llegó a aumentarse tan prodijiosamente qe ubo tiempo en qe la lejislacion positiva colonial formaba un verdadero laberinto. Era propiamente un acinamiento, sin plan ni sistetema; de cédulas, reales órdenes, cartas, provisiones, ordenanzas, instrucciones, autos de gobierno $i$ otra infinidad de despachos incoerentes, eterojéneos $\mathrm{i}$ absurdos, todos los cuales, por la di-

(1) Molina, Istoria de Chile. 
lacion i distancia de unas provincias a otras, no abian llegado si -3 qiera a noticia de los vasallos americanos (1). Diferentes tentativas se icieron para recopilar i ordenar todas estas disposiciones' durante el siglo XVI i tambien en el XVII, asta qe bajo el reinado Cárlos II, en 1680, se formó la célebre Recopilacion do Indias, en cuatro gruesos volúmenes, tomando en cuenta los muchos ensayos i proyectos de codificacion qe ántes se abian formado, sin el menor fruto (2).

Estas leyes an sido consideradas por algunos partidarios del sistema español como las mas justas, propias i adaptables a la prosperidad de las colonias americanas, deduciendo de esta peregrina opinion los mas fuertes cargos contra la independencia de la América (3). Entre nosotros mismos no falta qien participe asta cierto punto de esta creencia, i qien sostenga la sabiduria de tan monstruosa lejislacion, qe por desgracia i no sé porqe aberracion inexplicable se concidera vijente en una república soberana e independiente, qe dejó de necesitar las leyes colonales desde el momento qe proclamó su independencia. Por eso creo, señores, mui propio de este lugar acer un exámen, aunge lijero, de los vicios qe elevan este código al mas alto grado de imperfeccion.

Bastaria al efecto echar una ojeada a sus antecedentes, a los elementos qe se tomaron para componer este verdadero mosaico de variedad infinita, sin ajuste ni armonía en sus proporciones. Casi todas esas leyes abian sido expedidas por sujestiontes de los empleados qe la España mantenia en sus colonias; todas eran por lo jeneral referentes a circunstancias especiales, $i$ las qe no tenian este carácter, se dirijian a reglamentar la administracion independientemente de las modificaciones a qe podia dar lugar tanto la arbitrariedad de los mandatarios, cuanto las ocurrencias varias e imprevistas qe influian en el manejo de los negocios.

(1) Lei qe declara la autoridad de la Recopilacion de Indias.

(2) Id. Id.

(3) El observador de cóndres, en su número de enero de 1820, decia : a ninguna nacion a tratado a los pueblos en sus establecimientos ultramarinos con mas umanidad i blandura qe la nacion española. Los escritores mas juiciosos lo reconocen i entre ellos el mismo baron do Humboldt. "La blandure do las leyes ospanolas, dice 61 , comparadas con las del codigo negro do ta mayor parte de tas otras maciones, os insegablo."

Tambien abria podido el Observador citar la opinion de Rohertson, qe alucinado con la apariencia de las leyes de Indias intentó en algunos pasajes de su Istoria de América vindicar a los monarcas de Espnña $i$ disculpar su despotismo. 
I Los males qe nacian de estas causas, sin tomar en cuenta lo tiránico i absurdo de tales resoluciones, no se remediaron, pues, con aber reducido a un solo cuerpo sin doctrina ni sistema tantas i tan contradictorias disposiciones, sino qe por el contrario qedaron subsistentes i se multiplicaron asta lo infinito, porqe siempre continuó la práctica de expedir cédulas i reales órdenes para cada caso qe se ofrecia, sin tomar otros antecedentes qe los qe sujerian las pasiones mas viles a los qe tenian interes en qe se expidiesen. Mui pronto excedió el número de estas nuevas resoluciones a las recopiladas i se aumentaron tambien las contradicciones asta el punto de no ser posible distinguir las leyes vijentes de las que abian sido revocadas en todo o en parte. La ciencia de la lejislacion colonial española llegó a ser por este motivo una verdadera nigromancia, en suyos arcanos solo estaban iniciados los qe tenian bastante osadia para acer imperar su capricho o su interes, invocando en su apoyo una lei de Indias u otra cédula cualquiera de su majestad,

Por esto dice un observador qe " los juicios civiles i criminales, los asuntos de renta $\mathbf{i}$ los de policía sufrian tanta variedad $\mathbf{i}$ oposicion de decretos $i$ reales órdenes, qe nose allaba un fundamento en qe estribar ningun reclamo, qeja o solicitud. Todo nacia, dependia $i$ terminaba en la arbitrariedad de los ministros de la corte i de los jefes de América. Ellos siempre se daban entre sí la mano i las determinaciones eran mútuamente sostenidas. segun convenia a su ideas de gobernar despóticamente.... Al mismo tiempo, en cualqiera paso qe se diese en el gobierno de América se abia de encontrar siempre el obstáculo de alguno de los muchos fueros i privilejios de las corporaciones i profesores qe abundaban en ella (1). ") Todos estos vicios tenian su orijen i su mejor apoyo en las leyes mismas $i$ multiplicaban los embarazos qe acian mas oscura i absurda su aplicacion.

Esto en cuanto a la forma de la lejilacion. Su fondo era de otro carácter: un solo pensamiento rapital dominaba todas las resoluciones de la corte ide los mandatarios de las colonias, tal era el de mantener siempre a la América en una ciega dependenncia de la España, para sacar de su posesion todas las ventajas posibles. Bajo este punto de vista, la metrópuli tenia un sistema, un espíritu qe daba unidad a todas sus resoluciones i qe santificaba todos los arbitrios qe se le presentaban por inicuos i reprobados qe fuesen. El Nuevo Mundo era para ella una mina riqúsima qe debia explotar, aprovechándose de sus frutos, aun cuando fuer desvastándola $i$ sin curarse de acerla productiva para 
lo futuro. Con este propósito abia sujetado a los indijenas a la mas umillante i grosera servidumbre, declarándolos esclavos en ciertos casos i disfrazando en otros la esclavitud con un finjido $i$ sarcástico respeto a su libertad, sin embargo de sumeterlus a la mita, al repartimiento i a las demas cargas con qe los oprimia. Las leyes sobre impuestos estaban justamente calculadas para beneficiar las arcas reales, i sacar de las colonias todos los tesoros qe fuese posible, aun a costa de los mismos elementos de produccion. El comercio estaba monopolizado en beneficio de la misma corte, la industria fabril i la agricultura envueltas en mil trabas i gravadas con tantas gabelas, qe aparecia palmariamente. la intencion de estancarlas en su jérmen e impedir su desarrollo. El sistema financiero de la España abia sido trasportado en esta lejislacion a la América, con su verdadero carácter exclusivo i sin mas diferencia qe la de estar recargado de otros vicios i absurdos qe facilitaban a la corte los medios je obstruir i de cortar las vias del progreso en las colonias. La comunicacion i comercio con las potencias estranjeras se vedaban de tal modo qe no solo era un crímen mantener estas relaciones, sino qe tambien se apelaba a la mentida soberanía de los mares para mandar a los gobernadores, como se ordenó por una real cédula de 1692, "qe tratasen como enemiga toda embarcacion estranjera qe surcase los mares de América sin licencia de la corte, aunqe fuera aliada la nacion a qe correspondia.)

Las leyes i resoluciones dictadas para impedir el desenvolvimiento in telectual de los americanos atestiguan por otra parte la decidida intencion de mantenerlos en la mas brutal i degradante ignorancia, para acerles doblar perpetuamente la cerviz al yugo de su soberano natural $i$ de todos los mandatarios qe derivaban de él su autoridad. Estaba con severas penas proibido el vender e imprimir en América libros de ninguna clase, aun los devocionarios, $i$ para su introduccion se reqeria una licencia del consejo de Indias o de otra autortdad igualmente empeñada en no consensentir qe penetrase en el Nuevo Mundo la luz de la intelijencia (1). Las pocas universidades i colejios qe establecian i reglamentaban las leyes estaban perfectamente destinadas a separar al ombre de la verdadera ciencia; eran valiéndome de la feliz expresion de un americano, " un monumento de imbecilidad.) Sujetos enteramente estos establecimientos a un réjimen monacal, se abandonaba con exqisito cuidado la educacion intelectual i moral, se procuraba solo formar ministros del culto i cuando mas abogados o médicos, pero a todos se les submistraban falsas doc- 
triuas, se les acostumbraba a las sutilezas ia las mas estrav agantes teorías i se les acia adoptar por fórmula de esta ciencia inútil $i$ de sus errores un estilo grosero $i$ altisonante. De este modo conlseguia la corte pormedio de sus leyes i resoluciones extraviar la intelijencia $\mathrm{i}$ divertir a los Americanos con estudios antisuciales qe precisamente debian conducirlos al fin deseado de ofuscarles la razon para qe no viesen " en el rei de España mas qe a su señor absoluto, qe no conocia superior ni freno alguno sobre la tierra, cuyo poder se derivaba del mismo Dios, para la ejecucion de sus designios, cuya persona era sagrada $i$ ante cuya presencia todos debian temblar (1)."

Al acer este rápido exámen de la lejislacion de las colonias, con el fin de investigar su influeneia social, debo dar empero un testimonio de la imparcialidad de mi jułcio, declarando qe el tedio qe causa esta monstruosa recopilacion, descansa a veces con la lectura de algunas disposiciones qe prueban sentimientos piadosos en sus autores. Pero nada mas qe sentimientos piadosos, porqe en ellas, así como en las demas, no se descubre el tino ni Ja prevision qe resultan del análisis filosófico de los echos, cuyas prendas son los mas sobresalientes caracteres de la sabiduria de un lejislador. Con efecto, se rejistran varias leyes destinadas a regularizar el servicio de los naturales en las mitas, encomiendas i repartimientos a qe se les sujetaba, i otras qe tasaban sus tributos de manera qe no les fuese sobrado gravosa su exaccion. Las ai especialmente destinadas a protejer la libertad de los indios chilenos i a concederles mas privilejios i exenciones qe a los de las demas colunias, sin duda con el objeto de atraerlos $i$ de cortar la guerra por medio de estas medidas suaves i protectoras (2). E aqi las leyes qe sin duda an fascinado la mente de los defensores de esta lejislacion, si es qe ablan de buena fé, i de las cuales an deducido sus argumentos para probar su sabiduria i encomiar la proteecion qe la España dispensaba a sus colonias; pero recordando lo qe llevo expuesto sobre el espíritu de este código i acerca del sistema de la metrópoli, a qé otra cosa eran estas leyes sino cuando mas la expresion de un buen deseo aislado o talvez un arbitrio con qe se qeria disfrazar las intenciones $i$ opiniones qe abrigaba una corte corrompida i retrógrada sobre los degradados abitantes del Nuevo Mundo? Como qiera qe se piense, esas leyes protecteras eran una excepcion muda i sin efecto,

(1) Funes, Ensayo de la istsria civil del Paraguai, Buenos Airesi Tucuman, citado por el Repertorio Americano en este punto.

(2) Véanse las leyes del tít. 16 i algunas del tít. $2^{\circ}$, lib, 6.• de Indias. 
una letra muerta desde el momento qe su ejecucion, su interpretacion $i$ asta el derecho de modificarlas estaban en manos de los mandatarios de las colonias.

La metrópoli puso siempre el mas prolijo empeño en nombrar para todos los oficios $i$ empleos de las colonias americanas a individuos nacidos en España, siendo esta la principal cualidad qe reqeria, aun cuando el candidato careciera de las aptitudes i capacidad profesional qe la naturaleza del empleo exijia; de manera qe no era extraño ver investido de la majistratura judicial a qien por sus antecedentes faltaban aun los primeros rudimentos de la jurisprudencia i frecuentemente condecorados con altos puestos militares a los qe jamas abian empuñado una espada e ignoraban asta los preliminares de la táctica. Los americanos estaban rigorosanente excluidos de todo cargo público, a no ser los consejiles, qe por no tener onores, renta ni atribuciones eran mirados por los peninsulares como gravámenes qe solo debian soportar los colonos. Tan ciegamente se observaba esta práctica insultante qe llegaron a borrarse los escrúpulos qe la corte podia tener para erijirla en principio legal, i se avanzó a discutir en pleno Consejo de Indias, si bien qedó indecisa, la cuestion de si se excluiria de derecho a los americanos de los empleos públicos, declarándolos incapaces de desempeñar oficios onrrosos en las colonias. La istoria prueba ademas con millares de echos qe la España fue siempre consecuente a este propósito: de ciento sesenta virreyes qe ubo en América, solo culatro se numeran qe no fueron españoles, i entre mas de seis cientos presidentes i capitanes jenerales, solo se contaban catorce en la misma excepcion (1).

La istoria tambien nos patentiza qe todos los empleados qe la España mandaba a la América se convertian en déspotas verdaderos, qe ejercian la mas arbitraria autoridad para procurarse su particular beneficio: $i$ este era propiamente un resultado natural de la posicion en qe se les colocaba. La prolongada distancia en qe estaban las colonias de su metrópoli $i$ las dificultades con qe se acia entónces la comunieacion de ámbos continentes, les facilitaba la impunidad de sus crímenes; la doctrina qe sancionaba como justo i lejitimo todo acto de atrocidad ejercido sobre los colonos, les servia de suficiente excusa; la vaguedad, latitud i complicacion de la lejislacion de Irndias, les facilitaba una autoridad inmensa, absoluta, i siempre un apoyo legal, cuando les era necesario coonestar un abuso o lejitimar una usurpacion; la necesidad, en fin, qe la metrópoli tenia de asentir i deferir en todo 
a los informes de estos mandatarios, era un recurso brillante a qe apelaban para sancionar con la voluntad de la corona cuanto. podia convenir a sus niras i a sus intereses. Por esto, cada empleado superior era un rei absoluto i cada uno de los subalternos defendia sino con la aprobacion, con la tolerancia o el ejemplo de aqellos sus arbitrariedades i dilapidaciones. De aqí los frecuentes choqes escandalosos entre ellos mismos, las venganzas ruidosas i el uso de todos los resortes de influjo i de poder a qe se acudia para acer triunfar un capricho o dejar sin castigo al gun crimen funesto. De aqf nacia tambien la insuficiencia i nulidad de las leyes mismas: la lei de la América colonial era solo la voluntad de sus mandatarios inmediatos. Si se qiere ver una demostracion palmaria de este echo incuestionable, véase lo qe D. Jorje Juan i D. Antonio de Ulloa esponen en sus Noticias secretas a la corte de España, sobre el estado miserable i degradante, sobre la corrupcion i dislocacion social espantosa a qe abian llegado las colonias por la conducta de sus gobernantes. ácia la mitad del último sigło. En la relacion fiel $\mathrm{i}$ eircunstanciada qe acen estos sabios e imparciales observadores se patentiza qe todas las medidas benéficas de la metrópoli fracasaban en el formidable escollo qe les oponia la grosera arbitrariedad e insolente despotismo de los gobrernantes i empleados coloniales, i esto en todos los ramos de la administracion.

El servicio de la marinade guerra i mercante en los mares de la América meridional no se sujetaba a métodoni formalidades, sino qe dependia enterämente del capricho e intereses particulares de los qe lo acian, por muchas $i$ buenas qe fuesen las medidas qe para su arreglo abia expedido la metrópoli. Las plazas de armas se allaban en un completo abandono, i sus jefes entregados al lucro qe podia proporcionarles su posesion. Siendo, como era absoluta su autoridad, abuisaban en la misma proporcion qe los demas funcionarios, utilizándose asta de los situados qe recibjan para su guarnicion $i$ tiranizando por este $i$ otros medios a los qe tenian la desgracia de vivir brajo su de pendencia, como especialmente lo practicaban los gobernadores de la plaza de Valdivia (1).

El comercio, a pesar de estar sujeto a un perfecto monopolio, cuyas restricciones $i$ exclusiones estaban calculadas para reservarlo exclusivamente a la España, i sin embargo de estâr gravado con pesados impuestos en favor del real erario, era efectivamente un elemento de ganancia para los qe estaban encargados de mantener este monopolio i de asegurar sus productos a la 
real acienda, i al mismo tiempo un elemento de corrupcion para todos los qe se consagraban a su ejercicio porqe se acostumbraban al fraude i a los manejos ilícitos, ge los empleados sancionaban con su ejemplo. Estos patrocinaban el contrabando i cifraban enél la principal ventaja de su empleo, i si alguna vez apelaban a las leyes para impedir un fraude era o porqe así les convenia para evitarse un denuncio, o porqe necesitaban vengarse de algun enemigo, valiéndose de su misma autoridad. Exponiendo los autores citados las graves faltas de este ramo de la administracion, dicen qe seria mui regular imajinarse qe aqel paraje donde los virreyes tenian su asiento, deberia estar exento de estos desórdenes, a causa de su inmediata presencia, o qe a lo ménosfuese menor el fraude en el comercio, a vista de tánto tribunal, de tantos ministros, de tantos jueces i tan crecido número de guardas como abia para impedirlo, pero qe justamente llegaba aq́ este abuso a su mayor punto. Los efectos de contrabando se introducian en la mitad del dia sin el menor recelo $i$ custodiados por los mismos guardias, astadejarlos en lugar seguro i libres del peligro qe correrian en poder de sus dueños. Otro tanto se aciá con los efectos de lícito comercio, para libertarlos del pago de derechos qe les correspondia, i con este objeto se reputaban lejítimos los fraudes mas escandalosos tanto en el comercio terrestre como en el maritimo. De esta manera, c ni la conciencia, ni el temor, ni el reconocimicnto de verse estos empleados mantenidos por el soberano con salarios mui crecidos les servian de estímulo para celar en lo qe era de su obligacion ( 1 ). )

I si esto se practicaba por los funcionarios qe se allaban por la naturaleza de su empleo, bajo una inspeccion mas inmediata de la corte i por consiguiente mas apremiados a llenar con pureza i exactitud sus obligaciones, ¿qé sucederia con los qé ejercian una autoridad independiente, con aqellos cuyos actos no interesaban a la metrópoli de un modo tan directo? No es de mi propósito exponer aq́ las arbitrariedades espantosas, los abusos sin cuento, los absurdos, los crímenes qe ejecutaban i patrocinaban a cada paso los gobernadores, los inilitares, los majistrados judiciales $i$ asta los sacerdotes mismos encargados de la direccion i cuidado espiritual de los pueblos ( 2 ) ; solo debo sujetarme a la istoria para considerar en abstracto los echos i deducir de su exámen como una lójica conclusion qe toda iniqidad dejaba de serlo desde el momento ge se practicaba en los america- 
nos: qe, consid́derados estos como esclavos i como ombres de una naturaleza $i$ condicion diversas de la naturaleza $i$ condicion de los europeos, estaban sujetos solamente a las leyes qe el capricho i el interes de estos les imponian. La circunstancia de nacer americano sellaba la desgracia del colono, cualqiera qe fuese el orfjen de su estirpe. Con semejante preocupacion erijida en dogma, con el poder absoluto qe ejercian los mandatarios, ¿serian de alguna utilidad, producirian efecto alguno saludable esas leyes protectoras qe solia dictar la corte como para descansar del fiero despostismo qe ejercia sobre los americanos?

Con efecto, a pesar de esas leyes, sufrian los indijenas todo el peso de la preocupacion qe los condenaba $i$ todo el rigor de los mandatarios, qe, en lugar de protejerlos, se creian autorizados para tiranizárlos. "Tal es el asunto qe empezamos a tratar, dicen los sabios autores ge e citado, al trazar el cuadro del miserable estado en qe se allaban los naturales, cuando visitaron la América, qe no puede entrar en él el discurso sin qedar el ánimo movido a compasion, ni es posible detenerse a pensar en él, sin dejar de llorar con lástima la miserable, infeliz i des venturada suerte de una nacion, qe sin otro delito qe el de la simplicidad, ni mas motivo qe el de una ignorancia natural, a venido a ser esclava $i$ de una esclavitud tan opresiva qe comparadamente pueden llamarse dichosos aqellos africanos a qienes la fuerza $i$ razon de colonias an condenado a la opresion servil; la suerte; de estos es en widiada con justa razon por aqellos qe se llaman libres i qe los reyes an recomendado tanto para qe sean mirados como tales, pues es mucho peor su estado, sujecion i miserias qe las de aqellos (1) $\mathrm{D}$.

Este rasgo expresivo i sincero me aorra la angustiosa tarea de-describir la espantosa i miserable condicion a qe se vieron reducidos los indijenas por sus conqistadores $i$ me ofrece un testimonio irrecusable en favor de la verdad qe me propuse demostrar.

Resulta de todas estas observaciones una proposicion notable, tal es la de qe las costumbres de los españoles en América neutralizaban de tal modo el efecto de las leyes qe se dictaban para su gobierno, qe acian enteramente inútiles los beneficios de las buenas $i$ mas perniciosa la influencia de las malas. Cuando por accidentes qe no son raros en la istoria del jénero umano aparece una lei sabia o bienechora en el código de un pueblo

(1) Noticias secretas, cap. $1 .{ }^{\circ}$ part. 2.॰ 
corrompido, el poder de las malas costumbres la inutiliza, la corrompe tambien a por lo ménos la reduce a una disposicion sin vıgor, qe si bien se venera, no se cumple, porqe está en oposicion con los intereses inmorales i los vicios de los qe debieran ejecutarla u obedecerla. Tal a sucedido en la América española durante el coloniaje, pero como la corrupciun no abia subido al mismo grado en todas las colonias, to eran iguales en todas ellas los desórdenes ni las trasgresiones legales en la administracion. Es indudable qe la codicia era el elemento corruptor qe abia depravado a los conqistadores asta el punto de acerlos perder todo sentimiento de umanidad $i$ de relijion: a los vicios qe el atraso de la época les abia inspirado con la educacion, a las falsas doctrinas i preocupaciones antisociales qe una corte estúpida fomentaba en ellos como el mejor apoyo de su estabilidad, se agregaban pues los deseos inmorales, los intereses criminales i la corrupcion qe en sus corazones despertaba la codicia. De modo qe en donde no tenia esta pasion fuertes estímulos, no se multipliacaban los desórdenes ni los crímenes, ni el despotismo era tan feroz. En Chile, por ejemplo, sin embargo de qe todos los españoles tenian las mismas preocupaciones i la misma corrupcion de costumbres qe los del Perú, no eran tan innumerables los abusos i trasgreciones de las leyes, ni tan espantosa la tiranía como en este pais, por razon de no existir en nuestro suelo los alicientes qe despertaban en aqel mas vivamente la codicia. Las producciones agrícolas i los metales preciosos no se esplotaban aqí con la facilidad i exuberancia qe en el pais de los Incas, i por eso no presenta nuestra istoria los grandes crímenes qe la tiranía aguijoneada por la sed del oro obraba en los descendientes de aqellos monarcas desgraciados: nuestro comercio, si así puede llamarse el qe teniamos, no ofrecia bastante campo al fraude $i$ al contrabando, como en el Perú, porqe no era abundante i rico, porqe no abia capitalistas especuladores ni podia aberlos par razon del monopolio; i e aq́ tambien el motivo porqe no se nota aqella desmoralizacion excesiva qe se advierte en los empleados qe en otras colonias precisamente estaban encargados de la ejecucion de las leyes de acienda. Así sucesivamente en todos los ramos administrativos la corrupcion no se ostentaba entre nosotros con la misma deformidad, sin embargo de qe en la administracion de nuestra colonia existian los mismos vicios, las mismas preocupaciones i en fin los mismos elementos destructores $i$ antisociales qe en el gobierno de las otras.

Esta diferencia empero es mui secundaria i nada influye en favor de Chile en la época a qe me refiero, porçe es una diferen- 
cia qe si bien está en los efectos inmediatos, no existé en las causas qe la produjeron. Estas, al contrario, obran siempre de un mismo modo, influyendo en la sociedad i minándola en sus cimientos. Lo veremos.

\author{
$=$ \\ III. \\ Consideraciones JeNerales sober ta iNfluekcia det \\ sistema colonial ex Ceile.
}

Para acer algunas investigaciones filosóficas acerca de la influencia social qe a ejercido en nuestro pueblo el sistema qe acabo de diseñar, tenemos qe principiar por reconocer un fenómeno istórico peculiar de la América, el cual no se descubre tan a las claras en los paises colonizados por las naciones antiguas $i$ modernas, aunqe parezca propio de la condicion de todos ellos. La istoria de la lejislacion universal nos muestra patentemente qe las leyes adoptadas por la sociedades umanas an sido siempre inspiradas por sus respectivas costumbres, o diré mejor, an sido una exprecion, una formula verdadera de los ábitos i sentimientos de los pueblos, porqe cuando éstos an llagado a punto de necesitar reglas formales para su réjimen, ya tenian costumbres i prácticas, i no an echo mas qe formularlas, con mas o ménos modificaciones, con mas o ménos acierto, para gobernarse i reglamentar su vida social. Mas no a sucedido de la misma manera en la América toda: aq́ la lei a precedido a la costumbre: el pueblo no estaba formado aun, i ya existian leyes qe organizaban su administracion i definian sus relaciones, no guardando por cierto conformidad a las circunstancias i accidentes qe abian de desarrollarse con él, porqe eran imprevistas, sino consultando en todo los intereses, las opiniones, las preocupaciones $i$ aun los gustos de los ombres encargados de echar los fundamentos de la nueva sociedad.

Al raciocinar sobre este punto importante, pormas qe desée circunscribirme a nuestra patria, no me sera posible dejar de referirme a toda la América española, porqe en la época del coloniaje, cuya istoria examino, eramos un mismo pueblo todos los americanos, un pueblo omojéneo, qe partia de un mismo orijen i se encaminaba a un mismo fin: la denominacion de 
extranjeros no era entónces una voz de nuestro lenguaje de ermanos. Así me será pues permitido sentar como base del razonamiento qe tanto en Chile como en las demas colonias ispano americanas no a precedido a la formacion de la sociedad la organizacion de la familia, sino el interes de los conqistadores, consultado por leyes circunstanciales bajo todas las formas posibles. Bajo el auspicio de estas leyes nació la sociedad americana i de ellas recibió su fisonomia social i su educacion.

Las costumbres de un pueblo son su vida misma, su ser intelectual i meral, son sus ábitos, usos, gustos e inclinaciones: nacen con el ombre i se desarrollan espontáneamente con él, pero se modifican al mismo tiempo por mil circunstancias extrañas, ni mas ni ménos qe una planta cuyo jérmen prende en el ceno de la tierra i se desenvuelve bajo el influjo del clima i del cultivo. Una de esas circunstancias es la lei, $i$ sin duda es tambien la qe mas poderosamente influye en la direccion de las costumbres de un pueblo: su carácter augusto i sacrosanto, la omnipotencia de la autoridad qe la promulga $i$ su estabilidad aumentan su prestijio i fortifican su influeneia en la vida social de tal modo qe a sus dictados imperiosos se amoldan las inclinaciones $i$ toman la direccion qe ella les imprime, modificándose a veces o bien estinguiéndose del todo cuando el lejislador las a tildado con el signo de la ignominia. \& Tanta es la enerjía con qe las leyes obran sobre la nuoralidad de las sociedades umanas!

Pero si tratamos de investigar el influjo qe en nuestra nacionalidad tuvo el sistema colonial, es indispensable qe nos fijemos siqiera de paso en un antecedente de gran inportancia, tal es la situacion política i moral de la España en la época en ge principió la conqista de Chile i por consiguiente la existencia de esta sociedad ge oi vemos adulta.

La Europa acababa de conmoverse en sus cimientos i de variar sus faces política i relijiosa, porqe la reforma obrada por la revolucion alemana de 1517 se abia encarnado en el corazon de los pueblos i, propagándose con la furia de una tempestad, abia destruido la omnipotencia temporal de la santa sede $i$ amenazaba desqiciar los tronos de Inglaterra, de Francia i de España, a cuyo amparo se acojian las doctrinas añejas, para empezar la reaccion destinada a defender el poder absoluto de los reyes.

La España qe asta poco ántes abia sido el asilo, o mejor diré, la patria de las instituciones liberales, fue en aqel tiempo el escollo formidable en qe fracasaron los esfuerzos de la reforma relijiosa. Me abstengo de apreciar las ventajas espirituales qe este accidente istórico produjo para la Península, porqe no es de mi 
propósito ablar sobre la relijion, sino solamente de la influencia política qe pudo aber ejercido en la sociedad aqel movimiento de irritacion i de conflagracion jeneral. No penetraron pues en la patria de nuestros padres los beneficios de la revolucion, sino qe por el contrario los rechazó con enerjía, defendiendo la integridad de la monstruosa dictadura del trono i de la iglesia, qe desde entónces principió a preparar la ruina en qe aqella nacion desgraciada se a visto sumida posteriormente. Su rei entónces era el poderoso Cárlos V, emperador de Alemania, guerrero infatigable, monarca ambicioso i sin duda el mas ábil político de su tiempo. Este príncipe, qe se sobreponia al papa al mismo tiempo qe combatia la reforma, abia destruido en España las libertades i fueros de los pueblos, centralizando en sus manos todos los poderes: por una parte deslumbraba a sus súbditos con el brillo de sus triunfos militares $i$ por otra se aprovechaba de su ardiente celo relijioso para convertirlo en una ciega $i$ estúpida intolerancia. Bajo su amparo se abia extendido asta no tener límites el poder de la inqisicion, porqe asl le convenia para alejar de su dominios toda doctrina, todo sentimiento qe opusiese resistencia a su plan ambicioso de dominarlo todo. Este triBunal monstruoso qe a nadie respondia de sus operaciones, qe todo lo sometía a su juicio, qe protejia con el misterio a los acusadores, qe atormentaba a sus victimas $i$ al fin las consumia en una oguera, abia ya principiado en esta época su funesta carrera de desvastacion. Persiguiendolo todo i ollando con su planta ponzoñosa lo qe se oponia a sus dictados, aletargaba las facultades activas de la España, apagaba su espíritu i no dejaba a sus ijos mas qe la ignorancia i el fanatismo para apoyar en ellos su trono i el de los reyes, sus favorecedores. "La guerra continua con los moros, dice un sesudo escritor refiriéndose a este mismo período de la istoria, naturalmente abia preparado a los españoles para el mas feroz fanatismo. Las ideas de onor $i$ de nobleza se abian unido intimamente a las de fe $\mathrm{i}$ relijion. Desdoro e infamia eran inseparables de cualqiera creencia qe no fuese la de los españoles. Los moros por su enemistad nacional, i los judios por la envidia qe causaban sus riqezas $i$ el odio qe sus usuras producian, eran mirados como enemigos declarados del cielo i baldon de la umanidad. Bien pronto se valieron los primeros inqisidores de esta ocasion para confundir con moros i judios a todos cuantos se atrevian a dudar cualqier punto de sus doctrinas i sistemas; i la Erética pravedad, se ví́ con igual poder de contaminar la sangre, qe el descender de cualqiera de las dos razas malditas. Infeliz desde entónces el español qe qisiere usar de su propia razon: aun mas in- 
feliz el ge se atreviese a manifestar la ignorancia $i$ estolidez de los qe tomaban por su cuenta el pensar por todos los demaslo

Bugun esto es fácil concebir qe el español no servia entónces mas qe a su monarca i a Dios, a la manera qe la inqisicion los servia: la causa de la civilizacion era para él la causa de los réprobos; su conciencia i su corazon estaban educados tan solo para despreciar i combatir a los infieles, para perseguir a los erejes, qe eran todos aqellos qe proclamaban alguna verdad no sancionada por el santo oficio, i para llevar el estandarte del fanatismo, no la cruz del Redentor, a donde su amo les mandaba tremolar sus leones. Arrebatado por su ardiente amor a la relijion no perdonaba sacrificio por sostenerla i propagarla, pero su pasion i el poder del trono conspiraban para alucinarle i corromper en su corazon la pureza del evanjelio, inspirándole groseras supersticiones $i$ aciendo servir su fe al triunfo de la ambicion i a la perpetuidad del despotismo. Veamos un testimonio de estas preocupaciones en Pedro Valdivia, qe al emprender la conqista de nuestro suelo, proclamaba a sus soldados con toda la efusion de su corazon en estos términos: "introduzcamos la relijion cristiana en tan vasta jentilidad, dándole a la Divina Majestad todo el paganismo de Chile de adoradores; a la santa iglesia romana millones de feligreses; al obispado del Cuzco mas términus; a nuestro rei de España mas dominios; a la jcografía mas demarcaciones; a nuestras armas mas mérito; a nuestra onrra mas azañas; a nuestro interes mas conveniencia de tierra de indios, $i$ en fin a nuestros timbres los blazones de descubridores, primeros conqistadores, pobladores, pacificadores i conservadores de estos dilatados reinos (1).

Este era el pensamiento capital, estas las aspiraciones únicas en qe se reconcentraba toda la civilizacion del español del siglo XVI: su rei i su interes, Dios i la gloria de las armas.

Esa civilizacion fué pues el elemento qe constantemente predominớ en todos los acontecimientos realizados por aqel pueblo singular: ella fué la causa orijinal de sus estravios i al mismo tiempo determinó el rumbo de șus inclinaciones $\mathbf{i}$ dió forma a sus costumbres. Por eso creo qe al examinar las leyes políticas i civiles qe modelaron la existencia de nuestra sociedad, debemos considerarlas como un resultado lójico de aqella civilizacion, teniendo siempre presente qe zanjó los cimientos de nuestro edifi-

(1) Documento auténtico en los libros del cabildo de Santiago, coyiado en la Istoria de Chile de Gurman, lec. 90. 
cio social la España fanática i conqistadora, qe sirvió de funda mento al sistema administrativo de nuestra colonia la omnipetencia de Cárlos V, i qe nuestra relijion tuvo por base el terrorismo de la inqisicion.

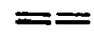

\section{IV.}

INfLuencia sogial del sistema político colontat.

Cualqiera qe sea el orijen de las instituciones sociales de un pueblo, de aqellas instituciones qe determinan su modo de ser, stt constitucion política i moral, es indudable qe por su naturaleza tienen su mas poderoso fundamento en las costumbres, por manera qe si ámbos no concuerdan, la constitucion social no produce buenos resultados. Puede sentarsis como un dogma sancionado por la razon i la esperiencia de los siglos qe ai tal reciprocidad de influencia entre las costumbres de una sociedad i su forma politica, qe esta no puede existir si no busca en aqellas su centro de apoyo, i qe las costumbres a su vez se van amoldando a ella insensiblemente. Por esto sucede con frecuencia qe las costumbres forman un escollo mas o ménos formidable, segun su moralidad en el cual se estrellan los avances del despotismo, qe consulta las miras de un ombre o de una familia poderosa, sin precaverse de ofender los intereses nacionales. Las leyes qe se forman por el egoismo de los tiranos, las qe atacan los privilejios de los pueblos, las qe arrebatan al proletario el pan de su subsistencia, sometiéudale a un trabajo duro i penoso, cuyo provecho reporta la nobleza, son leyes qe no triunfan sino a duras penas, por grande qe sea su prestijio i temible el poder qe las sostiene. Establécese desde luego el choqe entre ellas i las costumbres $i$ al fin se produce una crísis terrible, una revolucion sangrienta, en qe el triunfo no qeda siempre de parte de los pueblos. En este caso, del cual nos presenta varios desgraciados ejemplos la istoria de la umanidad, imperan las leves contra toda resistencia $i$ concluyen por someter a su capricho las costumbres, modificándolas $i$ aciéndolas tomar muchas veces un jiro opuesto al qe ántes segian. Tan cierto es esto qe los usurpadores mismos no lo desconocen, apesar de allarse arrebatados por su ambicion; $i$ cuando tienen bastante abilidad para evitarse una competencia; qe puede ser bien funesta a sus aspiraciones, acen frecuentes sa:crificios para alagar a los pueblos excitando sus pasiones, apro- 


\section{$-232-$}

bando sus errores i fascinándolos con el brillo de la gloria, para distraerlos i conseguir el fin de sus planes, sin violentar las costumbres.

Empero, el despotismo de los reyes católicos oncontró un campo vírjen al sentar su imperio en Chile, no abia aqi resistencias qe vencer, no abia un pueblo cuyas costumbres, leyes i relijion fuese necesario respetar; el chileno indíjena aparecia como un ser imbécil i degradado a los ojos de los conqistadores, al cual era necesario destruir o esclavizar, i ellos mismos, por otra parte, estaban ya educados para el despotismo i acostumbrados a soportarlo. De este modo la monarqia despótica de Carlos $\mathrm{V}$ fué establecida en todo su vigor en la colonia chilena, i si bien se erijí6 uncabildo para qe velase sobre los intereses locales de la primera ciudad qe se fundo, no fué esta institucion otra cosa qe una fórmula vana, una de aqellas farzas con qe los tiranos alucinan a los pueblos cuando les an usurpado sus derechos.

El poder municipal español abia sufrido el primero los redoblados i sordos ataques del trono, i en la época a que me refiero abia sido despojado de su independencia i de sus atribuciones: no existia entónces sino como un sımulacro ridículo. Antes estaba reconcentrada en él la suberanf́a nacional, era el órgano lejítimo de la expresion de los intereses sociales de cada comunidad, $i$ al mismo tiempo el mejor custodio de estos intereses; pero la fusion de las diversas monarqlas i señoríos en qe estaba dividida la Península i el plan de centralizacion desarrollado por Fernando el Católico i consumado por Cárlos V, completaron al fin la ruina de aqel poder precioso, de manera qe al tiempo de la conqista de Chile no qedaban siqiera vestijios de él en los cabildos qe ántes eran sus depositarios. La lejislacion de Indias posteriormente redujo estas corporaciones a una completa nulidad e invirtió el 6rden de sus funciones sometiéndolas del todo al sistema absoluto i arbitrario de gobierno adoptado por la metrópoli i sus representantes en América. De consiguiente, los cabildos de las poblaciones chilenas no tenian otra esfera de accion qe la jurisdiccion cometida a los alcaldes $\mathrm{i}$ los cuidados de policía encomendados a los rejidores en los casos marcados por la lei o por el capricho del funcionario qe gobernaba la colonia, a nombre i por representacion del monarca. No era por tanto esta institucion en manera ninguna ventajosa al pueblo, ántes bien estaba consagrada al servicio del trono del cual dependia su existencia: era propiamente un instrumento, aunqe mui secundario, de la voluntad del rei i de sus intereses. Podemos, pues, establecer como fuera de duda qe la monarqia despótica en toda su deformidad i con todos sus vicios fue la forma política bajo la cual nació i se desarrolló nues. 
tra sociedad, porqe esta fue su constitucion, su modo de ser, durante toda la época del coloniaje.

Esta forma política desenvolvió su influencia corruptora en nuestra sociedad con tanta mas enerjía, cuanto qe a ella sola estaba reservado crear, inspirar i dirijir nuestras costumbres, i cuanto qe se allaba apoyada en el poder relijioso, formando con él una funesta confederacion, de la cual resultaba el omnipotente depotismo teocrático qe lo sojuzgaba todo.

Como primer resultado de este órden de cosas debo señalar la carencia absoluta de virtudes sociales, porqe entre nosotros no existia entónces vínculo alguno de aqullos qe constituyen las relaciones del ombre con su patria i consiguientemente con sus demas coasociados. La union del interes individual con la utilidad pública no existia, porge predominaba en todo el egoismo, i el interes de la comunidad era dusconocido, violentado i contrairiado cuando se trataba del bien de la corona, del de sus empleados o del de rualqier qe tuviese la posibilidad de acer triunfar el suyo propio. La noble emulacion, el amor a la gloria eran sentimientos ajenos del alma del chileno, $i$ cuando en fuerza de la naturaleza aparecian, bajo cualqiera forma, eran sufocados i lo qe es mas orrible, condenados como asomos de una pasion criminal: los ijos de los ijos debian seguir la condicion de sus abuelos, por qe si procuraban distinguirse, eran tachados de peligrosos, de rebeldes a su rei i de perturbadores del órden establecido, a no ser qe dirijiesen sus esfuerzos a glorificar a la familia real o a proveer su acienda depositando en ella el fruto de los trabajos de la mitad de la vida, a trueqe de un título o de una onrra vana qe les dispensaba el despotismo para crearse mas prosélitos. Las virtudes en fin no tenian éco ni órgano alguno para manifestarse, eran aogadas en su jérmen o, cuando mas, dirijidas al fanatismo relijioso, qe constituia la mejor columna del sistema colonial.

Esta perfecta nulidad de todo lo qe ai de grande i de noble en el corazon umano dependia exclusivamente de qe el monarca lo ocupaba todo con su poder i majestad: dispensador de todos lus empleos, onrrasi preminencias; dueño absoluto de la vida i dela acienda de sus vasallos; con una voluntad superior a la lei misma, porge siendo esta su echura, cedia sin violencia a sus deseos i caprichos; consagrado i apoyado por la iglesia i representante de Dios en el gobierno de la tierra. era el rei lo mas allgusto i poderoso en la sociedad i dominaba con un prestijio irresistible $i$ fascinador. La primera virtud de los vasallos consistia en el sacrificio completo de su ser en onrra del soberano, este era la patria i la umanidad, de él procedian los onores i las riqezas, la posicion civil i cuanto valia el ombre en este mundo: abia pues 
necesidad de amarle, temerle i consagrársele sin escusa. Por esto, nada era el colono por sus talentos i virtudes, sino por la voluntad de su señor; los empleados públicos eran nulos por sí mismos i no valian sino por la augusta majestad qe representaban $i$ servian.

Esto explica sin dificultad el carácter arbitrario i despótico ge, como emos notado ántes. formaba la base de la autoridad de los mandatarios en América: representantes de un rei absoluto, lo eran tambien a su vez en el ejercicio de sus funciones, aciendo preponderar su capricho o su interes sobre los preceptos de la lei: dueños, como aqel, del Nuevo Mundo i conqistadores i señores de sus pueblos, los dominaban a su albedrio i tenian en su mano la vida i bienestar de los colonos.

De aqf la ciega umillacion i estúpida servidumbre con qe la sociedad toda se sometia a la voluntad del sin número de tiranúelos qe la oprimian, inrocando la representacion del monarca. De aqi tambien la costumbre perniciosa de esperarlo todo solamente del capricho de estos mandatarios i no de las determinaciones de la lei, la cual era impotente i estaba reducida a una fórmula vana al lado del inmenso poder qe ellos investian.

Con este antecedente se podrá ex plicar la conducta siempre observada de apelar primero al empeño i no pocas veces al coecho, ántes qe al precepto de la lei, cuando se imploraba el amparo de los tribunales de justicia o se recurria a la autoridad pública, con cualqier motivo qe para ello se tuviera. Este era el modo de proceder tolerado $i$ sancionado por la costumbre: el influjo ge nace de las relaciones de familia o de amistad i de la posesion de injentes rigezas era el único gran regulador de la eqidad i de la justicia en todos los casos, $i$ a sus dictados imperiosos se sometian no solamente las providencias de la autoridad, sino tambien asta las leyes mismas emanadas del soberano. En esta, así como en todas las circustancias en qe predomina la arbitrariedad, no abia otra garantia qe el carácter personal de los majistrados, i si pudieran citarse a millares los ejemplos del triunfo de las leyes i de la justicia entre nosotros, siendo este el resultado de aqella garantía efímera I precaria, no pueden formar un argumento contra la observacion qe acabo de acer fundado en la experiencia $i$ en la naturaleza de las cosas, acerca de una costumbre, qe vemos todavia palpitante algunas ocaciones. ¿̨No es verdad qé si en el dia se mira el coecho como un arbitrio qe a perdido ya su antiguo prestijiono, solo no se considera del mismo modo el $\mathrm{cm}-$ perio, sino qe por el contrario se usa de él como de un medio racional, justo, lejítimo i tolerado para alcanzar un triunfo?

La istoria del mundo nos enseña qe cuando la falta de respeto 
por las leyes $i$ la corrupcion de los mandatarios llegan a este gra= do, se desqicia el órden social, se rompen los vínculos qe ligan al ombre con la autoridad i se produce frecuentemente una de aqellas crisis espantosas qe consuman para siempre obien la ruina de un pueblo o su rejenerasion completa. Pero la istoria del nuestro nos presenta en esto otro fenómeno, qe si bien a existido en donde qiera qe el despotismo aya imperado, nunca se a desarrollado con tanta deformidad ni a sida tan duradero como entre nosotros. Cuando el desprecio por las lej es está solo de parte del soberano, no produce aqellos efectos ni obra como elemento desorganizador de la sociedad, porqe siendo su voluntad la única lei del estado, no se reputan como inmorales sus avances, sino como actos lejítimos i sagrados; pero cuando ese desprecio está en todos los majistrados i en todos los ombres qe tienen la conciencia de poder eludir la lei i pisotearla con solo acer valer su influjo o su autoridad, no puede explicarse la conservacion del órden social sino por razones mui especiales. Esto era lo ge sucedia en Chile, i el proletario, el colono sin valimiento sufrian todo el peso de tan funesta costumbre, pero en silencio i resignados. El pueblo padecia, no se desorganizaba; ántes bien, permanecia sumiso, porqe tenia la conviccion íntima de qe este era el único 6rden posible, puesto qe era el aprobado i sostenido por la voluntad del monarca i la autoridad de la iglesia, qe le aconsejaba respetar esa voluntad como la del mismo Dios. Su ignorancia era tan profunda, qe no le permitia concebir esperanza ni tan siqiera idea de otro sistema mas perfecto qe este, bajo el cual abia formado sus costumbres, modelado su vida social i echado por consiguiente ondas raices en su corazon. La crísis qe emos señalado como consecueneia fatal de la carencia de respeto a las leyes, no era por supuesto de temer entre nosotros, porqe el despotismo teocrático, apoyando su predominio en las costumbres i en la adesion del pueblo, tenia bastante poder para mantener la ciega sumision de sus rasallos i consiguientemente el órden establecido.

En conclusion, el pueblo de Chile bajo la influencia del sistema administrativo colonial estaba profundamente envilecido, reducido a una completa anonadacion $i$ sin poseer una sola virtud social, a lo ménos ostensiblemente, por qe sus instituciones políticas estaban calculadas para formar esclavos. La obediencia ciega i estúpida se consideraba como la única virtud i como el mérito mas singular qe podia recomendar al vasallo; todo bien se acia depender del monarca i a la gloria de este debian encaminarse los esfiuerzos de todos; semejante sistema, sino fomentaba i premiaba el vicio, condenaba al ménos i sufocaba en su jêrmen las inspiraciones del onor i de la patria, de la emalacion i de todos les sen- 
timientos jenerosos de qe nacen las virtudes cívicas. Las costumbres eran simples i modestas, es verdad, pero antisociales, basadas sobre errores funestos i sobre todo envilecidas i estúpidas, bajo todos aspectos: su sencillez era la de la eselavitud.

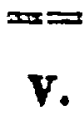

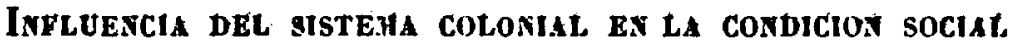
De los chilenos.

Si tan funesta i corruptora fue la influencia de las instituciones políticas de España en nuestra sociedad, no lo a sido ménos la de las leyes civiles qe guardaban con aqellas la mas precisa i exacta correspondencia. Difícil i aun imposible es practicar en los estrechos límites qe tiene el plan de mi discurso un exámen detenido de la lejislacion para seguirla en todos los casos qe a influido o podido influir sobre nuestras costumbres; por eso me contentaré con trazar líneamientos jenerales, fijándome en los puntos mas culminantes del cuadro de nuestra vida social, i dejando los detalles $i$ el análisis minucioso para otra ocasion mas oportuna. Continuaré sin embargo tomando mis observaciones de la istoria i de los echos qe nos rodean.

Ya e procurado dar una idea del sistema legal español en las colonias americanas, describiendo fielmente su forma, fijando su espiritu i demostrando, aunqe lijeramente, su perniciosa influencia en los destinos sociales del Nuevo Mundo. Entónces, como aora, no e debido tomar en cuenta para mis investigaciones las leyes qe fijan las relaciones privadas del ombre en sociedad, sino en cuanto por ellas se modela su vida civil, afectando sus facultades morales i físicas, o diré mas claramente, at acando - por lo ménos restrinjiendo demasiado sus mas preciosos dererhos naturales de libertad, igualdad i seguridad. En consecuencia, fijándome abstractamente en aqella parte de la lejislacion española qe a influido mas en la suerte de nuestro pueblo por atacar sin disfraz aqellas sagradas prerrozativas del colono, omitiré acer investigaciones sobre el influjo de las leyes qe arreglaban las relaciones de familia $i$ las qe nacen de los pactos $i$ demas actos lejítimos, las cuales no eran mas qe un verdadero trasunto de la lejislacion romana. La accion de esta en nuestras costumbres a sido sin disputa benéfiea, i si a dado orijen a algunos defectos, no son de aqellos qe con el trascurso del tiempo echan 
raices en el corazon de los pueblos; al contrario, el tiempo mismo los corrije i la civilizacion los estirpa.

-Empero qé cosa abia capaz de neutralizar siqiera las funestas consecuencias de las leyes qe la corte española dictó sobre los indfjenas americanos? Consecuentes tales diposiciones a los principios qe reglaban el derecho de conquista i a las abominables preocupaciones qe tenia la España respecto de los arnericanos, imponian a estos desgraciados ciertos deberes qe contrariaban sus costumbres, sus creencias i asta sus nas tiernas inclinaciones, i concluian por sumeterlos a trabajos violentos i a la mas umillante esclavitud. Cırando la lei callaba, el interes de los conqistadores dictaba preceptus, i si ella establecia privilejios o esenciones, el despotimo de estos las atropellaba, sufocando asta los desaogos de la piedad. De esta manera los naturales del Nuevo Mundo, léjos de abrir sus ojos a la luz del evanjelio i de la civilizacion, léjus de mejorar su estado social, soportaban un yugo de bronce qe los aniqilaba i los acia retroceder a la barbarie i a la miseria mas esprantosa: las injentes riqezas i los frutos agrícolas qe los esjañoles adqirian a costa del trabajo de estos infelices, jamas llegaban a sus manos ni servian tampoco para prestarles un débil consuelo en su desgracia: la relijion nisma era invocada para privarlos de los bienes escasos qe lograben escapar de la rapacidad de sus amos i para inspirarles superticiones groseras qe los alejaban del verdadero espíritu del cristianismo ( 1 ). Acostumbrados los españoles a despreciarlosi aborrecerlos, no los considerahan dignos de la umanidad i los oprimian en todos sentidos a nombre de la relijion $\mathrm{i}$ de las leyes.

El influjo consiguiente de esta conducta fue, pues, el exterminio de los pueblos americanos. ¿ A dónde buscarémos oi el vasto imperio de los Incas, con sus seis millones de vasallos? ¿Dónde está el numeroso pueblo indíjena ge cubria los risıeños valles de nuestro Chile? Preguntadlo a las leyes españolas i a su abominable derecho de conqista ( 2 )! Ellas os dirán qe lo icieron desaparecer con sus cruedades! Ellas os probarán con este ejemplo asta donde llega la profunda influencia del despntismo, qe, sin respeto a la naturalezá, oprime al ombre, impidiendo su desarrollo!

A decir verdad, el pueblo orijinario de Chile no sufrió con tanta frecuencia las atrocidades de qe fueron víctimas los demas ame-

(1) Noticias secretas, cap. 2.• part. 2.:

2) El censo de 1796, levantado en el Perú dió solameñte 608899 indios, como resto de 6 millones qe tenia al tiempode la conrista, segun Mr. Barry. 


\section{$-288-$}

ricauos, sea porqe sus conqistadores, parte consagrados a la guerra tenaz qe sostenia el araucano, $i$ parte distraidos o amedrentados por sus desastres, no tenian tiempo de emplear los brazos de los naturales en arrancar a la tierra sus riqezas; o sea porqe estas no eran tan exuberantes como lo deseara su codicia, en cuyo caso abrian usado de la mita, encomienda $i$ repartimientos del modo atroz i brutal qe lo acian los españoles en el Perú. Con todo, sujetos los chilenos en jeneral a las mismas leyes i cuando no a las mismas preocupaciones, al mismo odio i desprecio qe en toda la extencion de la América sufrian los indijenas, fueron sucumbiendo osteusiblemente al peso de la desgracia qe les causaba la pérdida de su independencia natural i la ndiosa esclavitud a qe vivian sometidos; $i$ los qe tuvieron la fortuna de sobrevivir, se incorporaron poco a poco en el pueblo criollo, asta qe se confundieron con él enteramente. A principios del presente siglo existian aun varias reducciones de chilenos naturales qe, sin mezclarse con la poblacion española, mantenian como en depósito sagrado los recuerdos i parte de las costumbres de sus antecesores, pero la sociedad actual las a absorvido o por lo ménos las a modificado sometiéndolas a su movimiento i arrastrándolas en su marcha (1). Así an desaparecido para siempre las numerosas tribus qe Amalgro i Valdivia encontraron diseminadas en el vasto territorio de Chile, llevando una vida apasible, decostumbres sencillas e inocentes. Tres cientos años, qe abrian bastado para levantar a este pueblo de su ignorancia i darleen el rango del mundo el lugar a qe tenia derecho de aspirar, an bastado tambien para exterminarlo i no dejar siqiera vestijios de su existencia, despues de aberlo oprinido $i$ vejado de una manera atroz. Mas no solo tenemos qe lamentar aora ese extcrminio, sino tambjen sus consecuencias sobre esa fraccion impcrtérrita de aqel pueblo, qe conserva su independecia $i$ su barbarie a despecho de los esfuerzos de tres jeneraciones, i qe sin dudo resistirá todavia el baustismo de la civilizacion, por un tiempo indefinido, porqe aqel ejemplo a refinado su suspicacia $i$ aumentado su osadia. $\mathbf{E}$ aqi en compendio los efectos de las leyes $i$ de las ideas de los conqistadores sobre la raza de los infelices americanos!

(1) En carta del presidente de Chile al rei, datada en marzo de 1750 se diee qe no pasaban de 22000 los indios capaces de tomararmas. Aciendo un observador juicioso sus cálculos sobre este dato, expone qe no pasaba en aqella época la poblaciun de naturales de Chile de 125000 almas. Véase en el semanario erúdito de Madrid, edicion de 1789, el informe dado a Fernado 6.0 por D. Joaqin de Villareal sobre reducir a la obediencia a los indios chilenos. 
De la mistion del pucblo orijinario con el criollo español resultó la numerosa raza secundaria llamada comunmente de mestizos, o sea de descendientes mistos de españoles e indíjenas américanos, la cual se abia multiplicado mucho ácia los treinta años (1570) despues del descubrimiento de Chile, época en qe los araucanos, considerando a estos individuos como miembros de su gran familia, confirieron el empleo de Toqi o jeneralísimo de sus ejércitos al temerario i valiente mestizo Painenancu (1). Esta raza, aumentada con las de mulatos izambos, qe an sido en Chile demasiado reducidas en su número, a causa de aberse contado siempre mui pocos negros entre nuestros abitantes, se multiplicó tan prodijiosamente: qe a fines del siglo pasado formaba la mayoría de la poblacion criolla. Humboldt, distribuyendo por razas la poblacion de la América española, ace subir la de los mestizos en Chile i el Perú a doble número qe el de la poblacion blanca (2); i no solo es probable sino tambien positivo qe en el dia pertenece la inmensa mayoría del pueblo chileno a las jeneraciones de aqella estirpe.

Las leyes $\mathrm{i}$ las preocupaciones españolas no echaron en el olvido a estos descendientes del pueblo orijinario: descargaron al contrario torpemente sobre ellos todo su peso e influyeron de tal modo en sus destinos sociales, qe no solamente formáron sus costumbres, sino qe ademas los condenaron a la triste condicion qe oi en dia aflije a los cuatro gintos de nuestra nacion.

Desarrollar esta verdad en todas sus consecuencias para conocer acertivamente el orijen, progreso i consistencia de las costumbres qe perpetuan el miserable estado de esta gran parte de la poblacion chilena, es a mi juicio el objeto de mas importancia i el trabajo especulativo mas susceptible de aplicaciones prácticas para los chilenos; porqe tengo la mas poderosa conviccion de qe nada o mui poco valdrá en Chile el aber proclamado i sancionado las garantías individuales, ni el favorecer el desenvolvimiento de la iudustria i el cultivo de las ciencias, si de preferencia no se estudia la condicion de ese pueblo desgraciado i iniserable, para ref ormarla i promover su mejora material i moral, aciéndolo partícipe de esas garantias i de los beneficios del movimiento industrial qe principia a obrarse en nuestra sociedad. , Su mejoramiento material ! e aqf el punto qe debe servir de meta a las aspiraciones del lejislador, del gobierno i de todo ombre qe tenga la conciencia de serlo. Conozco ge mis fuerzas no son bastantes para realizar un trabajo como el qe acabo de indicar, i qe aun 
cuando tuviera la osadia de acometerlo, no será por cierto este discurso el lugar mas a propósito. Por esto me contento con señalar ese campo vírjen a las invest igaciones de nuestros ombres de jenio i conocimientos. Permítaseme con tudo avanzar algunas ideas.

Los descubrimientos echos en Africa i América durante los siglos XV i XVI por los portugueses i españoles, dando lugar a qe se cruzaran las razas conqistadoras con las conqistadas, multiplicaron tambien las jeneraciones de sangre mezclada, las cuales fueron a su vez víctimas de las preocupaciones qe pesaban sobre los pueblos orijinarios de aqellos continentes. Los españoles no pudieron múnos de ser consecuentes a su ignorancia i barbarie respecto de los descendientes mistos de los americanos: el odis, i desprecio qe por estos abrigaba su corazon i la costumbre contsagrada por la opinion de aqella época de considerar a los indius i negros como razas degradadas, qe dejeneraban de láumana, destinadas al patrirnonio de los europeos, porqe eran infieles i bárbaros, inlluyeron sin disputa en la manera de considerar a los mestizos. Aunqe la sangre española corriera por sus venas, esa sangre estaba mezclada con otra impura, qe acia a los frutos del amor o sensualidad de los conqistadores sino en todo semejantes al indfjena degradado i despreciable. a lo ménos dignos como éste de la esclavitud i de la miseria. Isí el mas puro afecto del corazon, el amor paternal, se aogaba a impulsos de esta preocupacion monstruosa, contraria al interes de la umanidad, al espíritu del evanjelio i a la naturaleza mistna. ¿ Cuántas lágrimas i amarguras, cuántos desastres cuesta ese error funesto, de qe apénas aora principia a avergonzarse el mundo, a los abitantes de las colonias europeas en Imérical jQé baldon mayor podia manchar al ombre de entónces, qé crímen podia infamarle mas atrozmente qe la mezcla de sangre! El mestizo (1) llevaba en su frente la marca de la degradacion i de la infamia, su nacimiento le condenaba a la desgracia de ser el paria de la sociedad. Sı condicion era mil veces peor qe la delindijena: este comunmente se trataba como a enemigo vencido, aqel era despreciado i envilecido, porqe su sangre no era pura como la del indio! Pafa él estaban destinadas todas las cargas de la sociedad, los trabajos mas pesarlos i degradantes, la pobreza, la esclavitud!

Incrustada, por decirlo asl, esta. preocupacion degradante en nuestra sociedad, porqe tenia sus raices en el corazon $i$ en la ignorancia de sus fundadores, se comunicó de jeneracion en jeneracion con toda su enerjía i fue apoyada por las leyes. Estas

(1) E tomado i tomaré ssta valabra en su sentido jenérico. 
con su grave autoridad la erijieron en dogma, despreciando con la misma ceguedad a los mestizos, escluyéndolos de los oficios i destinos onrrosos, proibiéndoles severamente vivir en comunicacion con los indijenas $i$ aun valerse de ellos $i$ de sus servicios en las necesidades de la vida. El sacerdocio mismo, qe el salvador ofrece a la virtud i a la capacidad, sin fijarse en la raza o condicion social, les estaba vedado, salvo en casos mui excepcionales. Obsérvese ademas qe las leyes no solo formaban de los mestizos, mulatos i zambaigos una clase vil i despreciable en la sociedad, sujetándola a restricciones onerosas i diferencias ridículas qe atacaban su libertad i su dignidad de ombres, qe modelaban sus gustos, su manera de vivir $i$ asta sus vestidos $i$ usos mas insignificantes, sino qe tambien, cada vcz qe se referian a ella, lo acian en términos umillantes $i$ atribuyéndola viciosi sentimientos inmorales i denigrativos (1). Este absurdo modo de considerar a los mestizos, qe, como e dicho ántes, confirmaba la preocupacion qe contra ellos existia, no podia ménos qe envilecerlos i colocarlos en una posicion, no solo desesperante, sino la mas abyecta i abatida a qe las leyes pueden condenar al ombre; porqe basta tratarle i considerarle siempre como un perverso para conseguir qe Hegue a serlo, aun cuando su jenio i carácter sean naturalmente huenos. Semejantes leyes, así como todas las qe "son contrarias a los derechos i a las naturales inclinaciones del ombre, qe contienen e impiden su desarrollo, qe encadenan la libertad, qe ata can algunas de sus mas preciosas facultades, qe privan a la sociedad de los talentos mas apropósito para formar un foco de verdadera civilizacion $i$ de goces puros, qe irritan a los pueblos porqe los degradan ( 2 );" semejantes leyes repito obraron naturalmente sobre aqella desgraciada porcion de nuestra sociedad, aciéndola perder el sentimiento de su dignidad natural i desmoralizándola asta el grado de la depravacion.

Es fácil concebir qe tales leyes debieron exaltar la preocupacion de qe ablamos, radicándola i propagándola de modo qe no tuviese otra qe pudiera comparársele en enerjla i consiguientemente en sus perniciosos efectos. I a la verdad, $\tan$ asi se a rerificado, como podemos observarlo oi mismo, qe debe asegurarse qe aqella preocupacion, desarrollada en todas sus faces, es la qe a sido causa de las costumbres e inclinaciones mas viciosas i antisociales qe aflijen a nuestro pueblo i qe pesarán sobre él,

(1) Véanse en el código de Indias las leyes sobre la materia, disemin a das enlos títulos $7 . .^{\circ}$ i 23 , lib. $1 . .^{\circ} ; 8 . .^{\circ}$, lib. $5 . .^{\circ} ; 3 . .^{\circ}, 9 .^{\circ}$ i 12 , lib. $6 . .^{\circ} ; 5 . .^{\circ}, 1$ ib 7.०: i 62, lib. $9.0^{\circ}$

(2) Matter, Influencia de las costumbres sobre laz leyes i de las leyes. sobre las costumbres, cap. 6.0 part. 3.a 
por mucho tiempo todavía, como el mas funesto legado de nuestro padres.

Las leyes i la preocupacion de los conqistadores dieron, pues, orfjen al apego de la parte principal de la poblacion de la colonia chilena a las ideas de nobleza $i$ al desprecio inicuo por los mestizos i todo lo qe le pertenecia, apoyando solidamente las costumbres nacionales en este punto. Para calcular toda la fuerza de estas costumbres i explicar el respeto sagrado qe todavía se les profesa por gran parte de nuestra poblacion, es necesario qe consideremos su fisiolojía morat.

Con mucha exactitud i verdad a observado un escritor moderno qe ai en nuestra naturaleza una necesidad de emocion i de simpatía ge nada es capaz de satisfacer, ni el presente, nila realidad: el alma se encuentra estrecha en sus límites ordinarios i desea lanzarse a un campo mas vasto $i$ variado. Este excedente de actividad qe el creador no puede aber puesto en nosotros sin designo, es el principio de la perfectibilidad de nuestro ser: es necesario un empleo para esta superabundancia de vida, un alimento para esta necesidad de ambiciones qe nos ajita. Esta savia interior se abre paso por mil canales diferentes: el espectáculo de la naturaleza, la curiosidad instintiva qe nos estimula al desarrollo de nuestra intelijencia, alguna pasion enérjica i la esperanza de alcanzar algun gran fin, qe suelen arrastrar a los pueblos a consumar empresas eroicas, el cuadro de lo pasado i en fin la imajinacion, son otros tantos campos vastos en qe se desborda esa superabundancia de vida $i$ en qe el ombre encuentra un mundo ideal, mejor qe el mundo de la realidades ( 1 ).

Pues bien, un pueblo como el nuestro qe no tenia movimiento propio qe lo precipitase en esa fluctuacion social qe mantiene las facultades del ombre en perpetua actividad; un pueblo qe carecia de antecedentesistóricos qe lo lisonjearan; un pueblo qe vivia sometido a un rigoroso despotismo teocrático, el cual sufocaba con su planta ponzoñosa toda superioridad qe pretendiese desviarse de las estrechas barreras con qe aprisionaba la libertad, condenando como un crimen cualqiera expresion de la intelijencia o del corazon qe no aunciase la mas completa abnegacion individual en pro del monarca i sus secuaces; un pueblo de esta condicion, repito, ¿cómo podría desarrollarse, qé camino podria elejir para avanzar en su perfeccion social, sin estrellarse al instante en los formidables escollós qe le oponian las leyes i el interes de los conqistadores ? Por esto el colono qe poseia algunas rigezas $i$ el pobre qe vivia de 
811 trabajo no encontraban en esta sociedad, muerta para ellos, aliciente alguno qe los despertase de su letargo, i no poseian absolutamente recursos para salir de la situracion qe les abia cabido en suerte ni para mejorarla, porqe esa superabundancia de vida, qe es el jérmen de nuestra perfectibilidad, estaba condenada a estinguirse en su misma fuente, a consumirse en fuerza de su propia actividad. El rico i el pobre empleaban el tiempo qe sus tareas les dejaban libre en los placeres de la familiz i sobre todo en las distracciones i placeres qe encontraban en el culto relijioso i en la práctica de las supersticiones con qe se a manehado la pureza del evanjelio; i curando esos placeres no bastaban para saciar la necesidad natural qe el corazon tiene de impresiones nuevas o no tenian bastante fuerza para disipar ese tedio o fastidio qe qeda en el alma, despues de satisfechas las necesidades de la vida, se lanzaban a los vicios mas abominables o se dejaban arrebatar por pasiones violentas $i$ antisociales. De esta manera el ombre colocado entre esa necesidad de emociones i simpatias, cuya fuerza expansiva ajita el alma, i una sociedad qe no le presentaba estímulos ni arbitrios para el desarrollo de sus facultades individuales, ni mas medio lejítimo de proporciotlarse una posicion social lisonjera i provechosa, qe el de la noblera de sangre i los onores qe dispensaba el trono; el ombre colocalo entre estos extremos, digo, \& qé otra cosa podia acer qe aderirse de todo corazon i con todas las fuerzas de su espíritu a esta preocupacion qe tan de veras alagaba su vanidad? La nobleza de sangre era, pues, el único recurso qe le restaba para lograr en la sociedad un bienestar real i un porvenir alagüeño.

Fs. el corazon umano naturalmente ambicioso del respeto i de la adesion de los ombres; porqe ama decididamente la gloria o lo qe puede suplir por ella, la buena reputacion. La Próvidencia Suprema, siempre consecuente a sus altos designios, nos a suministrado sabiamente, para satisfacer aqella lei de nuestro ser moral, infinitos medios, qe podrian reducirse a una sola expresion-la virtud $i$ el talento, en toda la extension qe puede darse a este lampo de la intelijencia divina con qe se adorna el espíritu umano. Empero, las leyes i las preocupaciones qisicron sobreponerse a los dictados de la naturaleza: las virtudes, los talentos, las riqezas mismas no tenian valor alguno sin la nobleza de sangre, durante la época funesta del coloniaje, en qe lo llenaba todo un monarea, al cual-debia sacrificarse toda superioridad natural; i a cuya gloria debia referirse todo, i sin cuyo benepläcito no era dado al ombre aspirar a distincion alguna!

De esta manera la nobleza de sangre, qe no arguye prenda personal ninguna i:qe no puede representar jamas el mérito, vi- 
no a ser el único término de todas las aspiraciones, con la singutlaridad de santificar todos los medios qe podian ofrecerse para alcanzarlo. Los mestizos mismos, luego qe por cualqier accidente se procuraban algun acomodo en la sociedad o q 2 por el trascurso de la jeneracion lograban echar un velo sobre su orijen $i$ podian igualarse en el color a los españoles (1), eran los primeros en aderirse a aqella distincion i en adoptar la costumbre de odiar, despreciar i oprimir a los indíjenas i a los de su linaje. La nobleza de sangre era el supremo bien social: los colonos qe la poseian i los qe presumian poseerla, alegaban un título incontestable al aprecio o por lo ménos al respeto de todos, porqe la calidad de noble daba derechos, daba virtudes i traia consigo la facultad de acer el mal sin responsabilidad i de entregarse a los vicios sin desonrra.

Al trazar la influencia social de esta preocupacion, no creo poder acer una exposicion mas fiel qe la qe acen D. Jorje Juan i D. Antonio de Ulloa, estudiando las costumbres americanas: a ella sujetaré mis conceptos, porqe en todo es aplicable a nuestro pueblo i a los demas qe sufrieron la dominacion española.

Dicen aqellos respetables escritores (2) qe la vanidad de los cricllos i su presuncion en punto a calidad se encumbraba tanto qe cavilaban continuamente en la disposicion i órden de sus jenealojias, de modo qe les parecia no tener nada qe envidiar en nobleza $i$ antigüedad a las primeras casas de España; i como estaban embelezados de continuo en este punto, acian de él el asunto de la primera conversacion con los forasteros recien llegados; bien entendido qe con pocas investigaciones se descubria qe era rara la familia donde faltase la mezcla de sangre. Esta injustificable vanidad suscitaba mil qimeras ruidosas i no pocas veces era causa de crueles amarguras $i$ aun de la desonrra i completa perdicion de una amilia o de un ombre útil a la sociedad. Pero lo peor de los resultados es qe apartaba a les criollos de todo trabajo i de ocuparse en el comercio, único ejercicro qe abia en las Indias capaz de mantener los caudales sin descaecimiento, induciéndolos por supuesto a los vicios qe son connaturales a una vida licenciosa i de inaccion. Los españoles qe en calidad de tales poseian la mejor de todas las ejecutorias, esplotaban en su bene-

(1) De una i otra casta (mestizos i mulatos) ran saliendo con el discurso del tiempo, de tal suerte qe llegan convertirse en blanoos totalmente, de modo qe en la mezcla de españoles e indios, a la segunda jeneracion, ya no se distinguen de los españoles en el color, no obstante ge asta la cuarta no se llaman españoles." Noticias secretas cap. 8.ค, part. 2."

(2) Noticias secretas, cap. 6.•; part. 2." Véase todo el capitulo. 
licio esta preocupacion, aciéndose rendir todo jéncro de omena jes; pero como de este modo no qedaba satisfecha su codicia, no se desdeñaban de aplicarse al comercio i lograban a poca costa las ventajas qe los americanos despreciaban por creerlas indignas del lustre de su sangre.

Los europeos qe venian a la América eran por lo jeneral de un nacimiento bajo o de linajes poco conocidos, sin educacion ni otro mérito alguno qe los iciera recomendables; pero los criollos no acian distincion i los trataban a todos con igual amistad i correspondencia: bastábale a un ombre ser español para tener títulos suficientes a cualqiera preminencia, para qe los colonos iciesen de él la mayor estimacion i le tratarán como a persona de gran lustre, llegando esto a tanto grado qe aun las familias qe mas nobles se creian, admitian en su trato intimo a los españoles de mas baja condicion, dando muchas veces la misma consideracion a los sirvientes qe a los amos.

Este inconsiderado proceder ocasionaba males de funesta trascendencia para las colonias americanas: el español qe se veia tratado con tan alta distincion levantaba sus aspiraciones mas allá de los términos a qe podia llegar por su estado, su educacion i sus prendas personales; su orgullo subia de punto i luego se convertia tambien en opresor: si profesaba algun arte mecánico, algun oficio útil, lo abandonaba al establecerse en América, i por esta causa la industria fabril no podia adqirir en nuestros pueblos masperfeccion ni adelantamiento del qe tuvieron en su tiempo primitiro. Los indios i mestizos eran empleados en ella exclusivamente, por qe por su degradacion estaban condenados a los trabajos violentos (1).

No poco influia para esto la costumbre introducida desde el

(1) "La exclusion de los indios, mestizos i castas de color de toda ocupacion algo decente, i el allarse reducidos al solo ejercicio de oficios meeánicos, tiene otro orijen qe ace poco onor al sistema de gobierno practica do por los españoles en el Perú. La audiencia do Lima publicó un bando en 17 de julio de 1706 , mandando qe ningun negro, zamboo mulato, ni indio neto pudiesen comerciar, traficar, tener tiendas, ni aun vender jeneros por las calles, " en atencion a qe dicha jente tiene poca fe i llaneza en lo qe venden i no ser decente qe te tadden con lox qe temen eate jerciefo, i ge se ocupe cada cual de ellos en el ejercicio de oficios mecánicos, pues solamente son apropósito para estos ministerios. I si alguno se atreviese. a contravenir a ecta órden, qe sea preso i desterrado a Valdivia." Rarry.

Copio esta nota, aunqe contienc una disposicion de la real audiencia de Lima, porqe de los datos qe e recojido i de los estudios qe echo sobre la materia, deduzco como corolario qe tanto esta disposicion como las observaciones de los señores Juan i Ulloa, qe e extractado casi textualmente, son del todo aplicables a nuestro pueblo, por cuanto infiuia en el ánimo de nuestros antespasados del mismo modo qe en el de las demas colonias es- 
principio de la conqista de gozar fueros de nobleza todos los españoles qe venian a establecerse en América, porqe esta circunstancia no solo producia el efecto de colocarlos en la capacidad de aspirar a todas las dignidades, empleos i oficios lucrativos i onrrosos, sino qe tambien los acia abandonar su vida laboriosa i olvidar las artes ge en su patria profesaran.

i Ved aqí, señores, la causa qe a perpetuado asta nosotros la costumbre inmoral i perniciosa de despreciar a todos los ge se consagran a las labores de la industria! Jamas ubo mérito alguno para nuestros padres en las artes ni en el comercio, i si se prestó una débil atencion a la agricultura, fué porqe en ella se encontraba con mas abundancia la riqeza de Chile. si los nobles i los ricos qe pretendian serlo ubieran podido tener sus candales en otros objetos, la industria agrícola abria qedado tambien rel egada a los esclavos i a los mestizos! \& Qé eran durante el coloniaje los artesanos, los agricultores, los eomerciantes, los qe profesaban un arte liberal $i$ aun los profesores de ciencias $i$ los preceptores de de instrucion primaria ? Nada mas qe ombres envilecidos por su ocupacion, indignos de alternar con los qe poseian una ejecutoria de nobleza e incapaces por su condicion de aspirar a un puesto onrroso en la sociedadl Vigorosa todavía emos alcanzado nosotros; apesar de nuestros progresos, esta degradante preocupacion, esta aberracion inícua de nuestra sociedad, $i$ por desgra zia tenemos qe lamentar oi dia sus funestas consecuencias! Tolerable podria ser el atraso en qe por su causa se allan varios ramos de nuestra industria nacional, porqe pronto el desarrollo de la civilizacion no dejará siqiera recuerdos de este mal de tanto bulto; ¿pero cómo tolerar qe se perpetúen las mismas costumbres en daño cierto de nuestro bien? \&No es verdad qe todavía abundan ombres qe sin poseer capocidad personal alguna, se desdeñan de dedicarse a las artes, porqe se an imajinado qe su sangre es pura i su familja nuble? Esos brazos son muertos para nuestra industria, esos ombres son funestos para nuesta sociedad! Es necesario qe caiga sobre ellos el anatema de la opinion públca!

Proseguiré mis investigaciones. Creo qe de los antecedentes indicados resulta qe nuestra sociedad se dividia durante el coloniaje en dos grandes clases: en la primera debemos colocar a los culonos qe podian ostentar un título o una ejecutoria de nobleza, i a todos ayellos qe sin ser condecorados apoyaban su distincion en la pureza: de su sangre, ora fuosen o no propietarios, siempre qe por cualqiera circunstancia pudieran manifestar qe poseian, a-

pañolag. la funesta proocupacian de la noblezar de sangre i el despreeio por todas las jentes de castas. mestizas. 
yella calidad. A la segunda pertenecian todas las razids de color i los mestizos, cualesqiera qe fuesen sus virtudes, sus talentos $i$ aun sus caudales, siempre qe por algun accidente estuviese todavía manifiesto el orljen de su estirpe.

La primera de estas clases, fascinada con la posecion del ma yor de todos los bienes sociales, se creia superior a la otra, asta el punto de no reconocerle derecho alguno; antes bien se consideraba acreedora a sus servicios $i$ en su nobleza contaba un título suficiente para santificar el desprecio qe sentia por ella $i$ las vejaciones criminosas qe la prodigaba. Su nobleza le servia ademas para justificar sus usurpaciones, para coonestar sus propios vieios i paliar sus nulidades, porqe el colono qe era noble i católico, o mejor diré fanático, i profesaba una ciega adesion a su monarca, tenia las prendas mas seguras de su exaltacion social i el título mas incontrovertible a la supremacia sobre las castas de color.

Bajo la influencia de tales principios se desarrolló la de los mestizos, de manera qe cuando se multiplicó asta el grado de formar la mayoría de nuestra poblacion, se alló ocupando el último escalon de nuestra sociedad $i$ sometida a la mas umilde $i$ abyecta condicion. Los mestizos jeneralmente ablando descendian de los españoles 0 africanos, qe por sus antecedentes personales ocupaban la mas baja posicion entre los conqistadores i de los indijenas chilenos, qe, sojuzgados i pacificados ya, abian perdido sus propiedades i su libertad, i vivian sometidos a las encomiendas, ropartimientos $i$ demas cargas qe las leyes $i$ las costumbres les imponian. Por esta razon siguieron naturalmente la condicion de los autores de su existencia: eran consiguientemente pobres $\mathbf{i}$ desvalidos de todo recurso, sujetos a la esclavitud i con mas frecuencia a la servidumbre onerosa qe bajo denominaciones ipócritas imponian a aqellos las leyes i la codicia de los propietarios; vivian sumidos en la mas profunda ignarancia i ni la luz del eranjelio les era dado gozar, porqe la educacion relijiosa qe a veces se les subministraba se reducia a mostrarles un Dios de venganzas i enseñarles algunas prácticas de ruin supersticion para aplacarle.

Si persuadidos de la verdad de esta exposicion, recordais, señores, lo ge llevo dicho acerca de la influencia qe la lejislacion española i la preocupacion de la nobleza de sangre an tenido en los descendientes mixtos de indijenas i de europeos, formareis $u$ na idea aproximativa de la verdadera condicion del proletario chileno.

Sus relaciones con el noble i propietario eran precisamente las mismas qe existieron en Europa durante la edad media entre el señor feudal i sus vasallos. Para fijar mejor nuestras observa - 
ciones nos referirémos a una época en qe el sistema colonial abia desarrollado ya todos sus funestos efectos sobre los mestizos.

Amediados del siglo último la poblacion de la colonia chilena ascendia en su totalidad a 400,000 abitantes, de los cuales apénas 50,000 gozaban las conveniencias de la vida civil i cristiana (1). Este número no designa el de los propietarios solamente, sino el de todos los colonos reducidos a comunidad en los diversos pueblos qe asta entónces se abian fundado; el resto era el de todos los abitantes naturales i mestizos, qe vivian esparcidos en los campos sin conexion alguna entre sf i sin mas relacion social qe la qe tenian con sus amos. Deduciendo de los moradores qe gozaban los beneficios de la vida civil todos aqellos qe por la calidad de su sangre o por otras circunstancias estaban precisados a procurarse la subsistencia por su trabajo personal. qeda reducido el número de los propietarios a una fraccion insignificante. Estos eran los qe por su elevada posicion tenian en su poder la suerte social de toda o la principal parte de la poblacion.

Es sabido qe la riqeza de nuestro pais estaba entónces reconcentrada en la propiedad rural, qe se beneficiaba por medio del sistema de encomiendas i repartimientos, el cual mas tarde vino a refundirse en cierto feudo o vasallaje en qe el proletario, con la denominacion de inqilino, somete enteramente sus rervicios a la voluntad del amo, sin mas recompensa qe la escasa subsistencia qe puede procurarse con alguna parte del dominio útil del fundo qe cultiva. Con este arbitrio, los pocos propietarios qe existian no tenian necesidad de valerse del servicio de los proletarios libres, sino en señaladas ocasiones, i como el número de estos era excesivo, resultaba como consecuencia precisa i natural qe aqellos eran los qe fijaban el salario de tales servicios de la manera qe mas les interesaba i con absoluta libertad. No es por consiguiente exajerado establecer, en vista de tales echos, qe de los cuatro cientos mil abitantes de la colonia, por lo ménos trescientos noventa mil estaban sujetos a la voluntad del peqeño número restante, componiéndose la mayoría de infelices mestizos proletarios qe nada eran en la sociedad $i$ qe rivian condenados a una perpetua i desesperante esclavitud disimulada. Todavia observamos bien de manifiesto el efecto de semejante órden de cosas: el

(1) Consta de las cartas i autos del Conde de Superunda, Presidente del reino de Chile, examinados en el iaforme inserto en el semanante eriatito do Meadrid, tomo 23 , ya citado.

Segua las observaciones de D. Cosme Bueno, citado por Robertson, abia en Chile el año de 1761 sulamente 240,000 abitantes. 


\section{$-249-$}

proletario, es cierto, goza oi la libertad de aprovecharse del mo. vimiento i desarrollo de la industria para dar mas estimacion a sus servicios, pero el propietario conserva todavia el ábito antiguo de oprimirle i de aprovecharse de su trabajo; ya no le desprecia por mestizo, sino por miserable, porqe le considera depositario de todos los vicios, a causa de la abyecta condicion social a qe le redujeron las leyes i las preocupaciones del coloniaje. El propietario desconoce estos antecedentes, ve solo sus resultados i persiste criminalmente en sus costumbres, sin advertir qe contribuye por su parte a perpetuar una verdadera desgracia de nuestra sociedad.

Ai con todo en este asunto una singularidad qe creo debo señalar, valiéndome de las juiciosas observaciones de un ilustre chileno (1). Entre las innumerables i verdaderas desgracias qe causaba el uso de esa absoluta arbitrariedad con qe los propietarios fijaban el salario del pobre trabajador, imponiéndole la lei de su interes $\mathrm{i}$ comprimiéndole, por sus propias necesidades, abia un verdadero bien social qe a trascendido asta nosotros, tal - sido el qe nace del desprecio con qe se miró la esclavitud por los colonos pudientes, los cuales la consideraban como un arbitrio oneroso, qe ningun provecho reportaba. Este era un resultado preciso de lo bajo de los jornales, porqe siendo mas costoso un esclavo por su precio i los alimentos qe en todo tiempo i edad debian subministrársele, qe el servicio de un proletario qe no estaba sujeto a la servidumbre, se decidian fácilmente por no emplear esclavos propiamente dichos en las labores de la industria, $i$ cuando mas los adqirian como un objeto de lucimiento i ostentacion. De este modo la esclavitud de la necesidad, sin ser ménos odiosa, ocupó el lugar de la perpetua, qe las leyes i las costumbres reconocian entónces con criminal impudencia. Este accidente salvó a Chile, bien qe a costa de un verdadero sacrificio qe subsiste en parte, del verdadero mal social de mas funesta trascendencia qe oi degrada a los pueblos qe no an podido abolir la esclavitud apesar de su civilizacion.

Es fácil aora concebir por qe se mira como inculpable la dureza con qe tratamos al proletario i ese egoismo ciego i grusero con qe nos aprovechamos del fruto de su industria, apreciándolo jeneralmente sin estimar su trabajo i necesidades. Fácil tambien es explicar porqe yace aun en la miseria, en la corrupcion i en la ignorancia esa última clase de nuestra sociedad, qe demasiado bien a probado qe sus facultades físicas i morales no son degra-

(1) D. Manuel Salas, en su Representacion a la corte de España en enero de 1796. 
dadas. como lo crejeron los conqistadores, sino tan suceptibles de mejoramiento i de cultivo como las de los pueblos mas sobresalientes en civilizacion (1). Bástanos observar como complemento de esta asercion esa numerosa clase media, ge naciendo en grm parte de aqella, no existia ántes de nuestra revolucion i qe prepara un brillante porvenir a nuestra patria.

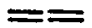

VI.

INFLUENCIA DEL SISTEMA COLONIAL EX LA IXDUSTRIA DE

\section{Cailr.}

Asta aqi e tratado de investigar la influenia del sistema colonial $i$ de sus leyes sobre los indijenas $i$ sobre las dos clases en qe e conciderado dividida nuestra sociedad durante la dominacion de los conqistadores, por lo qe respecta a la condicion social de cada una de ellas i a las relaciones qe mediaban entre ámbas; réstame, para completar el cuadro qe me propuse trazar acer algunas observaciones relativas a otras preocupaciones i a otras leyes no ménos funestas qe aqellas. Resaltan desde luego a la contemplacion, i con un carácter demasiado notable, las qe mantuvieron aprisionada la industria nacional, sujetándola a restricciones qe no solo prueban el atrazo en qe a causa de su ignorancia se allaba la metrópoli, aun para conocer sus mas sencillos intereses, sino tambien la cruel i pérfida intencion de comprimir todo desarrollo, todo movimiento en la industria americana, para mantener a los colonos en perpetua inercia i completa ceguedad sobre los elementos de poder qe la naturaleza les brindaba. $\Lambda$ esto estaba reducida toda la sabiduría, toda la prevision de la corte.

Basta un lijero conocimiento de la istoria de España para a-

(1) D'orblgny a observado qe los mestizos de españoles o ndíjenas chilenos están dotados de una extrema facilidad de intelijencias is ge no ceden en nada bajo mingwen respecto a la razel blamea de go proceden. L'homme amdricatn, part. 1." ch. $2 .{ }^{\circ}$

Peloaze sostiene qe los mulatos 1 mestizos no solo son mas faertemente constituidos qe los individuos de las razas de donde traen su orjjen, síno qe tambien poseen las mas felices disposicioues para las ciencias i para las artes mecánicas i agradables. Las pruebas qe tenemos cn Chile de esta verdad me escusan de mas citas: con los mestizos conqistamos nuestra independencia i con ellos acemos progresar nuestra industria. E aqi un testimonio irrefragable de su capacidad. 
cerse cargo de las causas qe prepararon i consumaron el estacionamiento industrial en qe aqella preciosa porcion de la Europa se a visto asta nuestros dias. Precisamente era a la época de la formacion de nuestro pueblo cuanto abian tomado todo su vigor en la Península las preocupaciones qe condenaban la industria a marchar con las infinitas trabas qe le imponian la ignorancia i ciega avaricia del trono por una parte i la intolerancia funesta de la inqisicion por otra, contra todo progreso cientifico $u$ artístico qe no fuese calificado de español i católico por los teólogos i canonistas. Los únicos empleos gloriosos i dignos de los ombres bien nacidos i de los qe aspiraban a ennoblecerse estaban en las armas, el sacerdocio $i$ asta cierto punto en las condecoraciones universitarias; pero el comercio, las artes i aun la agricultura se relegaban a la última clase de la sociedad sobre la cual se descargaban desapiadadamente el orgullo $i$ el interes de la nobleza.

Las costumbres qe naturalmente debian proceder de tan retrógradas preocupaciones se encarnaron en nuestra sociedad produciendo los mismos resultados qe en la metrópoli, pero en grado superior, por cuanto nuestros ábitos industriales tuvieron su orijen i se desarrollaron bajo la influencia exclusiva de tales preocupaciones.

Procediendo las leyes en consonancia con las costumbres $i$ encaminándose al fin qe la corte se proponia en la organizacion i mantenimiento de sus colonias, vinieron luego a sancionar con su augusta aprobacion tan monstruosas aberraciones. La España se reservó el exclusivo monopolio del comercio colonial de una manera tan torpe qe no solo proibia bajo la pena capital toda comunicacion con los extranjeros, sino qe ademas impedia a sus nacionales toda especulacion i comunicacion con la América, miéntras no seiciera bajo la inspeccion de la Casa de contratacion de las Indias i precisamente en las dos únicas flotas qe zarpaban anualmente de los puertos de la Península. I con el fin de asegurarse el expendio de sus producciones imponia severas penas a los colonos qe intentasen fabricar o cultivar otros artículos qe los de primera i precisa necesidad qe no podia ella suministrarles. Curioso es $\mathrm{i}$ aun sorprendente el observar en el código de Indias las multiplicadas resoluciones con qe se reglamentaba el comercio colonial, la navegacion de los mares americanos i la industria de los colonos, en todo sentido; pero siendo ajeno de mi propósito qe yo iciera la exéjesis de la lejislacion española sobre este asunto, solo debo penetrar en su espiritu e investigar su influjo social, para cuyo fin me basta sentar con toda la buena fe de un istoriador qe en el laberinto de aqellas disposiciones ridículas, absurdas, crueles i exqisitamente ignorantes solo impera i resalta el 
propósito de trasladar a España todas las riqezar de la América, manteniendo a los desgraciados colonos en una completa ignorancia de sus recursos, separados de todo movimiento industrial i sin mas empleo de sus facultades físicas i morales qe el necesario a la consecusion de tan ignominiosos fines. Los pechos i gabelas qe con diversas denominaciones establecian las leyes, eran todos encaminados a este propósito, i trababan por consecuencia la industria de modo qe, por lo jeneral, no podia el americano proveer a su propia subsistencia sino comprando al rei el fruto de su mismo trabajo por medio de los tributos desproporcionados a qe se le sujetaba.

Es incuestionable la funesta influencia qe ejercen las leyes coercitivas de este jénero en la sociedad qe por desgracia debe soportarlas. «L0s intereses materiales son el principio i fundamento de todos los demas, dice un profundo i sabio escritor, qe ya e citado (1); i los ai tan esenciales; tan puros i tan sagrados, qe violarlos es retener al ombre en un estadó de violencia, de pobreza, de vergüenza i de mediania, qe le degrada, le embrutece i le arranca la real diadema con qe el Criador ciñó la sienes del señor de la tierra. Tales son las leyes qe constituyen los privilejios de fortuna, los derechos de primojenitura, o sea la vinculacion de bienes, los monopolios de industria o de cultura en favor de determinadas familias i clases de la sociedad; tales son tambien las qe gravan con onerosos tributos los objetos de primera necesidad para el proletario, ora sea sobre el pan qe come, ora sobre la sal con qe sazona sus alimentos, ora sobre las erramientas o útiles de qe ace uso para ganar su sustento. Dar semejantes leyes es cometer un asesinato moral i positivo. Directa o indirecta, voluntaria o involuntaria, una lejislacion de esta clase, bien qe su influencia no sea $\tan$ funesta como la qe ejercen las leyes inmorales, es lamentable i peligrosa.»

A pliqemos esta teoría a nuestro pueblo i la veremos completamente verificada, porqe la experiencia realiza siempre los pronosticos de la filosofía, cuando esta raciocina examinando los echos pasados con la luz de la razon. Empero i qién mejor puede darnos a conocer la influencia de aqellas leyes i preocupaciones qe un testigo presencial, un chileno qe a su veracidad i sabiduría juntaba la circunstancia inapreciable de conocer bien a fondo el estado de nuestra sociedad a fines del siglo pasado, época qe e señalado como la mas a propósito para mis investigaciones, por

(1) Matter De la inlluencia de las costumbres subre las lejes etc. part. 3." cap. 6.॰ 
allarse en ella desenvueltos ya en toda su deformidad los resultados característicus del sistema colonial? El testimonio qe invoco, en calidad de irrecusable para nosotros, es el del filántroyo Salas, qien en una representacion a la corte de España de 1796, describe con vivo colorido el miserable estado de uuestra industria i la consiguiente degradacion de nuestro pueblo.

Segun él era portentoso qe entre los abitantes de los feraces campos de Chile, cuyo moderado trabajo alimentaba a otras naciones, ubiese muchos cercados de necesidades, pocos sin ellas i raros en la abundancia; $i$ sobre todo qe fuese comun ver en los mismos lugares qe acababan de producir pingües cosechas, extendidos, para pedir de limosna el pan, los mismos brazos qe las recojieran. En las plazas, calles i caminos públicos se veia ordinariamente a los desgraciados proletarios ofrecer sus servicios i malbaratarlos en cambio de especies inútiles, porqe no allaban qien les suministrara trabajo para adqirir su sustento. La agricultura i las minas no eran suficientes para entretener la numerosa clase jornalera, pues qe las tierras no se cultivaban sino en proporcion de los consumo so pena de tocar en la decadencia o carestia, i las minas no se laboreaban en todo tiempo, bastando por consiguiente para el beneficio de unas i otras la asistencia de los inqilinos i mitayos o cuando mas la de un peqeñlsimo númeto de braceros libres. De aqí la ociosidad forzada i con ella todos los vicios qe son su consecuencia i a qe el pobre se entregaba con ardor para sobrellevar su desesperante miseria. Iguales desgracias se acian sentir entre aqellos colonos qe a pretesto de su nobleza desdeñaban los trabajos manuales i qe por su indijencia no tenian medios de entregarse a otro jénero de índustria: de este modo la sociedad se consumia por la inercia i se degradaba por los vicios, siendo poseedora de un territorio sobre el cual derramó la naturależa sus preciosos dones con prodigalidad.

El comercio no presentaba mejores arbitrios de ocupacion i lucro a los colonos: reducido el jiro de sus especulaciones « al arte de comprar barato i vender caro, w la concurrencia de especuladores acia vacilar este fundamento erróneo i producia estorbos i desastres qe arredraban. El monopolio qe la metrópoli se abia reservado orijinaba necesariamente demoras e incertidumbres qe embarazaban este jénero de industria: a ninguno le era permitido comprar otros efectos qe los qe de vez en cuando arribaban a nuestras costas en alguna embarcacion de las privilejiadas, i era de todo punto imposible exportar las producciones de nuestro suelo, a no ser qe se vendieran a los qe tenian el derecho de comprarlas i trasportarlas al Perú, aprovechándose siempre de las necesidades de los productores para tiranizarlos e imponer- 
les las condiciones onerosas qe su interes les sujeria (1) . Los impuestos, por otro parte i los defectuosos medios de comunicacion se unian a las infinitas trabas qe nacian de este órden de cosas i anulaban los bienes qe la nacion podria aber reportado del comercio, ciñendo sus provechos a un peqeño número de individuos.

El estado de las artes era proporcionalmente mas degradado, solo existian las mui necesarias a la vida i en tan completa imperfeccion qe sus toscos i deformes productos apénas bastaban a subministrar una escasa subsistencia a los pocos qe se dedicaban a ellas para desertar luego con mas vicios a soportar la miseria en la ociosidad.

Ved aqí en compendio el deplurable estado de nuestra industria i los efectos qe en nuestro pueblo producia la influencia profundamente corruptora del sistema legal i consuetudinario de los conqistadores. La metrópoli misma los conocia demasiado bien i participaba asta cierto punto de estos males con una incuria en mi concepto bien extraña. El mejor comprobante qe puedo presentar en este punto es el informe echo a Fernando VI con motivo del espediente formado en Chile para contener i reducir a debida obediencia a los Araucanos. El autor de tan interesante documento, despues de aber descrito con exactitud el reino, discurre acertadamente sobre su despoblacion i acerca de la pobreza i miseria en qe se allaba despues de mediado el siglo último, a pesar de sus exuberantes campiñas $i$ sus infinitos elementos naturales de riqeza, i continúa en estas razones. (Falta a la mayor parte de los abitantes de Chile lo mui pre") ciso para una decente pasadia. El teniente jeneral, Conde de "Superunda, siendo gobernador del reino, izo extender por " todos los partidos la voz del beneficio de los seis títulos de „ Castilla qe V.M. se dignó conceder el año de 1744 para la » fundacion de los nuevos pueblos, qe se proponia en los pro") yectos citados. Nas no ubo qien se alentase al beneficio de nin" guno de ellos, como costa del espendiente, donde tambien se * allan muchas pruebas de la suma pobreza de agellos na" turales: basta saber qe a excepcion de las cercanías de Santiago „i de las inmediaciones de los pocos pueblos qe ai en el reino i) no vale cada fanega de tierra buena mas de un real deplata.....

(1) El valor de todos los frutos nacionales qe se exportaban por los monopolistas era el siguicnte:

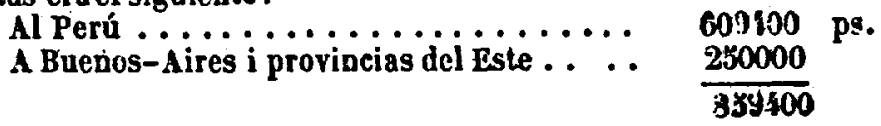


"Ya no es de extrañar, qe en vez de conseguir algunos calln dales para los gastos inexcusables de la corona, tenga de costo " a V.M. la manutencion de aqol reino la cantidad de ciento ") setenta mil pesos fuertes, qe se remiten anualmente de las caग) Jas reales del Perú; los cien mil para el ejército o tropa de " Chile i los setenta mil para el precidio de Valdivia, i toda* vía se reqieren mayorescantidades; pues el teniente jeneral, ") conde de Superunda, ministro tan celoso de los intereses rea" les, representa a V. M. ser necesarios anualmene otros 62000 " pesos fuertes, para conservar el reino sobre la defensiva, como " se verá en breve. I no ai qe esperar la redencion de este pe) sado gravámen dela corona, mientras permanezcan la despo" blacion i miseria de aqel reino.

( Este es el estado infeliz de la parte ge ocupan los españoles " i no es mas próspero el qe se esperimenta en la parte de los in" dios rebeldes. ..... (1)."

Basta en mi concepto este lijero apunte para concebir asta qe grado llegaba el funesto influjo de las leyes industriales i extravagantes costumbres de nuestros conqistadores para mantener en deplorable indijencia a nuestra sociedad $i$ en una completa $i$ degradante inercia al individuo. La metrópoli llen aba con esto su propósito i se desdeñaba por supuesto de remediar aqellas desgracias, porqe eso abria sido apartarse de su sistema; sin fruto cierto i con peligro:

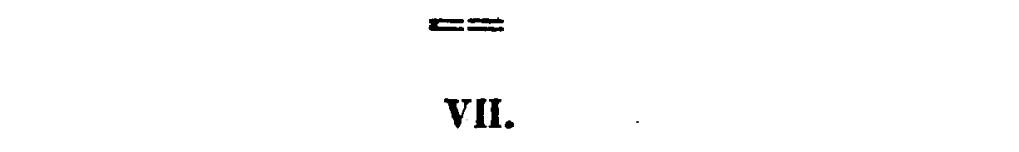

INTESTIGACIOŃBS SOBRE IA INYLUENCIA DEL SISTEMa

COLOKIAL EN LAS COSTURBRES PRIVADAS I EN FL

Cabactbr DR los chilemos.

Ya abreis observado, señores, qe me e esforzado en estudiar el carácter i tendencias de nuestra sociedad, analizándola imparcialmente en los principales elementos qe la componen. A efeeto de conocer como an venido estos elementos a formar esa unidad de nuestro pueblo, qe podemos llamar su existencia moral, los e observado en su orfjen, en las fuentes de donde emanan, es

(1) Vénse el Remanando emoitito de Fadrid, tomo 23. 
decir, en las leyes i preocupaciones de la nacion qe nos dió vida, i los e seguido en todo su desarrollo progresivo asta manisfestar como an influido en las costumbres, en las creencias i en la condicion de los ombres qe constituyen las dos clases de nuestra sociedad durante el coloniaje. Para completar mi plan será preciso qe observe todavía al colono en su vida doméstica, en sus costumbres privadas, qe son las qe mas propiamente revelan su fondo e inclinaciones individuales, para deducir de á los antecedentes necesarios a fin de conocer el carácter de las jeneracionee qe oi forman la nacion.

Mas ya e sentado las bases de estas indagaciones: al ablar de las leyes i preocupaciones españolas qe esclavizaban la intelijencia del colono chileno, impidiendo su desarrollo natural, amortiguando su actividad i fatigándola en cuestiones antisociales calculadas para mantener el fanatismo i la servidumbre perpetuamente; al ablar de las leyes i preocupaciones qe icieron desaparecer al pueblo indíjena, qe condenaron a la degradacion a los mestizos, qe fascinaron con qimeras i monstruosas aberraciones a la primera clase,qe estancaron en su jérmen los elementos de la prosperidad material de la nacion, encadenando la industria i aciendo necesaria la pobreza i el aislamiento; al ablar de todo esto, repito, znó e disceñado $i$ aun descrito ya las costumbres privadas i el carácter de esta sociedad a qe se dirijen mis investigaciones? Tengo para $\mathrm{ml}$ como fuera de duda qe an debido influir tambien en la vida del colono, dando cierto colorido $i$ estabilidad a sus ábitos domésticos i a sus inclinaciones individuales una propension especial, esas mismas causas qe an orijinado i desenvuelto sus costumbres sociales; aciendo de ellas un todo moral, qe constituye el espíritu de nuestra sociabilidad i qe se descubre en donde qiera qe observemos al ombre en contacto i relacion con el resto de sus coasosiados, Fijemos sino la atencion, para convencernos de qe así se a verificado, en lo qe nos refieren todavía de la sencillez, inocencia i pureza de las costumbres coloniales los ombres de tradicion qe aun recuerdan aqella época fatal, lamentando no pocas veces con una candorosa falta de juicio su desaparicion; oigamos discurrir al dignísimo obispo Villarroel, qe a mediadus del siglo diez i siete ablaba sobre las costumhres de su diócesis de Santiago, i nos convencerémos de qe el ombre en sus relaciones privadas no era diferente de lo qe aparecia cuando se le consideraba como ombre social: al contrario, siempre llevaba la marca indeleble del sistema de sus dominadores. Para comprobar aqel santo prelado la simplicidad de la vida de los chilenos, pondera detenidamente la castidad $i$ recato deámbos sexos, "su entereza en la fé cristiana i su ca- 
ridad, considerando sobre todo esta virtud en relacion con la relijion, porqe para el culto divino eran los abitantes tan profusos qe al parecer no daban sino qe derramaban " (1). Ya e indicado otra vez la causa qe acia refluir toda la actividad del colono sobre los placeres del culto relijioso i de las prácticas supersticiosas, $i$ las palabras qe acabo de citar vienen a corroborar mi indicacion, ántes qe a comprobar qe el pueblo supersticioso, ignorante $i$ escla vo no estuviese ocultamente corrompido por todos los vicios propios de su degradacion. El mismo dignísimo prelado no pudo excusarse de aludir a las providencias qe en varias ocasiones abia sido necesario tomar contra el juego, el cual, por sus desórdenadas consecuencias, turbaba la aparente virtud de los colonos. Ese i otros vicios corroian en silencio el corazon de una manera qe no alcanzaba a disfrazar el disimulo, por esto podria aberse dicho con mas propiedad de ese pueblo lo qe Je sucristo decia de los Escribas i Fariceos, qe de fuera se mostraban justos a los ombres, estando por dentro llenos de ipocrecía e iniqidad (2). La práctica del culto externo no supone siempre la bondad en las costumbres ni arguye el conocimiento i práctica del evanjelio, $i$ la sencillez de vida qe se alaba no es otra qe la qe producen en el ombre la esclavitud i el enbrutecimiento.

Es cierto qe las virtudes cristianas no son las qe ménos aprovechan a un pueblo, por cuanto siempre son el oríjen i el fundamento mas sólido de su moralidad; pero sucede necesariamente ge cuando no se mira la divina doctrina del 'Salvador como la hase de la civilizacion i de la libertad, cuando en lugar de considerarla como la mas bella garantía de los derechos del ombre, se la ace servir de instrumento del despotismo, entónces aqellas virtudes no pueden neutralizar los vicios ni disminuir la influencia antisocial qe ejercen los errores $\mathrm{i}$ las preocupaciones qe ejendra i mantiene un gobierno opresor, qe en su propio bien aniqila la sociedad impidiendo su desarrollo. Tal era lo qe sucedia precisamente entre nosotros, de manera qe el fervor conl qe el colono se entregaba al culto externo i a la práctica de sus supersticiones, no puede induciŕnos a creer qe éste poseia realmente las virtudes cristianas, sino qe por el contrario viene a servirnos para esplicar su cordial adesion al sistema qeé le oprima, porqe esas costumbres propendian a mantener siempre en aumento el poder teocrático i el rejio i a fundar mas sólidamente su prestijio. Aqel fervor, siendo resultado natural de este sistema, era propiamente el fanastismo estúpido en qe se apoyaba, era, mas claro, la ciega in-

(1) Gobierno eclesiástico pacífico por el obispo villarroel, tom. 2.•, part. 2.a, cuest. 20, art. 2.॰

(2) S. Mat. cap. XXIII.v. 28. 
tolerancia contra todo to nuevo, de la cual necesitaban esos poderes para mantener al pueblo estacionario e ignorante $i$ dominarlo perpetuamente.

No niego por estio qe la relijion divina del Redentor tenga el mas poderoso inflajo sobre la moralidad de las sociedades qe por fortuna la profesan; ni qiero decir qe en cuanto pudo conjprenderla el pueblo de Chile, dejase de influir benéficumente en su carácter i sus ábitos, para darles simplicidad, para alejar de los ánimos la corruptora desesperaciou qe la esclavitud produce $i$ aun para templar asta cierto panto los efectos funestos de las preocupaciones antisociales ge le acian desgraciado. Al considerar sus costumbres privadas solu atiendo a la parte qe en su orijen i desenvolvimiento a tenido el sistema colonial de la metrópoli. No estoi distante sin embargo de establecer como consecuencia de unis investigaciones, qe el benigno imperia del cristianismo i la pureza de sus máximas an contribuido enérjicamente a despertar i a dar cousistencia a los sentimientos de filantropía i ospitalidad, qe son característicos en el chileno, i juntamente al respeto por la lei i la antoridad, qe tan radicado parece estar en su corazon. No es extraño tampoco qe estas virtudes privadas, qe tanto figuran en los fastos de nuestras costumbres, tengan su orijen en alguna feliz disposicion del carácter nacional i qe deban su cultivo tambien a la influencia de las prendas personales de los majistrados, sacerdotes i demas españoles qe ocuparon la colonia en los primeros tiempos. Mas como giera qe esto sea, no podemos dejar de reconocer el apoyo qe de la relijiun debe aber prestado a esas virtudes, bien qe a mi juicio an contribuido mucho a acer abitual el respeto por las leyes i la autoridad, el poderoso influjo del despotismo por una parte iel réjimen militar por otra, a qe mas - ménos estuvieron sujetos los colonos durante la prolongada guerra de la conqista.

Debo convenir aqf en qe e llegado a tratar una cuestion la mas difícil a mi ver, por la multitudi seriedad de las observaciones qe exije. ¿Q Qé podrẻ decir sobre el cartácter naciunal? \&Es acaso el resultado de las costumbres o influye por el contrario en ellas imprimiéndoles su tipo i trazándoles su curso ? Creo ge es rechproca esta irifluencia, porqe si bien no cabe duda en qe el carácter de un pueblo modifica $i$ aun determina muchas veces fijamente sus costumbres, tampoco la ai en qe estas a su vez modifican el 'carácter, a porqe es evidente qe una abitud qe nos repugna i nos inspira orror al principio, puede llegar a sernos natural con el trascurso del tiempo ( 1 ). 
Reconociendo este principio, justificado por la ist oria, no puedo ménos qe establecer como inconcuso qe al considerar nuestro carácter nacional emos de reconocer como elementos infuyentes en él, tanto las costumbres, i con ellas las leyes i preocupaciones de los conqistadores, cuanto las del pueblo indijena, en la intelijencia de qe la mayoría de nuestra nacion se compone de la raza mista qe deriba su existencia de la union de aqellas dos fuentes orijinarias. Los accidentes físicos de la localidad por otra parte, tambien an debido modificar indudablemente las inclinaciones características de nuestro pueblo, porqe es evidente qe la latitud, la situacion orográfica $i$ en fin el aspecto físico de la naturaleza influyen poderosamente, no tan solo en la organizacion física del ombre sino tambien en la mural (1). En la extension qe media entre los 30 i 50 grados de latitud, qe estaba ocupada por los naturales a la época de la conqista i qe a servido de asiento a la colonia española i consiguientemente a nuestra sociedad, se encuentran diversos climas i variados aspectos naturales: en la parte austral, espesos bosqes, caudalosos rios, espaciosos lagos i elevadas montañas, cubiertas casi perpetuamente de nieves, las cuales cruzan el territorio en complicadas direcciones, encerrando valles profundos vestidos de una vigorosa vetejacion: en la setentrional por el contrario se ostentan dilatadas llanuras, qe se prestan fácilmente al cultivo, colinas apacibles, risueños torrentes i un clima templado i dulce. Estos variados accidentes an determinado el jénero de vida i por consecuencia an modificado tambien las inclinaciones de los abitantes, dando a unos mas severidad, mas independencia i a otros mas suavidad, mas. sumision: en aqellos a debido predominar un elemento disolvente qe propendia a debilitar los vínculos sociales i a dar a las relaciones un colorido agreste $i$ salvaje, $i$ en estos un principio contrario qe los a eho mas pacíficos i mas amantes de la cultura i de la sociedad. El influjo de estas causas se manifiesta incuestionablemente en el pueblo indijena, sus diversas tribus ge tanta omojeneidad tenian entre si qe llegaban a formar una perfecta unidad, diferian nas o ménos en la rudeza de sus costumbres i en la mayor - menor firmeza de su carácter: unas se sometieron casi sin resistencia al yugo del conqistador, adoptando su relijion $i$ confundiéndose con él, $i$ utras permanecen aun con su independencia, su relijion i sus costumbres primitivas (2). ¿ Por qé, pues, no emos de creer, aciendo una induccion rigorosamente lojjica, qe las localidades de nuestro territorio an influido en el carácter

(1) Herder, véase Idées philosophiques sur la histoire de l'humanité.

(2) D'Orbigny, L'homme américaio, 2.॰ part, 3.॰ rameau. 
español trasplantado a esta banda de los Andes, dándole ciertas peculiaridades, qe, modificadas a su vez por sus propias preocupaciones i por las costumbres indijenas, an debido determinar el carácter nacional de este pueblo de qe aora formamos parte?

Con todo, no seria posible diseñar bien a las claras los rasgos peculiares de este carácter, aunqe se pueda fijar el orijen de las preocupaciones $\mathrm{i}$ la tendencia de las costumbres de las jeneraciones criollas qe se an sucedido asta nuestros dias, i la razon de esta imposibilidad se encuentra en varias circunstancias, entre las cuales figuran como las primeras la corta edad de nuestra uacion i la reaccion casi viulenta qe a obrado en ella la revolucion de nuestra independencia. La época de transicion en qe nos allamos ace, pues, demasiado ditfcil este estudio, aunqe no asta cl grado de impedirnos vislumbrar algunas modificaciones de nuestra nacionalidad. Procuremos investigar: observemos al araucano, infatigable viajero, ciego amante de su independencia; veamos su carácter soberbio, independiente, valeroso, inconstante, disimulado, irritable, poco jovial i siempre taciturno (1); i preguntémonos si jeneralmente ablando no se descubren estos mismos rasgos en todo nuestro pueblo i particularmente en el mestizo. Atendamos por otra parte a la influencia del sistema colonial $i$ al conocido carácter español, i encontrarémos un medio lójico de explicar en nuestra sociedad el fanatismo, la intolerancia, el disimulo, o mas bien la ipocrecía con qe se encubren las emociones mas tiernas del corazon i las opiniones mas justas i lejítimas por temores qiméricos; explicaremos finalmente esa lealtad i nobleza de espíritu, esa cordial fraternidad, ese entusiasta amor a la patria, esa feliz docilidad sin abatimiento qe siempre an caracterizado nuestra nacionalidad. Estos diversos caracteres forman todavia una muestra incoerente de lo qe somos, por qe a veces se confunden i se chocan, otras desaparecen o se muestran en todo su esplendor, porqe, como lo e indicado ya, la época de transicion en qe nos allamos i la poca luz qe la istoria de nuestro pasado arroja sobre este punto, acen qe nos sea difícil, sino imposible por aora observar a punto fijo las prendas jeniales de nuestra sociedad. 


\title{
$-261-$
}

VIII.

\section{Algunas ideas sobre ha INFLUERCIA SOCLAL DEL SISTEMA}

\author{
Colontal español en La revulucion D . ha
}

INDEPENDEXCIA.

El estudio de la istoria de nuestro pueblo, en los doscientos setenta años qe permaneció bajo la tutela i servidumbre de la metrópoli, autora de su existencia. me a dado por resultado lójico i necesario las observaciones qe asta aora e apuntado sobre la influencia social de la conqista i del sisterra colonial. Ellas no podrán bastar sin duda a presentar con verdadera precision istórica un cuadro completo de nuestra sociedad, durante la época a qe me refiero, pero a lo ménos podrán subminustrar una idea mas qe aproximativa del estado i de la condicion de nuestro pueblo al tiempo en qe preludió la revolucion de su independencia. ¿Qé era, pues, el chileno en 1810 ? La solucion de esta cuestion importante se encuentra en la exposicion qe e prese ntadu.

Importante llamo esta cuestion i deberia calificarla de fundamental, por qe sin resolverla filosófica e istoricamente, es imposible qe podamos estudiar i conocer de un modo exacto los resultados de nuestra revolucion ni mucho ménos la tendencia qe debemos darla para completar su desarrollo. Sin tomar en cuenta los antecedentes de nuestra sociedad, sin acernos cargo de nuestras preocupaciones antisociales, de sus costumbres i de sus inclinaciones características. ¿Cómo es posible qe veamos en los acontecimientos de nuestra independencia otra cosa qe echos aislados $i$ sin consecuencia ? i cómo es posible qe podamos aprovecharnos de las ventajas de la forma de gobierno qe emos adoptado. Cómo podremos apreciar debidamente el movimiento reaccionario obrado por la revolucion en nuestra sociedad? Es erróneo $i$ aun peligroso juzgar de otra manera: por eso vemos a los pensadores vulgares, cuyos raciocinios 110 tienen otro punto de partida qe las impresiones del momento, encastillarse ciegamente en el vituperio o en el elojio, en temores qiméricos o en esperanzas locas: sin atender a la fuerza de lus antecedentes i sin ver otra cosa qe a las personas, califican los echos de la revolucion de eróicos o ignominiosos a su arbitrio, se asombran de los acontecimientos políticos $\mathrm{i}$ pronuncian sin apelacion su injusto fallo contra las formas i garantías democráticas o bien acojen un buen 


\section{$-262-$}

sotros nos allamos aqi reunidos por la voluntad del pueblo, todos tomaron su partido, cada uno ocupó su puesto en las filas i se trabó el combate (1)).

Fueron pues radicales las revoluciones de Francia i Norte-Amériea porqe apoyándose en las costumbres, $i$ allándose el individuo con la conciencia de su importancia moral i de sus derechos, la fuerza de la reaccion fue necesariamente espansiva i abrazó todos los extremos, aciendo completa la reforma. La nuestra, por el contrario, no siendo consecuencia de iguales antecedentes ni estando apoyada en las costumbres, debió seguir el curso ordinario i fatal de la naturaleza de las cosas i no pudo ménos de ser disimulada en su orfjen i parcial en su objeto i en su desarrollo.

Si los americanos qe al travez de las tinieblas del coloniaje abian columbrado el esplendor de los triunfos de la libertad i de la intelijencia en el Norte de nuestro continente i en la Francia, en lugar de conservar en relijioso silen:io su ilustracion $i$ sus vastas aspiraciones ubiesen tentado romper bruscamente los vínculos qe nos unian a la metrópoli, no solo abrian tenido qe vencer formidables obstáculos para llegar a inculcar su pensamiento en los ombres mas aventajados de aqella época i preparar los elementos $i$ arbitrios qe necesitaban para emprender nuestra emancipaeion politica, sino qe tambien abria fracasado necesaria mente su empresa eróica en el escullo insuperable de las costumbres. Era necesario qe acontecimientos enteramente extraños $\mathbf{j}$ casuales para los colonos vinieran a despertarlos del letaryo $i$ a presentarles una ocasion feliz para emanciparse. Las juntas provinciales gubernativas qe se improvisaron en España con motivo de la prision de los reyes católícos en Bayona, en abril de 1808 i su posterior reclusion en Valencey, sirvieron de estimulu a MIéjico i a Buenos-Aires para qe erijiesen tambien sus juntas soberanas. Tan notables acoutecimientos despiertan la apatia de la servidumbre en Chile i llaman la atencion de los mas ilustrados para imitar aquellos ejemplos; porqe en Chile abia tambien corazones qe en el centro de la esclavitud latian por la libertad. ן Tan cierto es qe el depotismo por fiero ye se muestre, no puede sufocar jaınas aqellos arranqes espontáneos de la naturaleza qe revelan al ombre sı dignidad I Un accidente feliz en aqellas circunstancias viene: a avivar la exaltacion, tal es la oposicion tenaz qe desplega el Presidente Carrascu contra lus deseos de los revolucionarios; desde este momento comienzan a chocarse las

(1) Matter. De lia infuencia de las costumbres sobre las leyes.ptc. part. 2.a, cap. 3.० 
resultado i exajeran sin freno ni cordura su bondad; divisan alguna espontánea manifestacion del desarrollo natural de la intelijencia o de las facultades materiales de la sociedad, i segun la primera impresion qe les produce, alaban o vituperan con frenesí pensando siempre qe de su parte está el acierto i la justicia.

Este modo de proceder injusto por demas i constantemente odioso i perjudicial, debe abandonarse cuando tratemos de apreciar los echos de nuestra vida presente. Atendamos a lo qe fue nuestra suciedad para ver lo qe debe ser i lo qu será. : Estaba o no preparada para entrar a nueva vida i someterse a un sistema diametralmente opuesti: al qe la rijió tres siglos $\mathrm{i}$ bajo el cual se desenvolvi6 su existencia? No por cierto: el colono abia sido precisamente edneado para vivir siempre ligado a la servidumbre i para no desear ni conocer siqiera una condicion mejor qe aqella a qe estaba sornetido; las leyes i las costumbres conspiraban de consuno a ocultarle su importancia moral i a destruir su individualidad; el colono en fin no tenia conciencia de sí mismo i todo él, su vida i sus intereses, estaban absorvidos en el poder real i teocrático, del cual dependia integramente. El sistema colonial se apoyaba pues en las costumbres i marchaba con ellas en íntima unidad i perfecta armonía. Esta verdad nos dá a conocer cuán absurdo seria cunsiderar nuestra revulucion cumo un efecto de nuestra civilizacion i de nuestras costumbres, tal como puede considerarse la de Norte-América i asta cierto punto la de Francia. Los anglo-americanos tenian una manera de vivir profundamente democrática, tenian sobre todo costumbres industriales e intereses mercantiles qe elaboraba en aqel pueblo desde mucho tiempo atrás un elemento poderoso de independencia; así es qe desde el instante mismo en qe estas costumbres i estos intereses Hegaron a ponerse en conflicto con los de la metrópoli, se rompió bruscamente el vínculo debilitado qe a ella los unia, i apareció una república omnipotente qe luego se atrajo los respetos del mundo entero: La revolucion de Francia por otra parte fue un resultado lójico de antecedentes conocidos: desde la muerte de Luis XIV principió a debilitarse el trono $i$ a dejar de estar en armonía con las costumbres e intereses populares, i en la época de Luis $X V$, atrono, parlamento, nobleza, clero, relijion i filosofía, todo se allaba ya en completa guerra u; $i$ no podia ser de 0 tra manera, puesto qe las costumbres estaban en pugna abierta con las leyes i con los intereses del clero i la nobleza. Ubo un tiempo de indecision, las opiniones no podian definirse ni clasificarse, “pero a la primera ráfaga de luz qe esclareció algun tanto el orizonte político i moral de la Francia, al oir de boca de Mirabeau resonar aqellas palabras $=i d$ idecid a vuestro amo qe no- 
opiniones i a dividirse los ánimos. Esta excitacion de todo punto extraordinaria en la colonia ajita de tal modo a los chilenos qe relaja en sus almas los vínculos qe los unian al sistema antiguo: se abla de responsabilidad, se somete a exámen la conducta irregular del presidente, se ridiculiza su ineptitud, se vituperan sus arbitrariedades $i$ al fin se le depone por medio de un movimiento popular ordenado i pacífico, dirijido i promovido por el ayuntamiento de la capital. Estos preludios de la revolucion produjeron por resultado una junta gubernativa qe se instaló en 18 de setiembre de 1810 con el título de conservadora de los derechos del rei durante su cautiverio.

Observando la marcha de los acontecimientos revolucionarios asta julio de 1811 se vé todaría patente el predominio de las costumbres i de las preocupaciones coloniales; todo el pasado aparece influyendo en las deliberaciones $\mathrm{i}$ en las medidas del nuevo gobierno, la idea del monarca sojuzgaba los ánimos i su bien i libertad personal era el único objeto ostensible de todos los procedimientos, por qe no abria sido posible despreciar violentamente su empresa de una manera deplorable. Mucha luz nos dá sobre el estado moral de nuestra snciedad en aqella época, para siempı e metnorable, el discurso pronunciado en la apertura del primer congreso de representantes comvocado en Santiago en julio de aqel año (1), En él aparece ya un feliz desarrollo de las ideas, se concibe la utilidad pública, el bien de la patria, se proclama la soberanía del pueblo i se reconoce la importancia d.l ombre, se inculca la necesidad de una constitucion i aun se deja entrever el deseo de estatuir una forma de gobierno qe contenga al pueblo en la justa obediencia i a los gobernantes en el ér sulo de sus atribuciones, aciendo de la lei el centro de la dicha cornun i de la recíproca seguridad. Empero, estos principios se disfrazan todavía con los antiguos: se lamenta el cautiverio de la augusta familia de los royes, se protesta en qe toda la ndcion obedecerá exclusivamente a Fernando VIl i le reservará a toda costa sus dominios de Chile, aun cuando pierda los demas, $i$ en fin se funda en el bien de este monarca la necesidad de sostener al gobierno qe acaba de establecerse. De esta manera disfrazan i prosiguen su conducta los revolucionarios, mas la idea del soberano va desapareciendo paulatinamente $i$ perdiendo su prestijio en fuerza de los acontecimientos, asta qe es reemplazado por la de la independencia de la patria, cuando la conflagracion llega a acerse jeneral, tomando parte en el movimiento la mayoria de la nacion. 
Es para mi todavía un problema si en este modo de proceder influyó la prudencia de los fautores de nuestra revolucion, o el temor de chocar bruscamente con las preocupaciones sin tener elementos para vencerlas, o bien la limitacion de sus aspiraciones reducidas talvez únicamente al bien de no ser gobernados por un poder extraño qe no estaba revestido de la majestad de los reyes. Curioso i en gran manera útil seria investigar, para resolver esta cuestion, cual de esos móviles o si todos cllus simultáneamente produjeron la conducta de nuestros revolucionarios; pero yo no me detendré en ello, porqe lo expuesto basta a mi propósito de manifestar la influencia del sistema colonial en lus primeros actos de la revolucion de nuestra independencia. Como qiera qe sea, estoi persuadido de qe esta fue lenta $i$ progresiva, parcial i no radical, obra de unos pocos varones ilustres i no nacional, precisamente a causa de ese influjo. No estando preparada la sociedad para recibir el impulso rejenerador, era de consecuencia fatal qe se ciñera únicamente a combatir por su libertad politica, por qe si se ubiese avanzado a romper bruscamente con el pasado, a proclamar su completa rejeneracion, aun tentendo jenios elevados qe la dirijieran en su santa empresa, se abria estrellado en mil resistencias poderosas i no abria alcanzado su triunfu, sino con un completo exterminio i derramando proporcionalmente mas sangre qe la qe costó la revolucion de Franeia. Esto explica a mi modo de ver, no solo las dificultades qe a tenido qe vencer el sistema democrático adoptado en Chile para Hegar a acerse tolerable, no digo firma, sino tambien las causas ge an suscitado la animadversion contra algunos de los caudillos de nuestra independencia, qe pretendian al parecer dar a la revolucion una tendencia radical.

Los ye no se detienen a meditar sobre los acontecimientos i pasan por sobre ellos rápidamente, i los qe se arrogan la facultad de juzgarlos siendo impulsados por intereses viles o pasiones mezqinas, censuran amargamente la conducta de los patriarcas de nuestra libertad. Unos los atacan porqe no supieron dirijir sus esfuerzos contra todos los vicios de la sociedud para rejenevarla de improviso, otros los condenan calíficando de imtempestiva la revolucion i alegan contra su oportunidad los argumentos ge proporcionan la desmoralizacione irregularidades de qe an sido presa los estados independientes americanos. Los primeros cometen un error en qe incurren siempre los qe por un exajerado amor a la umanidad qisieran precipitar los acontecimientos, invirtiendo el órden natural del universo moral. Nuestra revolucion no podia ser completamente rejeneradora ni terminarse tampoco en la última batalla en qe triunfaron los independientes, porqe el 
pueblo solo pretendia emanciparse de la esclavitud sin renunciar a su espíritu social ni a sus costumbres. Es fácil qe el ombre se connaturalize con las preocupaciones antisociales qe le an sido trasmitidas de jeneracion en jeneracion como creencias sagradas i lejitimas, i qe con las costumbres qe en ellas tienen su orijen intime de tal modo su existencia, qe las mantenga i se esfuerze en defenderlas como parte integrante de su ser; pero no es tan fácil abituarle a la esclavitud i a las arbitrariedades del despotísmo. porge siempre geda en el alma algun concepto vago de la dignidad natural $i$ una vez qe un rayo de la libertad fecunda el entendimiento, despierta éste de su letargo i ve a la tiranfa, tal como es, en toda su deformidad. Al proclamarse en Chile la emancipacion del poder monstruoso de los reyes católicos denunciando sus iniqidades i revelando al pueblo sus derechos, mide éste sus fuerzas, se ace cargo de su importancia moral i a la fascinacion de la esclavitud se sostituye la de la libertad; la revolucion se jeneraliza i se encarna en el corazon de la sociedad, todo conspira entónces contra el poder absoluto, la victoria exalta el entusiasmo i redobla los esfuerzos, asta qe se consuma la ruina del despotismo, sellando para síempre la independencia i personalidad de la república. Empero, ¿cuáles son las preocupaciones, las inclinaciones características, cuales las costumbres de esta nacion qe va a constituirse, de este pueblo qe ya no volverá a ser ollado por la planta de los monarcas españoles? ¡Son las ge le inspiró el sistema colonial qe le dió existencia i qe lo dirijió por el espacio de tres centuriasl , Cayó el despotismo de los reyes, i qedó en pié i con todo su vigor el despotismo del pasado, porqe así debia suceder en fuerza de los antecedentes! Los padres de la patria i los guerreros de la independencia obraron en la esfera de su poder, Jlenaron su objeto $i$ al disiparse con el umo de la última victoria el imperio del despotismo, el cañon de Chiloé anuncio al mundo qe estaba terminada la revolucion de la independencia política i principiaba la guerra contra el poderoso espíritu qe el sistema colonial inspiró a nuestra sociedad!

Sobre la opinion de los qe acusan de intempestiva nuestra revolucion es preciso observar en onor de la justicia qe se alla mas fuera de camino i mas escasa de fundamento qe la qe acabo de examinar. Si era icontrovertible el derecho qe la América tenia a ser considerada como una preciosa e importante porcion de la umanidad; si es de todo punto imposible qe pueda llenar los fines de la naturaleza una sociedad qe posée dentro de sí misma todos los elementos de su ventura, cuando está sometida a un poder extraño qe no la conoce i qe la sujeta a su capricho, solo con el fin de sacar de ella todas las ventajas posibles; si una sociedad 
tal no abria podido proveer a su existencia i perfeccion sin usar del derecho natural qe le corresponde de rejirse i gobernarse por leyes emanadas de su propia soberanía, es tambien fuera de toda duda qe lo tenia para emanciparse del poder destructor qe la $0-$ primia, i qe el ejercicio de este derecho augusto e imprescriptible no podia pertenecer a otra qe a ella misma. ¿A qién se abria confiado la facultad de fijar la época mas oportuna para verificar esa emancipacion sino es al mismo pueblo qe debia reportar sus felices resultados? ¿La España acaso u otra nacion cualqiera abrian ofrecido suficientes garantías de imparcialidad i de rectitud en el uso de tan inmensa facultad?

Si los americanos ubieran despreciado la brillante ocasion qe les proporcionó el receso, el aniqilamiento del poder absoluto de la metrópoli, causado por la prision de los reyes católicos; si ubieran permanecido impasibles al mismo tiempo qe la Europa entera se removia en sus cimientos i sus carcomidos tronos se desgajaban con el aliento solo del ombre del siglo; si los chilenos, desperdiciando la alarma qe fomentaba el estupido despotismo de su gohernante, se ubieran limitado a conservar el dominio del reino a un monarca qe principiaba a perder su prestijio i qe carecia de autoridad i de poder para mantenerlos en la esclavitud, abrian tambien sellado su perpetua dependencia, aciendo imposible para In futuro su libertad política. Restablecido Fernando en el gobierno de la Península, destruyó con alevosía las instituciones liberales qe se improvisaron durante su ausencia, desplegó un sistema doblemente mas tiránico $\mathrm{i}$ espantoso qe el de sus antepasados i reintegrando el antiguo poder de su trono, se izo bastante fuerte para mantener su despotismo a pesar de los esfuerzos qe la nacion acia para libertarse. Al considerar tales echos ¿qién puede vacilar en creer qe la Ámérica abria sido tambien presa de su ferocidad, si ubiera tenido el candor de mantenerse bajo la odiosa dependencia del coloniaje, por respeto a los mentidos derechos de la metropoli? Con efecto, las leyes restrictivas i las arhitrariedades de los mandatarios abrian continuado umillando a las colonias i redoblando su dureza, a fin de impedir qe jerminaran los principius de libertad i de civilizacion qe con motivo del interregno pudieran aber prendido en algunos corazones. Y si en algun tiempo la España advertida de sus aberraciones i conociendo mejor sus propios intereses, ubiera moderado su sistema colonial del modo qe lo a practicado últimamente, su prestijio i su poder se abrian robustecido i la emancipacion de la América abria llegado a ser de todo punto imposihle, o a lo ménos infinitamente mas costosa qe lo qe a sido. ¿Se cree por ventura qe abia de llegar una época feliz en qe los colonos preparados por la 
ilustracion i por los ábitos democráticos pudiesen emanciparse sin peligro i adoptar una forma de gobierno liberal sin exponerse a los contrastes qe ocasiona la falta de preparacion? ¿Qimera es esta tanto mas infundada cuanto qe no se advierte qe la metrópoli por su interes mismo, por sus costumbres i por su lejislacion no podia ménos de extinguir todos los jérmenes de civilizacion i libertad qe pudieran con su desarrollo poner en peligro su imperio i disminuir las ventajas de su dominio en el Nuevo Mundo, aun cuando ubiera mejorado su sistema despojándolo de las trabas i restricciones inútiles! Así de todos modos la libertad de los colonos abria qedado reducida a una vana esperanza, cuya realizacion, demasiado costosa en todo tiempo, abria traido sicmpre desastres mas o ménos terribles, qe sirviesen de argumento en favor de la esclavitud. Es, pues, necesario confesar qe los libertadores de América obraron no solo con oportunidad sino tambien con la cordura i fortaleza qe exijia la eroica i dificultosa empresa qe acometieron bajo su responsabilidad.

La influencia fatal de la España i de su sistema en nuestras inclinaciones i costumbres abria sido en todas las épocas bien funesta a nuestra emancipacion, i talvez en otras circunstancias abria opuesto obstáculos mas insuperables a nuestra organizacion i rejeneracion política qe los qe aora tocamos, si los fautores dela revolucion no se ubieran aprovechado de los incidentes felices qe la facilitaron en 810. Vituperar su obra grandiosa, echándoles en cara las desgracias qe a producido el choqe violento de los. antecedentes españoles con los principios rejeneradores es proceder de mala fé o discurrir a tientas : estas desgracias son un resultado necesario, un mal inevitable a qe debieramos abernos sometido, como a una consecuencia natural de nuestra emancipa cion, cualqiera qe ubiera sido la época en qe esta se verificase. Era necesario procurarnos la libertad con todos los males qe nuestra inesperiencia i falta de preparacion debian orijinarnos.

Mas los qe no consideran estos males como un resultado fatal de nuestra educacion, miran en ellos las consecuencias qe arguyen mas elocuentemente contra nuestra libertad i contra la forma politica de nuestra actual organizacion; $i$ esto es atribuir injustamente a distintas causas unos mismos efectos, es cometer el error en qe groseramente incurren los qe atacan la relijion por atacar la supersticion i los abusos de los ombres. Las desgracias qe se deploran no deben arredrarnos ni acernos renegar de nuestro propósito; ántes bien, ellas son el mejor testimonio de qe todavia existe poderosa en América la funesta influencia del sistema colonial qe nos oprimió tres siglos; ellas nos advierten qe, cuando la forma de gobierno establecida i la reaccion qe se em- 
prende no tienen todavia raices en el corazon de la sociedad, debemos ser mas circunspeclos $i$ juiciosos en la reforma i en nues tro ataqe a los antecedentes qe acen difícil la rejeneracion del pueblo. Lil mas sabio i profundo político de los tiempos modernos, al reconocer las causas qe an preparado la crísis qe en el siglo presente sufren las instituciones liberales qe se an pretendido adaptar a los pueblos envejecidos de la Europa i América, se espresa en términos qe convienen del todo a mi propósito.

" Toda la parte servil de la Europa, dice, qe es todavía mui numerosa, a lanzado gritos de alegría, viendo la causa de la libertad desonrrada por los qe se dicen sus defensores. Los escritores retrógrados, admitiendo por un momento nuestros principios, a fill de retorcerlos contra nosotros, i conviniendo en qe deben juzgarse las instituciones politicas segun su tendencia a producir el bien $\mathrm{i}$ perfeccion de todos, an pretendido qe abia mas felicidad i perfeccion en Prusia, Dinamarca i aun en Austria, qe las qe an próducido las decantadas instituciones de la América meridional, de España i Portugal, i aun las de Francia e Inglaterra .... I I aciendo ver el mismo escritor qe este grito insultante a la umanidad no tiene mas qe una falsa apariencia de verdad, porqe no se debe juzgar por las descripciones exajeradas qe acen lus partidarios del despotismo de los desastres qe ocasionan los ensayos de la libertad en los pueblos nuevos, sin tomar en cuenta las desgracias mil veces mayores i mas degrandantes qe causa el sistema absoluto, exclama con la calma del filósufo i la enerjía de la justicia. “Despues de aber repetido a los serviles qe no es dado a ellos triunfar de los liberales, qe todos los errores, qe todas las desventuras de estos no acen qe sus esfuerzos dejen de ser justos i jenerosos, ni convencen de qe el sistema qe se proponian destruir no fuese vergonzoso i culpable, i qe la esclavitud no sea siempre la mayor de todas las degradaciones; convendrémos tambien en qe los propagadores de las ideas nuevas an caido en errores fundamentales; qe advirtiendo el mal qe pretendian destruir, se an formado ideas falsas del bien qe deseaban fundar; qe an creido descubrir principios, cuando solo poseian paradojas; i qe esa ciencia social de la cual depende la dicha de la umanidad, exije estudios nuevos, mas serios i mas profundos; exije qe la duda filosófica tume el lugar de las aserciones i de los axiomas empíricos; exije qe la esperiencia del universo sea evocada para descubrir los vínculos de las causas i efectos, porqe en todas partes ella presenta dificultades qe vencer i problemas qe resolver ( 1 ). )

(1) Sisınondi, Etudes sur les constitutions des peuples libres, intro. pag. 15. 
No existe pues la causa de los males qe. se lamentan en la inoportunidad de nuestra revolucion, sino en la influencia del sistema qe dió vida a esta sociedad qe se rejenera i por consiguiente en sus costumbres, en su espíritu social, en la inesperiencia de los ounbres. Tampoco esos males arguy en contra la emancipacion ni contra la reforma política, sino contra esa influencia mortífera i esas costumbres retrógradas qe obstruyen el curso de la civilizacion en América $i$ acen dificultosa su rejeneracion.

Estudiemos a nuestros pueblos, conozcamos sus errores i sns preocupaciones para saber apreciar los obstáculos qe se uponen al desarrollo de su perfeccion i felicidad, i para descubrir los elementos de ventura qe podemos emplear en su favor. Los éroes de nuestra independencia terminaron su espinosatarea, destruyendo el poder qe nus esclavizaba, i dieron con esto principio a la reaccion social qe en el dia se opera contra lo pasado: a la jeneracion presente i mas qe todo a los ombres públicos qe tienen en sus manos la suerte del Estado, corresponde apoderarse de esa reaccion para encaminarla asta destruir completamente las resistencias qe opone el sistema español antigno ençırnado en la sociedad. Cada paso qe demos en esta revolucion importará uu triunfo sobre los principios retrógrados. La reaccion tuvo su órijen en una guerra a muerte i tomó vigor con el entusiasmodel triunfo; pero aora la paz a' venido a regularizarla i a sostituir la razon cevera al entusiasmo abrazador. Por esto es qe la inlluencia del sistema español, aprovechándose de la calma, se aparece a veces chocando violentamente con la rejeneracion i sublevando contra ella todas las pasiones mezqinas, el fanatismo i lus errores del vulgo; entónces se reproducen los odios de la revolucion, se diseñan $i$ alu se forman los partidos $i$ se preludia una crísis verdadera. Esta pugna es perpetua, aleve, ipócrita i en ella se proclaman falsamente no pocas veces los intereses de la nacion i las yerdadez eternas, para asegurar el triunfo; mas en todos estos movimientos de la parte retrógrada de la sociedad no se divisa otra cosa qe las últimas convulsiones del agonizante poder de la ominosa influencia española. Algun dia llegará la oportunidad de filosofar sobre este combate sordo del pasado con el presente i de manifestar los efectos de la lucha; por aora solo se puede señalar el sitio de la batalla i llamar a todos los buenos chilenos, a los ombres ilustrados para ge tomen parte en ella, siqiera alistándose bajo el estandarte de la civilizacion i reconociendo la criminalidad de los qe excitan la preocupacion i engañan el interes de la sociedad para acerla retroceder! 
Conceusron.

Creo aber llenado mi propósito, señalando la influencia de la España i de su sistema colonial en nuestra sociedad, pero tan léjos estoi de considerar completo mi trabajo, qe no lo miro sino como un simple bosqejo de lo qe a de ser una obra destinada a presentar la istoria de Chile de esta manera filosofica, investigando todos los resultados de aqulla perniciosa influencia. Puede ser qe mi amor a la libertad, mi odio a la tiranía i mis principios me ayan echo alguna vez juzgar nuestros antecedentes istóricos de una manera errónea, en sentir de algunos; pero si tal sucediere, no estoi distante del convencimiento de la verdad, cuando veo qe ella se encuentra en una opinion ajena, mas bien qe en la mia.

E tomado la istoria de mi patria desde el momento en qe el cañon de la conqista conmovió con su estampido nuestras fértiles llanuras i la e seguido asta el primer dia de nuestra gloriosa emancipacion, asta ese dia venturoso i memorable para siempre, en qe comenzó a desgajarse el carcomido trono del despotismo colonial: $\Lambda$ unqe a sido rápida la marcha de mis investigaciones, e señalado el orijen de nuestras inclinaciones i costumbres sociales i e diseñado el cuadro de nuestra vida civil al tiempo de principiar la reaccion obrada por nuestra independencia. Sin el conocimiento de estos antecedentes, no podrémos jamas apreciar esta segunda época, sin duda la mas brillante, de la istoria de Chile.

El desaliento qe se a apoderado de mi alma al contemplar mi trabajo i convencerme de qe no me a sido posible realizar mis deseos, porqe el tiempo i la capacidad me an escaseado, deja de atormentarme cuando veo ge siqiera contribuyo con mi pensamiento a encaminar el estudio de nuestra istoria por la senda qe le traza la filosofía. I Aceptad, señores, con induljencia mi obra, i me dareis en esa aceptacion una recompensa onrrosa qe siempre estimaré con todo mi corazon! 
BESUMBX.

de la remorla núm. 1 sobro la disenterla, presentada a la racultad do Medielna do santlago.

El autor de esta memoria principia por definir la disenteria: Verdadera inflamacion de los intestinos qe tiene comunmente por sitio primitivo el colon $i$ el recto, $i$ le asigna por síntomas característicos evacuaciones mui repetidas con tenesmo de mui poco excremento mezclado con mucosidades sanguinolentas, qe se convierten luego en una serosidad mezclada con sangre, la cual produce grande escosor en el recto i peso sobre este intestino, qe aumenta a medida qe el enfermo ace esfuerzo para expeler estas materias.

Sigue ablando de la antigüedad de la disenteria i de las epidemias desastrosas qe en diversas épocas an asolado grandes ciudades, en qe esta enfermedad a presentado los mismos síntomas qe se notan en el dia; i se contrae a tratar solo de la disenteria epidémica conocida en Chile, donde se le advierten particularidades distintas de las qe se observan en otros paises; fundándose solo en su propia práctica.

Divide la disenteria en lijera, en aguda i en crónica, $i$ les asigna por causas principales el uso de alimentos de diff́cil dijestion $i$ de Irutas inmaturas; el abuso de sustancias estimulantes, de los licoros alcoólicos, del emético i de los purgantes drásticos, como tambien la acritud de la bilis qe en algunas personas puede ser causa de disenterias graves.

Fuera de estas causas enumera otras jenerales no menos poderosas para producirla. Tales son el estado de la atmósfera i las emanaciones de miasmas putridos, a los cuales se debe principalmente la disenteria epidémica qe reina en el verano, en qe sucediendo una impresion de frio en la noche al calor del dia, puede sobrevenir una conjestion sanguinea en los órganos interiores mas propensos a ella. Entre estas causas cuenta tambien la posicion topográfica, pues qe se a obscrvado qe en los paises bajos i pantanosos $i$ en la zona torrida i templada la disenteria es mas frecuente; al paso qe no lo es entre los abitantes de las montañas i de la zona fríjioja.

Esta enfermedad|, esporádica en el invierno i primavera i epidémica en el verano i otoño, ataca indistintamente a toda clase de 
personas sin distincion de sexos, edades ni temperamentos; puede sin embargo decirse qe es mas propenso a ella el temperamento bilioso-sanguíneo.

Observa en seguida qe no debe sorprender qe la disenteria sea el azote mas terrible de la capital, donde ademas de obrar de consuno todas las causas antes enumeradas, los abitantes acen uso por gusto o por necesidad de abundancia de frutas qe no estan en sazon, i de los estimulantes de todas clases, a lo qe se agrega la falta de policia pública i el desaseo de las calles, principalmente en los arrabales de la poblacion. Apesar de la opinion de varios autores respetables, la disenteria, aunqe sea epidémica, no es contajiosa por faltarle todos los caracteres de tal; pues qe no reconoce un principio comun ni una causa única, ni tiene duracion determinada. Sin embargo esta enfermedad puede contraerse por infeccion en personas qe por otras causas estan predispuestas a ella.

Pasa en seguida a describir los síntomas de la disenteria como dolores en el estómago, en el bajo vientre, inapetencia, sed, amargura en la boca, diarrea etc., qe son los precursores; despues dolores en el recto qe se aumentan al tiempo de las evacuaciones qe se acen mas i mas frecuentes; éstas consisten en mucosidades con algunas rayas de sangre, cuya cantidad disminuye a medida qe su número aumenta; pulso mas o menos lijero; semblante pálido, abatido. La disenteria lijera dice ser raras veces epidémica i qe su pronóstico es favorable por lo comun.

La disenteria intensa qe en este pais aparece en verano i en otoño puede ser epidémica, por lo cual se propone fijar en ella su atencion: suele acometer sin síntomas precursores, i desde el principio el enfermo tiene un semblante pálido mui abatido i los ojos undidos, gran fiebre, el pulso mui frecuente e irregular, siente dolores insoportables en todo el vientre i mas en la rejion del coIon i del recto qe se propagan asta la vejiga, produciendo retenciones de orina qe complican gravemente la enfermedad principal; las evacuaciones mui frecuentes son de una serocidad sanguinolenta de color rojo, moreno $i$ algunas veces negro o purulento con algunos pedazos de la membrana mucosa de los intestinos. Si la enfermedad a de tener una terminacion féliz, a los ocho dias todos estos síntomas van disminuyendo por grados; pero en el caso contrario, qe es lo mas comun, aumeitan su gravedad. Las evacuaciones qe se repiten continuamente toman un color negro i una fetidez insufrible; el enfermo en un estado de demacracion extrema tiene el pulso imperceptible e irregular, frias las extremidades $i$ la respiracion-anelosa; el tenesmo $i$ todos 
los dolores cesan i aparece el ipo preeursor de la muerte qe llega de un modo mas o menos brusco.

La disenteria suele acerse crónica cuando ataca suavemente a una persona qe no ace curacion formal contentándose con combatirla cada vez qe ai exacervacion en los síntomas, persistiendo en las mismas causas qe la an producido. A este estado crónico puede pasar tambien la disenteria intensa por consecuencia de alteraciones qe aya dejado en algun punto de los intestinos. En este caso es mas grave qe la primera. Si en esta disenteria llega a formarse infiltracion jeneral, es raro el enfermo qe deje de sucumbir.

No puede aber confusion entre la disenteria intensa $i$ otras enfermedades; pero si puede aberla entre la suave i la crónica i otras afecciones del recto principalmente con las almorranas. Sin embargo es fácil el diagnóstico a la simple inspeccion de las partes i de los sintomas.

Merced a la anatomía patolójica, la naturaleza de la disenteria es perfectamente conocida. Lo primero qe se presenta en la autopsia son las uellas de una inflamacion en la membrana mucosa del conducto dijestivo, en la del intestino grueso i en la cavidad de este las mismas mucosidades qe el enfermo arrojaba en las evacuaciones cuyas mucosidades, algunas veces toman tal consistencia qe parecen imitar a la mucosa misma, aciendo creer qe el enfermo a arrojado pedazos de esta membrana. Se nota en ella un color mas subido, negrusco algunas veces $i$ con un espesor mayor qe en su estado normal. Hai ulceraciones en la última porcion del colon.

Aunqe los autores dicen qe solo por una excepcion de la rugla jeneral la disenteria termina por grangrena, desgraciadamente en Chile esto es lo mas comun, i no ai facultativo qe no cuente un gran número de casos de esta especie.

El autor entra aqi en varias conjeturas sobre la causa de esta grangrena, i sin allar razon para atribuirla a ninguna en particular asegura ser el echo positivo i característico de la disenteria chilena. Empero no cree qe este echo anatomo-patolójico sea suficiente para considerar esta enfermedad como una rectitis, lo cual podria traer mui fatales resultados, sobre todo si se fundase en ello algun método curativo.

Despues de exponer la variedad de sistemas adoptados por los autores para la curacion de esta enfermedad, dice qe el masseguro es el qe suministre la práctica por la observacion de los casos en qe el facultativo aya tenido ocasion de asistir, i aconsejando qe se empleen siempre aqellos medicamentos qe surten in conocido buen efecto, segun la naturaleza de los casos, pasa a manifestar el plan de curacion qe debe seguirse. 
En la disenteria esporádica lijera, dice ser bastante las mas veccs observar nua rigorosa dieta i el uso de la ipecacuana en peqeñas dosis, asta producir el vómito, para descargar las primeras vias, siguiendo un suave laxante para impcdir la irritacion qe pudiese causar la acritud de la bilis; i finalmente el uso de aguas musilajinosas un poco aciduladas a pasto. En la misma disenteria, cuando es epidémica, acons.ja el opio con un poco de acetato de plomo, disminuyendo las dosis si el enfermo se siente narcotizado. Con este remedio asegura aber sanado a muchos enfermos en qe la disenteria se presentaba con un aparato imponente; i recomienda qe se emplee despues de los evacuantes, siempre qe predomine el dolor a la fiebre. En el caso contrario, en qe la disenteria está acompañada de gran fiebre, usa, en su lugar, la ipecacuana en dosıs de vomitivo al principio, i luego en peqeñas cantidades o solas o combinadas con el opio de manera qe produscan un lijero efecto purgante $i$ un estado nauseabundo. Aconseja igualmente en todos los casos medias lavativas de un veiculo emoliente con algunas gotas de láudano, a menos qe el tenesmo sea mui fuerte, o aya almorranas irritadas, en cuyo caso es mas ventajoso aplicar cataplasmas emolientes sobre el vientre. En todas las disenterias dice ser absolutamente necesario, ante todas cosas, sangrar o aplicar sanguijuelas al enfermo, siempre qe su estado de plétora jeneral o local asi lo exijan, a fin de disponer su organismo por este método antillojístico para qe los otros medicamentos produscan su accion de un modo mas seguro.

Cuando la disenteria aparece con todos los síntomas de una fiebre biliosa o qe de simple qe era a pasado a este estado, despues de las evacuaciones sanguineas segun el estado del enfermo, deben examinarse con sumo cuidado las funciones epáticas, y si ai ipertrofia del igado, acritud o dificultad en la circulacion de la bilis o disposicion a la epatitis debe usarse el calomelano como remedio ol mas a parente. Lo administra con mui buenos efectos combinato con peqeñas dosis de nitrato de potasa en unos casos y en o tros con el opio; i si el enfermo tiene mucha propension al vómito, le agrega por toma una cuarta parte de grano de idrocyana. to de potasa; sustrayendo al enfermo de la accion de este último medicamento, en caso necesario, con un lijero laxante oleoso.

En cuanto a los alimentos dice qe solo permite el mui preciso para mantener las fuerzas del enfermo, tomándolo con preferencia del reino vejetal.

Si la disinteria, curada con la ipecacuana, el opio, los evacuantes, etc., lejos de ceder a estos remedios, le a agrav ado presentando síntomas de ulceraciones, debe emplearse el mercurio, aunqe no aya indicio alguno de lesion epática, porqe este medicamento como contra estimulante $i$ absorvente es bastante pode- 
roso para mudar la vitalidad de una membrana qe estando en estado de flogosis por algun tiempo tiene demasiada tendencia a una terminacion fatal. Cuando ai gangrena en la membrana mucosa de los intestinos deben abandonarse todus los medicamentos indicados i usarse los tónicos $i$ anti-cépticos solamente, ya sea en bebidas ya en lavativas, ya en aplicaciones tópicas; i recomienda para las bebidas, la infuciun de quina con el electuarıo de catedra i los jarabes balsámicos; i para las lavativas el clor uro de cal i el nitrato de plata. Recomienda en particular este último en los casos en qe el enfermo arroje pedazos de la mucosa del recto, i sobre todo cuando van mezclados con una sangrasa negra mui fétida, prescribiendo dos o tres granos en un veiculo mucilajinoso combinado con tintura de opio en lavativas administradas tres reces al dia. Dice tambien qe en estos casos se administra con ventaja el nitrato de plata en píldoras qe contengau la dosis de un tercio o un cuarto de grano, aumentada gradualmente asta obtener una curacion completa.

Para la curacion de la disenteria crónica aconseja los mismos medicamentos, con la diferencia de qe es preciso mantener al enfermo en un réjimen dietético por mucho tiempo, aciéndole usar un vestido completo de franelainteriormente. Solo emplea la simaruba i otros tónicos aromáticos, recomendados para esta enfermedad, a fin de restablecer al enfermo en la convalecencia.

Concluye diciendo qe en vista de todo esto seria mui desacertado el pretender curar la disenteria con un solo medicamento, pues qe siendo necesario usar con variedad los remedios segun lá diversidad de los casos, seria una qimera buscar un específico para una enfermedad qe presenta tan numerosos aspectos en su marcha $\mathrm{i}$ terminacion.

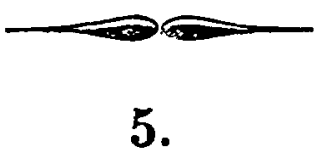

BISAYO

wohre la dimentería en chile.

La memoria marcada con el númuern 2, qe lleva este título, comprende un tratado sobre las diversas clases de disenteria qe se conocen en el pais i qe el autor se propone analizar para exponer por último resultado el plan de curacion, a su modo de ver, 
el mas acertado para esta enfermedad. Para dar una idea de este trabajo a qe la Facultad no a podido ménos qe conceder un mérito relativo respecto de los otros qe se presentaron a su exámen en el presente año, aremos un resúmen sucinto de las 111 pájinas qe abraza.

El autor de esta Memoria principia por manifestar Ins diferentes aspectos bajo los cuales varios escritores de nota, tales como Chomel, Blanche, Sauvaje, Hipocrates, Sydenham i otros an considerado la disenteria, ya con relacion al sitio qe ordinariamente ocupa, ya con respecto a los diversos caracteres qe la acen distinguirse de otras enfermedades con qe parece tener alguna semejanza; $i$ sin aceptar ninguno de los sistemas qe expone, toma por guia a la naturaleza para entrar en el exámen de esta enfermedad, como se conoce en Chile, donde la considera de un carácter especial, de una orijinalidad marcada qe la acen de una naturaleza diferente a la enfermedad qe se conoce con el mismo nombre en las otras partes del mundo, i solo análoga a la ge se conoce en Bengala $i$ en las costas de Africa. La variedad misma de las opiniones de los autores qe cita parece inducirle a formar este juicio, pues qe cada uno de ellos a tomado un camino distinto en fuerza de las observaciones qe a echo en el pais de su residencia.

En seguida despues de definir esta enfermedad, i de describir las div rsas formas en qe se presenta i las complicaciones en qe suele encontrarse con otras afecciones, entra a considerar los distintos estados en qe se encuentran los pasientes segun la especie de disenteria qe sufren; i siguiendo siempre el plan qe se a trazado de observar la marcha de la naturaleza ace tres divisiones de la disenteria, a saber:

La disenteria aguda.

La disenteria flegmonosa.

La disenteria crónica.

Ademas de estas tres divisiones comprende en un capitulo separado las complicaciones de la disenteria con otros estados mórbidos en qe se observa una influencia recíproca.

En la descripcion de la disenteria aguda qe dice ser la mas comun i frecuente en toda la república donde la cree esporádica, i en la capital donde la juzga epidémica en la estacion del verano, le atribuye por única causa el uso de alimentos indijestos i le asigna por sintomas principales: una incomodidad i un abatimiento de fuerzas en todo el cuerpo qe ace repugnante cualqiera clase de trabajo; falta de apetito a algunos dolorcillos e incomodidad en el vientre $i$ una sensacion rápida $i$ jeneral de frio qe se estiende por todo el cuerpo. Hai otros casos en qe la disenteria no se 
halla precedida de estos síntomas, sino qe aparece de repente, pero tanto en unos como en otros se anuncia por un dolor agudo en el vientre qe parece mudar de un lugar a otro i qe mitiga la compresion: sobrevienen en seguida copiosas evacuaciones naturales acompañadas de vientos $i$ dolores en el vientre, las cuales van disminuyendo a medida qe se acen mas frecuentes $i$ convirtiéndose en mucosas i sanguinolentas, asta tomar el caracter verdaderamente disentérico. Estas evacuaciones son precedidas de dolores i acompañadas de pujo mas o ménos fuerte segun la intensidad del mal.

Es de notar qe si el enfermo ace esfuerzos para resistir en cuanto le sea posible a la frecuencia de las evacuaciones, mudan estas de caracter aciéndose menos frecuentes i tomando la forma de un mucus blanco disuelto en una serosidad mas o menos abundante de color trasparente i manchado con olgunas rayas de sangre. Es notable tambien la ausencia dela bilis en tales evacuaciones, en qe no se manifiesta, a no ser qe el enfermo aya tomado purgaute o vomitivo; por lo qe parece qe la parte superior del intestino, el ígado, i las glándulas anexas a él an dejado de funcionar. Ademas de esto prosigue el autor describiendo otros síntomas no menos importantes para caracterisar la disenteria aguda: tales son la sequdad, frialdad $i$ asperesa del cutis, la gran fatiga qe abitualmente se ace sentir en la rejion del estómago, el color blanco de la lengua, la auseneia total del apetito, la blandura del vientre, la debilidad del pulso i la diminucion i calidad de la orina, a lo ge se agrega una perdida completa de las fuerzas.

Aqi el autor de la memoria apunta algunas observaciones qe tiene echas en los adultos i en los niños qe padecen este mal; en aqellos sucede qe despues de algunos dias de curacion con remediog caseros se qedan esperando del tiempo la mejoria, la cual depende por lo comun de la conducta $\mathrm{i}$ temperamento del individuo. Lo mismo dice qe sucede con los niños de los pobres qe, ya sea por falta de medios para curarlos o por neglijencia de sus padres, son abandonados despues del primerperíodo de la enfermedad; de aqí es qe estos enfermos entregados a su antojo, sucumben por lo desordenado de sus alimentos i falta de curacion, siendo mui corto el número de los qe salvan, los cuales vienen a sanar a la entrada del invierno. Del resto, unos mueren de consuncion, la mayor parte cun aftas en la boca 1 con erupcion cerea del orilicio; $\mathbf{i}$ otros con un edema jeneral en todo el cuerpo.

Observa tambien qe si en las personas qe an padeciojo disenteria aguda ai alguna predisposicion a otra enfermedad, desaparece aqella, i esta toma un impulso extraordinario. En este caso se alla la tisis principalmente en los jovenes. 
Respecto de la disenteria flegmonosa, qe se observa en Chile con un carácter particular de malignidad, dice ser $u_{n}$ error creer qe es peculiar a este pais, pues qe se conoce tambien en la India, en el cabo de Buena Esperanza i otros lugares; siendo de notar qe es mui poco frecuente en los paises cálidos como en el Brasil, el Perú, las Antillas i el Ejipto donde raras veces se observa, apesar de lo comun qe es la disenteria aguda. Lo mismo dice respecto de la Europa donde solo se a visto aparecer esta disenteria gangrenosa en los ospitales, en los campos de ejército $i$ en las cárceles; por lo qe solo puede atribuirse a influencias puramente locales. Sin embargo no trepida en asegurarqe aun cuando esta enfermedad aparece en otras partes, en ninguna es tan frecuente ni ace mayores estragos qe en Chile. Atribuye esta circunstaneia a la complicacion con las afecciones crónicas o agudas del ígado ge tambien son mui frecuentes, aunqe por otra parte sun de extrañar tales afecciones por ser propias de los paises cálidos.

Despues de analizar los fundamentos qe an tenido algunos escritores celebres para dar a esta enfermedad varios nombres, tales como el de disenteria tyfoida, disenteria maligna idisenteria flegmonosa, el autor de esta memoria adopta este último por ser el mas comprensivo de todas las disenterias verdaderamente inflamatorias $i$ qe tienen mas analojia con el flegmon difuso del ilustre Dupuytren, a cuya opinion lo conduce la marcha dela gangrena observada en esta enfermedad, en qe los pacientes arrojan no solo membranas, sino pedazos del intestino mismo en qe tiene su sitio; i para confirmarla mas expone un echo observado en Santiago por el doctor Cox $i$ otro en el ospital de Valparaiso observado por el autor. En el primero, en qe la enferma felizmente fué salvada, qedó con una fístula recto-vajinal, i en el segundo en qe el mal términó por la muerte, la autopsia del cadáver manifestó todas las lesiones de los intestinos producidas por la gangrena.

Pasa en seguida a describir los síntomas qe acompañan a esta clase de disenteria $i$ los signos qe pueden acerla reconocer con distincion de la disenteria aguda simple, cuya confusion puede traer consecuencias las mas funestas.

En el principio el vientre se pone duro, doloroso al tacto, especialmente en la parte inferior al ombligo ien la rejion del estómago; la cara manifiesta tirantez i los ojos i el semblante todo expresa in : qietud: el enfermo desea estar acostado de un lado, con el cuerpo i las piernas encojidas; la lengua es plana, blanqisca en la base $i$ colorada en la punta; es tambien, oseca i pegajosa o úmeda, colorada i aguda; gran sed, $i$ algunas veces vómilos; las evacuaciones 
son mui frecuentes, aunqe no distintas de las descritas en la dísenteria aguda; el orificio anal se irrita, se pone doloroso i el enfermo por esta causa repugna las lavativas. En un período mas avanzado las sfincteres pierden su elasticidad i la parte inferior del recto sale fuera; la respiracion es ajitada $i$ algo contenida a causa de los dolores qe produce en el vientre; la orina mui encendida deja un sedimento abundante de nitrate de amoniaco i ácido urico; el pulso frecuente, algo lleno i el cutis caliente i seco.

Estos síntomas qe asta aqí no manifiestan sino la disenteria en estado inflamatorio son dignos de ta mayor atencion, porye luego la enfermedad dejando su sitio primero, se extiende a otros; i si entónces no puede contenérsele, el enfermu se enflaqece en extremo, las evacuaciones siguen en su frecuencia, toman un color negrusco, como de sangre corrompida, se ponen mas fétidas i se arrojan en ellas unus pedazos verdosos o negruscos qe parecen partes de la membrana mucosa. El abdómen se llena de gaces, se eleva i se pone sonoro en todas sus partes, lo qe depende de la poca elasticidad qe tienen los intestines para espeler tales secreciones i de la fermentacion pútrida qe principia a establecerse en ellos; la lengua se pone seca, áspera o lisa; la sed continua, i la orina qe exala un olor amoniacal, se ace mas turbia qe ántes, sucediendo no pocas veces qe personas qe nunca an padecido de las vias urinarias son acometidas de una disuria o extranguria tan tenaz qe ace necesaria la sonda; las lesiones del cutis se ponen azules i esqimosas como en las tifoides; el cutis en jeneral se pone frio i cubierto de un sudor pegajuso; las extremidades se enfrian, $i$ el pulso es peqeño, insensible $i$ frecuente como en las inflamaciones profundas del vientre.

En este estado pueden aun los enfermos, segin el autor de esta memoria, adqirir todavia su restablecimiento $i$ se observa qe en este casu arrojan con ménos dificultad las menbranas qe antes a indicado, advirtiendo qe esto suele suceder aun despues de algunas semanas de convalescencia.

Despues de describir la naturaleza de estas membranas; prosigue indicando los síntomas qe denutan la diminucion del mal: la sangre desaparece poco a poco en las evacuaciones qe se acen cada vez ménos frecuentes i mas copiosas; la bilis vuelve a presentarse principalmente si el enfermo a tomado algun remedio para promover las segreciones ipáticas; el vientre está mérıos adolorido i mas blando; la leırua se umedece; el apetilo principia a acerse sentir; el pulso se eleva, adqiere mas fuerza, mas volúmen i se ace ménus frecuente, i por último vuelve el calor a las extremidades.

Lo qe acaba de decirse se refiere solo al caso en qe el enfermo 
recupere la salud; pero en el caso contrario prosiguen los síntomas de una funesta terminacion, particularmente si el enfermo está privado de la asistencia de un médico atento i experimentado a cuyos cuidados, por la impaciencia de los deudos del enfermo, suelen sostituirse por la desgracia los de una médica casera o del campo.

$\Lambda$ este estado crítico sucede el desencajamiento del semblante, poniéndose la cara completamente ipocrática, la flaqeza i debilidad llegan a su extremo; el paciente pierde el movimiento, le sobrevienen el ipo, el delirio, sudor frio, el pulso se ace intermitente $e$ insensible i por fin mnere.

La disenteria aguda i aun la flegmonosa podrian considerarse como cronical, cuando toman un carácter de duracion qe se extiende mas alla de lo qe ordinariamente podria esperarse, i cuando el individuo atacado despues de cierto tiempo recupera en todo o en parte la salud, recayendo en la enfermedad con alternativas mas o ménos frecuentes. Sin embargo, como ai otras varias circunstancias qe dan a esta enfermedad un carácter verdaderamante crónico, se ace necesario formar una especie separada.

Divide el autor esta disenteria en cuanto a su oríjen en tres clases. En la 1. coloca a los enfermos qe recuperan enteramente la salud: en la $2 .^{\circ}$ a los qe qedan con gran susceptibilidad en los órganos dijestivos, de manera qe el mal reaparece por la influencia de causas casi insignificantes; $j$ en la $3 .^{a}$ a los qe por efecto de la disenteria aguda o flegmonosa an qedado con alguna desorganizacion en el intestino.

El autor de esta memoria se detiene algun tanto en explicar les fenómenos qe se observan en los enfermos atacados de la disenteria crónica i los motivos mas o ménos graves qe la acen tan tenaz, agregando algunas observaciones qe a echo por sí mismo.

Entre aqellas menciona el apetito extraordinario qe sobreviene a algunos enfermos qe parecen no saciarse por mui copiosa qe sea la cantidad de alimentos qe tomen; i entre éstas la observacion de un niño a qien curó por algun tiempo, i en cuya autopcia pudo reccnocer las causas del mal i su marcha asta su término. Algunas veces, dice, qe esta enfermedad cesa de repente por la expulsion de alguna membrana aderente al intestino qe la mantenia, pero qe las mas veces, siendo causada por alteraciones incurables de este órgano, consume al enfermo lentamente, el cual llega a su última ora conservando su entero juicio $i$ aciendo grandes proyectos como sucede en los tísicos.

La disenteria ademas de los estados en qe el autor la a considerado asta aqí, la mira tambien como complicada con otras en- 
fermedades i especialmente fija su atencion sobre la disenteria emorroidal.

Esta enfermedad, qe es compañera o consecuencia de las otras disenterias, consiste en una relajacion de los vasos emorroidales complicada con úlceras en el recto $i$ ordinarianıente con dilatacion de los esfínteres del ano. Su tenacidad la ace considerar como una de las lesiones mas difíciles de curar; i aunqe esto se consiga a fuerza deconstancia $i$ trabajo, vuelve a aparecer de nuevo con mucha facilidad.

Principia la disenteria emorroidal por unos tenesmos mas o menos fuertes i evacuaciones mas o menos frecuentes ya de sangre pura, ya mezclada con algunas mucosidades, ya de mucosidades solas, ya en fin naturales, sólidas sin sangre o seguidas de un poco de sangre fluida. Esto último es el signo mas propio para pronunciar el diagnóstico con toda certidumbre.

Los pacientes no sufriendo mas incomodidad qe unos dolorcillos en el vientre i las dichas evacuaciones, se acostumbran con su mal i lo miran con la mayor indiferencia. Descuido es este de mucha trascendencia por cuanto esta enfermedad los expone a contraer la disenteria llegmonosa, o mas bien una epátitis crónica qe tarde o temprano no deja de aparecer como sucede en la disenteria crónica.

En la complicacion de la disenteria con la epátitis, observa el autor qe la epátitis crónica como la aguda, qe son propias de los temperamentos cálidos como los tropicales, se encuentra en Chile con tanta frecuencia, al paso qe apenas se advierte en otros paises análogos, como lo son el Portugal, la España, Arjel, NápoJes, etc.; i no alla a qe atribuir este fenómeno sino a uno de aqellos misterios naturales qe no es posible explicar.

La epátitis complicada con la disenteria, aunqe ocasionada por ésta, toma el carácter predominante, permaneciendo siempre la disenteria en el segundo grado. Advierte tambien qe es tal la disposicion en este pais a la disenteria, qe muchas enfermedades como la tisis, el cancer de la madre iotras qe en Europa u otras partes se complican con la diarrea, aqú toma ésta al momento el earácter disentérico; de aqi es qe por esta predisposicion, por la qe tambien ai a la epátitis i por la gran simpatia qe existe entre los intestinos ì la glándula epática, mui pocas veces podrá permanecer una de estas dos enfermedades sola, sin qe al cabo de algun tiempo no suceda la complicacion, la cual se efectua en cualqiera de los tres períodos de la lesion epática.

Comprueba este echo con una observacion qe izo en el ospital de Valparaiso en un enfermo de 30 años de edad i de buena cons" 
litucion, qe entregado con exceso a las bebidas alcólicas, se vió por consecuencia atacado de epátitis aguda. Principió por sentir un dolor sordo en el costado derecho i en la cintura, inapetencia i frio de pies. El igado aparecia inchado pasando de pulgada i media del burdo inferior de las costillas. La lengua estaba blanca i algo colorada ácia la punta. Tenia sed, anorexia. A este estado sucedieron algunos calofrios, pero al dia siguiente abia aumentado la inchazon del igado -qe abia pasado tres pulgadas i media para abajo de las costillas, formando un tumor considerableqe se levantaba mas de una pulgada sobre el nivel del vientre i mui doloroso al tacto. El aliento fétido, el cútis frio, el pulso peqeño manifestaba la gravedad en qe se allabael paciente, lo cual fué prosiguiendo, apesar de la actividad de las medicinas qe se le aplicaban. Tres dias despues el dolor persiste i se estiende asta el ombro derecho $i$ un sudor pegajoso se manifiesta. Abiéndose curado un sedal qe se le abia aplicado en el sitio del dulor con unguento mercurial, se mejora el enfermo, el dolor disminuye, el apetito vuelve $i$ el sudor desaparece. En seguida aunqe el tumor se ablanda i parece fluctuar, ai dolores en el sitio qe ocupa, gran debilidad en el pulso i notable abatimiento en las fuerzas del enfermo. El mal siempre sigue su marcha, se aumenta pasteriormente la fluctuacion del tumor, aparece el edema en los pies i un calor excesivo en las espaldas. La orina deja un sedimento mucoso i toma un color mas pálido; ien ocho dias mas se presenta la ictericia, el edema seace mui considerahle, $i$ elcalor de las espaldas impide dormir al enfermo, asta qe por último sobrevienen las evacuaciones disentéricas, vómitos $i$ expulsion de materias color de ez de vino, en cuyo estado murió despues de cuatro meses de enfermedad i $\mathbf{5 3}$ dias de cama.

En la autopsia se encuentran los intestinos azulejos i llenos de sangre; el tumor del igado está fuertemente aderido al peritóneo; este tumor chteramente fluctuante, encerrado en una membrana es formado del lobulo izqierdo del igado e iguala en volúmen al lobulo derecho; conteniendo dentro como una botella de un líqido verde en qe nadan algunos pedazos grangrenadus 0 sueltos 0 aderentes por un estremo. Se advierten otras muchas lesiones en el estómago i priucipalmenle en los intestinos, en cada uno de los cuales se notan las alteracionez mórvidas qe an producido la disenteria.

Asi como la epátitis aguda puede ocasionar una disenteria aguda, puede tambien suceder lo contrario, de lo cual ai numerosos ejemplos; i el autor en confirmacion cita el testimonio de un profesor de Santiago, miembro de la facultad, qien asegura qe al acer algunas investigaciones anatómicas sobre la disenteria, muirara vez 
a dejado de encontrar en los cadáveres apostemas en el igado.

La misma complicacion qe existe entre la epátitis i la disenteria aguda puede tambien efectuarse en la disenteria crónica. En este último caso, dice el autor de esta memuria, sucede la complicacion de un modo tan insensible qe al paso qe produce tan grandes alteraciones mórvidas, no provoca ningun síntoma positivo de la lesion epática. Se advierte apenas, una qe otra vez, un poco de dolor debajo del omoplato o en el ombro derecho; un semblante triste i un color amarillento, semejante al qe se observa en la diátesis cancerosa. Estos pocos indicios son suficientes para excitar la atencion necesaria sobre esta afeccion qe si no se combate a los principios, es mui difícil contener despues; $i$ cuando se a. desarrollado de un modo indudable, suceden a las evacuaciones disentéricas otras verdes, amarillas o negras espumosas i mui fétidas, qe muchas veces son consideradas por el vulgo como una mejoria en el enfermo. Este sin embargo se va acercando al sepúlcro, i en él se van notando sucesivamente mui mala dijestion, mal gusto en la boca, inchazon i flato en el vientre, tumor o prendimiento en el ipocondrio, edema parcial o jenerali una emanacion estrema.

Fuera de esto existen otras complicaciones de la disenteria, tales como la qe se observa en una enfermedad crónica de la madre, un cancer, una tisis $\mathbf{i}$ otras consunciones; en una neumonia i catarro de los bronqios etc. En Eüropa se a visto en las cárceles i ejércitos complicada con el tifo i entonces parece ser contajiosa. En Chile no se a notado esta complicacion, i puede asegurarse qe ni la ai en los ospitales de Santiago, donde existen reunidos muchos disentéricos, sin peligro de semejante contajio, ni aun bajo la influencia de los calores mas excesivas del verano.

La disenteria suele dejar tras de sí algunas consecuencias qe por su naturaleza son bastante graves i funestas. La mas comun es una estrechez en el canal alimentario, ocasionada de alguna cicatriz; pero el sitio mas comun qe tienen es cerca de la reunion del colon con el recto. Al principio son atormentados los enfermos por un fuerte pujo en ge arrojan algunas mucosidades semejantes a la clara de uevo mas o menos teñidas de sangre, o solamente blancas. El autor a citado ántes el caso de una mujer qe por consecuencia de la disenteria tenia una fístula recto vajinal, i observa qe tambien suele producir la ipertrófia de las glándulas mesentéricas, qe en los niñosi jóvenes predispone a una dejeneracion tuberculosa $i$ en los adultos a indijestiones frecuentes, etc.

Como segun el autor raro es ol enfermo qe se cura de esta enfermedad completamente i para siempre, qedan expuestos a re- 
caidas, principalmente en el verano en qe esta enfermedad es mas comun.

Tratando de las alteraciones anatómicas, asegura qe no a dejado de encontrar ulceraciones en los cadáveres qe a observado, cuando la disenteria a sido aguda, i cuando a sido crónica a reconocido los signos o las consecuencias de tales ulceraciones. Sin embargo cree qe no es necesaria su existencia para qe se produzcan evacuaciones con sangre, $i$ prueba este aserto con la inspeccion qe a echo de los intestinos afectados por medio de un lente fuerte i con la descripcion qe el Sr. Gely de Nantes ace en una memoria notable sobre esta enfermedad, de una especie de pezon formado por un grupo de papilas inflamadas. Para explicar esta opinion qe el autor dice ser exclusivamente suya, entra en detalles mui minuciosos qe omitirémos por no acer demasiado largo este resúmen, contrayéndonos solamente a la teoría en qe se funda. Como las válvulas i papilas son en los intestinos gruesos mas peqeñas i numerosas qe en los delgados, los folículos mucosos qe son en mayor número en los primeros qe en los segundus, deben con toda probabilidad ser afectados mas bien en caso de disenteria o cuando existe una enteritis papilária situada en jeyuno. Es sabido qe la inflamacion de las papilas es la causa de los emorrajias disentéricas; pero en este caso sucede lo contrario, i esplica este fenómeno del modo siguiente. Cuando se inyecta en las arterias mesentéricas de un cadáver alguna materia tenue, eneuentra ésta un pasaje por el interior de la papila i cae en la cavidad del intestino; de manera qe no tiene nada de extraño qe estando estas papilas inflamadas pierdan su elasticidad natural i dejen caer la sangre al intestino durante la vida, asi como sucede con la inyeccion despues de la muerte.

La naturaleza rudimentaria de la papila intestinal en el colon i en el recto, es pues la qe da lugar a la facilidad de las pérdidas de sangre en esta enfermedad. Al contrario las ulceraciones no son las qe producen la emorrajia, pues qe no ai motivo para qe suceda en el interior una cosa distinta de lo qe sucede en las ulceraciones exteriores qe no expelen sangre a no ser ge so las violente. De aqi deduce el autor qe la papila es el primer punto en qe el mal aparece, i qe las ulceraciones qe despues sobrevienen son puramente secundarias.

Por lo demas no creemos necesario insistir mas en este punto en qe el autor se extiende largamente, pues qe las alteraciones de qe trata no son otras qe las qe lleva referidas en las observaciones qe asta aqí se an pasado en revista.

Por lo qe ace a la naturaleza de la disenteria, emite algunas ideas acerca de su fisiolojía mórvida. En primer lugar, dice qe la 
alteracion mas notable $i$ constante qe se advierte despues de la lesion intestinal es la injestion de los intestinos qe cree ser precedida $i$ provocada por una excitacion mecánica en la mucosa dijestiva. Ella, por otra parte, segun la variedad de estímulos, puede determinar aciidentes diversos: puede por ejemplo, en uua mujer jóven, determinar una emorrajia uterina i despues la disenteria; $i$ al cuntrario en un anciano, una emorrojia emorroidal i despues la disenteria; en una persona entregada a los licores, una epátitis i en seguida la disenteria etc. Sin embargo, algunos autores opinan qe esta enfermedad tiene su orijen en una suspension de la secrecion biliosa i cuticular; otros la consideran como reumatismal, i no falta qienes la crean producida por la fiebre intermitente; mas esta variedad de opiniones proviene do la diferencia de climas en qe an escrito : todos tienen razon, por qe, como se a dicho, esta afeccion depende de diferentes estímulos.

Pasa el autor en seguida a considerar las causas especiales de esta enfermedad en Chile i para ello principia por examinar la complexion de sus abitantes. En su primera edad el chileno, segun él, es robusto i fuerte i a los ocho o diez años es ya débil i su estómago está perdido, siendo raros los qe llegan a veinte o veint einco años sin aber sufrido en los órganos de la dijestion. Atribuye este cambio en su naturaleza al modo de alimentarse enteramente desordenado, ya con respecto a la calidad de sus alimentos, ya con relacion a las oras o falta de método para comer. En cuanto a lo primero, reprueba el modo de acer el pan formado con arina las mas veces alterada, mal fermentado i cocido; el uso de la grasa qe para qitarle el olor a sebo se mezcla con ají, el uso de gran cantidad de frutas muchas veces verdes $i$ de mala calidad, de ensaladas compuestas con aceite impuro i rancio, como lo es cl qe comunmente se acostumbra; $i$ por fin, de dulces mas - ménos pesados e indijestos qe producen un efecto laxativo. En cuanto a las bebidas, reprueba tambien el uso de la chicha i chacoll medio fermentados o picados, $i$ el del ponche, elados, como tambien el del mate i té mui calientes. En cuanto a lo segundo, nota qe los alimentos se toman sin ningun órden, pues qe se suceden unos a otros de una naturaleza peligrosa para la salud $i$ esto sin excepcion de oras en circunstancias, lo qe forma una especie de gula de mui mal gusto.

Este desórden trae por resultado la debilidad del estómago i esa susceptibilidad qe es tan jeneral, de donde proviene lo qe se llama flato; enfermedad qe una vez contraida permanece siempre por la persistencia de las causas qe la an producido. Por otra parte, el ígado excitado por los licores u otros estimulantes, tales 
como el mate caliente i el caldo con aji, echa en los intestinos un fluido abundante e irritante qe los mueve demasiado, acelera la marcha de la masa alimentaria, e impide su perfecta alteracion; por cuyo motivo son tan frecuentes los empachos o lienterias i la susceptibilidad de la parte inferior del tubo dijestivo. Asi, pues, puede decirse ge ai una predisposicion a una inflamacion o cualqiera otra lesion intestinal.

Ademas de esto ai otras causas no ménos poderosas ge directamente influyen contra la salud; éstas son las aceqias i pantanos qe se allan en continua putrefaccion, de donde están emanando constantemente gaces mefíticos e insalubres; la disposicion de las puertas i ventanas de las abitaciones, i últimamente el desabrigo en qe jeneralmente viven los niños i las mujeres. El autor entra aql en unos detalles tan minuciosos sobre este punto, qe nos parect qe refiriéndolos se aria mui largo este resúmen, sin necesidad, tanto mas cuanto qe son jeneralmente reconocidos los efec. tos qe producen las causas qe se acaban de exponer.

En cuanto a la curacion de la disenteria, observa el autor de esta memoria qe son innumerables los sistemas qe se an presentado en todos los tiempos i en todos los paises; qe estos sistemas por mui opuestos i chocantes qe sean, an tenido cual mas, cual ménos una roga qe a parecido acerlos exclusivos: asi es qe se an aplicado a la curacion de esta enfermedad los laxantes, astrinjentes, cálidos, frios, aperitivos, desumorantes, alterantes, antıllojísticos, tónicos, excitantes, etc. Sin contar con otras recetas especiales de algunos médicos $i$ aficionados, qe desde la aplicacion al vientre de la sangre de murciélago en cataplasma, aconsejada por el empírico Marcelinus, asta la lavativa del Dr. D. Juan Blest, an llamado mas o ménos en todos tiempos la atencion del público. Cree sin embargo qe apesar de tantos remedios con qe se a creido enriqecer la materia médica, la curacion de esta enfermedad se alla mui atrasada i expone el método qe observa en la chracion de las diversas clases de disenteria qe a enumerado, segun los estados en qe se alla.

En la disenteria aguda dice qe si es poco violenta, administra un purgante suave de maná o aceite de pralma cristi mezclado con aceite de almendras, al dia siguiente un vomitivo de ipecacuana i una lavativa laxante o emoliente, prosiguiendo con estos remedios asta qe se disminuye la irritacion local, en cuyo caso continua con el vomitivo solo por la mañana i el uso de los polvos de Dower por la noche, con lo cual va cesando el pujo $i$ las evacuaciones se van aciendo mas i mas raras. Para el caso en qe sobrerenga seqedad de vientre, qe pucde causar una recaida, administra larativas emolientes $o$ algun purgante tónico, tal como una in- 
fusion de ruibarbo o la disolucion de alguna sal neutra en una infusion de cuasia amara, cáscara de naranja u otra semejante, impidiendo así qe la dureza de los excrementos dañe a las cicatrices recien formadas en el intestino, i procurando al mismo tiempo el completo restablecimiento del enfermo.

Aconseja tambien las bebidas emolientes o temperantes, como la infusion de linaza, de malva, la solucion de goma arábija i limonadas o naranjadas i tambien las aguas de arroz, de cebada, de pan qemado, qe usa cuando ya es preciso alimentar al enfermo.

Los alimentos qe prescribe a los enfermos, tanto en esta disenteria como en la flegmonosa, son compuestos puramente de farinaceos, administrados al principio con musha escasez i aumentados despues gradualmente, asta ge por fin les permite el uso del chocolate, del café i té con leche, de uevos frescos asados i poco, cocidos i dulces de menbrillo, limon, naranja, etc. ; les priva sí el uso de las frutas porqe éstas, siendo mal dijeridas, producen vientos incómodos, cólicos, $\mathrm{i}$ ablandan demasiado el vientre.

Cuando el mal es ménos grave i consiste solo en evacuaciones con sangre, pero sin pujo, dice ser bastante para una completa curacion un purgante oleoso seguido de la agua de ruibarbo, En algunos casos solamente recomienda el uso del opio, porqe aunqe suspende las evacuaciones momentáneamente, suelen éstas volver con mayor fuerza i con grande exasperacion nerviosa principalmente en los niños i mujeres ; por lo qe aconseja qe se administre solamente en la forma qe se alla en la preparacion conocida con el nombre de polvos de Dower, en qe va combinado con la ipecacuana, i obra como sudorífico. No recomienda el uso de los astrinjentes porqe por lo comun prolonga demasiado el mal, i le acen tomar un carácter crónico. Concluye diciendo qe esta clase de disenteria es la mas fácil de curar, pero qe es necesario no cometer ningun desarreglo en la convalescencia, porqe puede volver mui fácilmente bajo una forma mui grave i peligrosa, i por esto aconseja qe se observe el réjimen profiláctcio qe se observaria si tuviese peor carácter.

En la disenteria flegmonosa advierte qe si el mal toma este carácter, debe el médico cambiar al momento de plan para atacarla con suceso. Principia por una o dos aplicaciones de sanguijuelas al vientre i en algunos casos por una o dos sangrias, para lo cual se guia por la violencia de los síntomus locales, i al mismo tiempo administra un purgante disuelto en un líqido mucilajinoso qe ace tomar caliente i en peqeñas dosis. $\boldsymbol{\Lambda}$ esto sigue la aplicacion de cataplasmas emolientes sobre las picaduras de las sanguijuelas, unturas oleosas i lavativas emolientes o laxantes. Administra las mismas bebidas qe en la disenteria aguda i recomienda una mui 
buen aunqe los enfermos la repugnan mui luego, la cual se compone de dos libras de agua, seis claras de uevo, onza i media de azúcar i la suficiente agua de azahar. Al dia siguiente continua el purgante o en su lugar da un vomitivo por cucharadas, cada media ora, asta determinar ánsias i no vómitos, siguiendo con el romitivo, así como con los purgantes, por tres o cuatro dias o mas asta la diminucion de los accidentes.

En algunos casos, cuando teme la supuracion emplea el calomelano, ya solo, ya acompañado con opio o ipecacuana, en altas dósis para obtener pronto la salivacion, algunas veces con fricciones al vientre de una o dos onzas de untura mercurial. Luego qe aparece la salivacion vuelve a los purgantes combinados con alguna infusion tónica, o receta la agua de ruibarbo en dósis purgantes, asta reconocer qe el mal a cedido, lo qe se indica por el pulso qe se pone mas grande i blando; por la menor sensibilidad del vientre $i$ por las evacuaciones qe son mas copiosas i ménos frecuentes $i$ sangrientas.

Cesando este período inflamatorio i volviendo la disenteria a su estado agudo simple o amenazando pasar al estado crónico, prosigue atacándola con los polvos de Dower i los astrinjentes.

Asta aqí solo considera el mal en su principio, pero cuando aparecen los síntomas tifoides, de manera qe ya existe la supuracion o la gangrena, o qe sean tan eminentes qe no den tiempo a qe obre el mercurio, recurre a otros remedios mas eficaces, tales como el nitrato de plata, el sulfato de fierro, el ioduro de fierro i los administra en pildoras cchas en una solucion concentrada de alcanfor, opio i goma arábiga, las cuales deben tener un cuarto de grano de las tres principales sustancias; tomando cl enformo una de ellas cada tres o cuatro oras i aumentándolas en seguida o disminuyéndolas segun sus efectos. Ayuda estas píidoras con lavativas compuestas de las mismas sustancias o creosota en una solucion de goma, alternándolas con las de infusion de café, de rosas, de vino aguado o de agua de malvas o linaza con un poco de agrio de limon, de opio o de bella dona. Con estos remedios cesa la gangrena ; pero como todavia permanece el intestino grueso inchado, es preciso para acerlo volver a su estado normal, mantener las secreciones mórbidas producidas en su cavidad i entonar al mismo tiempo el individuo, i para ello emplea los purgantes ya descritos unidos a los tónicos, junto con un alimento delgado $i$ sustancioso ; i cuando ya es necesario suspender las eracuaciones, por denotar la cicatrizacion de las úlceras pasa a los astrinjentes como en los casos anteriores.

Ace aqi el autor una larga explicacion fisiolójica del modo de obrar de estos medicamentos: en ella se refiere a algunos escrito- 
res qe a tenido por maestros i a lo qe por si mismo a observado Su objeto es, al administrar el purgante, evacuar los intestinos de los excrementos qe pueden irritarlos ; i como tambien es preciso disipar la conjestion de los vasos mesentéricos i destruir la inflamaciou de la mucosa, usa los romitivos i con el mismo objeto las lavativas laxantes. Reducida ya la inflamacion, es necesario suspender el flujo, qe, si persiste todavia, es solo producido por la flojedad de los tejidos qe an perdido su elasticidad i para esto emplena los tónicos. Los opiados qe obran del centro a la circunferencia atacan la conjestion central, i por último los astrinjentes aseguran la curacion i restituyen al intestino su elasticidad primera.

Entre los purgantes da preferencia al calomelano, porqe reune los modos mas eficaces de atacar el mal, aumentando las secreciones intestinales i excitando al mismo tiempo el fgado, las glándulas salivares i el cutis.

El objeto con qe emplea el nitrato de plata, el sulfato $i$ ioduro de fierro, etc., en la forma tifoide es para concentrar el mal en la membrana mucosa i qitarle su carácter de espansion facilitando mucho la supuracion qe es tan ventajosa para contener la inflamacion en sus límites primitivos; i para inpedir la reaccion qe pudiera sobrevenir, i disminuir los dolores i el pujo ocasionados por las la vativas de nitrato de plata, etc., administra luego las de opio o belladona.

En la disenteria crónica, ya sea producida por la aguda, ya por la flegmonosa, ya aya aparecido de repente, aconseja el autor los mismos medicamentos qe acaba de esponer aplicados al último período, es decir, a la supuracion o gangrena, pero sí en dosis adecuadas a la violencia del mal i a las fuerzas del paciente. Ademas si despues solo ai debilidad i supersecrecion recomienda como medicinas mui ventajosas las preparaciones de nuez vómica de Strichnina combiuadas con el láudano, o las limonadas sulfúricas o nitricas, combinadas tambien con los opiados, como igualmente los bálsamos de tolu, copaiba $i$ el agua de a!gitran, alternando unos u otros con un purgante $i$ un vounitivo d:sdo de tiempo en tiempo para mantener el vientre arreglado; i los vomitivos principalmente para cuando ai mala dijestion o sobrevienen dolores flatulentos. Si ai seqedad en el vientre se deben usar lavativas de infusion de manzanilla o de corteza de cidra con aceite de comer o de palma cristi con un poco de jabon u otra semejante. Si ai evacuaciones se remediarán tomando el enfermo la cresa preparada, el subnitrato de bistmulo, las decocciones de campeche, de qina, de simaruba de cáscara de granada, o la solucion de extracto de ratania, etc., lavativas de agua de cal i tintura de opio. En cuanto a los ali- 
mentos, reprueba en este caso los farinaceos qe ántes a recomendado para los otros i prefiere el uso de la carne cocida i sustanciosa, el vino añejo, la buena cerveza inglesa, tomado todo esto en mui peqeña cantidad.

lara la disenteria emorroidal prescribe al principio un purgante $i$ uno o dos romitivos i despues segun la constitucion del paciente, sangrias derivativas al brazo, de una o dos onzas; o sanguijuelas debajo de los brazos, despues de lo cual puede atacarse el guimal sin temor con la vativas de nitrato de plata s̀eguidas de otras de agua blanca o agua de cal en agua de arroz o de linaza con algunas gotas de tintura de opio o de belladona. Suele suceder qe a algunas personas a consecuencia de las ayudas excitantes, sobreviene un estado de infla macion, pero ésta desaparece por medio de lavativas emolientes. Durante esta curacion el alimento debe ser escaso como en la disenteria aguda i deben continuarse la dieta $\mathrm{i}$ los remedios por algun tiempo despues para evitar las recaldas.

Ademas de los medicamentos indicados, expone la curacion profeláctica qe debe observarse en esta enfermedad. Los enfermos atacados de cualqiera clase de disenteria usar deben por algun tiempo camisetas i calzoncillos de franela de lana o de jalgodon; no exponerse al frio o al sereno de la noche sin estar bicn abrigados; tener mucho arreglo en las comidas $i$ almuerzos qe deben componerse de manjares lijeros $\mathrm{i}$ bien cocidos; abstenerse de los licores ácidos i mal fermentados como son la chicha $i$ el chacoli, del té i del mate mui calientes; no comer nunca entre la comida i el almuerzo ni por la noche, principalmente en el verano; i por último no abitar en lugares proximos a pantanos 0 aceqias inmundas.

Sobre la curacion de la disenteria er sus complicaciones no se detiene el autor de esta memoria por ser una materia demasiado larga qe pluede encontrar su lugar cuando se trate de cada una de las enfermedades de qe se suele acompañar. Observa sin embargo, aun qe de lijera, qe los remedios qe lleva indicados modificándolos segun las circunstancias, son los qe pueden producir los mejores resultados.

Aqi concluye el autor pidiendo se le disculpen los defectos qe puedan notarse en su escrito, producido solo por el deseo de corresponder al llamamiento echo por la nueva Universidad a todos los facultativos sobre investigaciones tan importantes para la ciencia. 
6.

RESUMEN

de In Nemorla número 3 .

La Memoria núm. 3, despues de un preámbulo en qe su autor trata de manifestar qe la medicina es una ciencia qe emana de principios jenerales deducidos de verdades compiladas, i qe la disenteria es una de aqellas partes de esta ciencia qe a sido considerada de un modo mas variado, por la diversidad de aspectos qe en todos tiempos a presentado, pasa a describir esta enfermedad enumerando los síntomas qe la preceden i acompañan hasta su terminacion.

Al principio, segun él, siente el enfermo algunos dolores en el vientre, dispepcia, mal gusto en la boca i a veces estipticidad. $\mathrm{A}$ parecen despues evacuaciones desde luego poco frecuentes i naturales, $i$ despues mas repetidas i líqidas mezcladas con sangre; $i$ prosigue describiendo uno a uno todos los demas síntomas qe ya se an visto en las memorias anteriores; con la diferencia qe reconoce una especie de disenteria mas benigna cuando las evacuaciones no pasan de ocho al dia i son ménos fétidas i desnaturalizadas, la cual puede despues de algunos dias tomar una marcha aguda i grave, o lenta i lijera, i termina la descripcion de los síntomas disentéricos con esta conclusion.

« Es pues evidente qe el cuadro sintomático de la disenteria se m nos presenta bajo mil distintas formas; en unas con intensa fie》bre, en otras sin ella; en éstas con evacuaciones en gran nú" mero i sanguineas, en aqellas con escasas deposiciones i no de 》) mal aspecto; ora el organismo todo se conmueve, ora ninguna 》) parte toma en la conmocion.")

De aqi deduce qe es necesario establecer diferencias i variedades qe merecen una atencion separada, para lo cual es indispensable asegurarse del principio o causa a qe debe su orijen el mal.

Ablando en seguida de la teoría de esta enfermedad, encuentra el autor de esta memoria una gran diferencia entre la disenteria de Europa i la de Chile; pues qe aqella, segun la describen los autores, es comunmente el efecto de una selajacion intestinal o de una postracion de las fuerzas vitales, qe mas bien puede considerarse como una diarrea grave, mientras qe en Chile se presenta bajo otro aspecto mui distinto, tanto por su frecuencia como por su 
malignidad; $i$ de esto infiere qe en este pais deben reconocérseles causas locales, constantes $i$ de una decidida enerjía, asi como las reconocen el tifo icteródes en Vera-Cruz, la Plica en Polonia i las intermitentes en el Perú.

Las causas a qe atribuye la frecuencia i malignidad de la disenteria en Chile son: $1 .^{\circ}$ los cambios repentinos de atmósf ıra qe producen contínuas excitaciones en el órgano cutáneo qe simpaticamente se trasmiten al tubo intestinal, comunicándole un aumento de nutricion qe constituye una verdadera irritacion fisiolójica : 2. ${ }^{\circ}$ la sustraccion de la enerjía de los intestinos qe por consecuencia de los calores de la estacion es llamada a la periferie del cuerpo, la cual da lugar a indijestiones, acedias, etc.: $3 .^{\circ} \mathrm{El}$ frio qe en el verano se sucede por la noche a los calores del dia reduce a losintestinos a un grado de espasmo a qe seguirá la atonía, puesto qe no ai fuerzas para una cabal reaccion: $4 .^{\circ} \mathrm{el} \mathrm{u}-$ so qe en dicha estacion se ace de multitud de frutas (las mas de ellas impropias para la asimilacion animal en el estado valetudinario de los intestinos por consecuencia de las causas atmosféricas ántes enunciadas) qe no pueden ser elaboradas completamente $\mathbf{i}$ obran como cucrpos estraños produciendo irritaciones intestinales: 5." el desarrollo de los miasmas pútridos qe en la estacion del verano producen las aguas encharcadas $i$ los restos de materias animales i vejetales qe se allan en fermentacion en todos lus puntos de la capital, principalmente en los arrabales qe la rodean. Esta última causa a dado lugar muchas veces a mortales disenterias, i los anales de la medicina están llenos de echos de esta naturaleza.

Por consecuencia de algunas de estas causas o de todas ellas reunídas sobrevienen al tubo intestinal, principalmente al colon, irritaciones mórbosas, qe alteran su movimiento peristáltico, qe acen desprender demasiadds mucosidades i con ellas mas o ménos sangre; no ai contractibilidad normal en el esfínter del ano, i de aqí las evacuaciones continuas de materiales diversos i la participacion del organismo entero en el sufrimiento de aqellas partes manifestadas por síntomas de fiebre i de afecciones en el estómago $i$ aun en la vejiga.

De aqi tambien las varias formas en qe aparece la disenteria: unas veces es gastro-mesentérica, otras biliosa, otras inflamatoria, otras nerviosa tifoidea; sucediendo otras qe si el organismo se alla bajo la influencia de causas prediponentes a estas afecciones, la disenteria se combine con ellas i determine una complicacion gastro-mesentérica-bilio-inflamatoria-tifoidea.

La disenteria en Chile, segun esta memoria, es por lo comun de una índole inflamatoria, i se reconoce por la fuerza del tenes- 
mo, por lo sanguíneo de las deposiciones, por la sensibilidad dolorosa del abdóınen i por la fuerza del pulso. Su nıarcha suele ser aguda i funesta, pues suele aparecer la grangrena en la mucosa intestinal qe luego sale mezclada con las evacuaciones. Prosigue el autor en la indicacion de los síntomas qe caracterizan las disenterias gastro-mesentérica, biliosa i tifoida, i pasa a varias consideraciones para fundar su opinion de qe la disenteria no es específica en Chile i qe tampoco es de carácter contajioso.

La disenteria de este pais dice ser igual a la qe se conoce en otras partes en qe se an observado epidemias de ella, i segun el testiunonio de muchos-autores, siempre an sido precedidas de las nismas causas, $i$ an obrado las mismas circunstancias, $i$ an cesado luego qe éstas an desaparecido.

Observa qe si en la capital es tan frecuente esta enfermedad es por qe siempre subsisten estas causas, i para probarlo cita por ejemplo lo qe actualmente sucede. En la jente de clase, por las comodidades i la sobriedad en qe vive, raros son los casos de disenteria, al paso qe entre los pobres e infelices del pueblo ace estragos espantosos; i la razon es porqe aun qe los primeros están como los demas sujetos a las mismas influencias atmosféricas, en Jos últimos obra particularmente como causa tópica sobre el conducto intestinal la mala calidad de sus alimentos i bebidas, mayormente cuando ai exceso en ellas. A esto se agrega el mayor desprendimiento de miasmas deletereos en los arrabales de la ciudad, debido a la seqedad del año, qe no puede ser una causa ménos poderosa para la jeneralidad de la disenteria entre los infelices qe los abitan.

No cree insostenible qe la disenteria pueda comunicarse por contajio; pero al ménos tiene por indudable qe se estiende por infeccion, pues qe abiendo predisposicion, puede ser suficiente la mas leve causa para producirla, como se nota cuando aparecen ciertas disenterias intensas qe en breves momentos destruyen el organismo mas robusto i presentan fenómenos ignales a los qe se observan en el tifo. La presencia de muchos enfermos puede causar una alteracion en la atmósfera capaz de producir la misma enfermedad; i si esta infeccion no es suficiente para causar la diserteria, lo es al ménos para predisponer a ella.

En cuanto al tratamiento, dice qe el pronóstico debe ser siempre reservado, aunqe el caso sea de poca consideracion, por cuanto esta enfermedad tiende a prolongarse $i$ a tomar mayor intensidad, principalmente en las personas de mal estado constitucional en qe casi siempre termina por la muerte.

La disenteria debe ser combatida segun el carácter con qe se presenta ; i por esto es qe no puede aber un plan curativo jeneral 
i ménos medicamentos especificos qe surtan buen efecto invariablemente. Las indicaciones qe ace el autor respecto del método qe observa en la curacion de esta enfermedad son las siguientes :

Si la disenteria proviene o es sostenida por una causa saburrosa o biliosa situada en las primeras vias, i si ai una calentura análoga a dichas causas, deben usar los eméticos i purgantes, prefiriendo entre los primeros la ipecacuana, de la cual aconseja qe se aga cocimiento de una dracma en cuatro onzas de líqido i se tome una onza cada ora, consiguiendose con esto desembarazar las primeras vias $i$ aun aniqilar la causa determinaute. Mas si ésta residiese en el bajo vientre se emplearán los laxantes sub-ácidos, principalmente si el gastricismo es bilioso o si ai dejeneracion en los umores gastro-intestináles. Para este fin receta diez granos de acido tartárico, una dracma de sulfato de potasa o de magnesia con medio escrúpulo de nitrato de potasa por toma, la qe se repite asta seis veces en las veinticuatro oras.

En la disenteria inflamatoria, qe es la mas comun, solo aconseja la sangria cuando ai una plétora mui declarada, pues de lo contrario, no sanando el enfermo, podria sobrevenirle un colapso mas temible qe la misma disenteria. En tal caso son buenos los baños atemperantes de todo el cuerpo i sanguijuelas al derredor del ano; tomando ademas seis onzas de emulsion simple con dos de aceite de palma i algunas gotas de láudano. Si apesar de esta medicina persiste la enfermedad en el mismo estado, se apelará al mercurio asta producir una infeccion mercurial, lo qe se consigue con una dracma mas o ménos en las 2'r oras, segun la susceptibilidad del paciente. Es ventajoso acompañar al mercurio el nitrato de potasa por sus virtudes sedantes i resolutivas, pero en repetidas i no en gruesas dosis. Sin embargo, cuando el mal parece invadir la vejiga debe darse en dosis progresivamente mayores.

Si apareciere la gangrena debe cesar esta série de medicamentos $\mathrm{i}$ reemplazarse por bebidas demulcentes anodinas $\mathrm{i}$ algun oleoso, i el nitrato de plata en cortas dosis interiormente i en lavativas.

En la disenteria qe llama nervosa o tifoidea debe adoptarse un plan tónico i lijeramente estimulante, i para ello aconseja la infusion de simaruba a pasto alternada con algun ácido. Las píldoras del electuario Catechu o la disolucion de éste en el cocimiento blanco de Sydenam son medicamentos excelentes cuando la disenteria es sostenida por relajacion intestinal.

Despues de las indicaciones qe a echo del uso de los antiflojísticos, oleosos, demulcentes, del mercurio de los tónicos i de los 
astrinjentes, pasa a ablar de los narcótices i de los especificos.

Entre los primeros coloca el opio recomendado por muchos autores para la curacion de esta enfermedad, pero cree qe no debe administrarse indistintamente $\mathrm{i}$ exceptuarse los casos en qe la disenteria sea biliosa o inflamatoria ; prescribiendo qe se dé en cortas dosis combinado con los oleosos, los demulcentes i con el mercurio i qe siempre se dé con la ipecuacana, ya sea como emético, ya en píldoras mezclada con alcanfor, ya en lavativas.

Entre los especificos porie la ipecacuana, aunge segun su opinion no la considera como un antidisentérico reconocido, a lo qe muchos se inclinan qizas por no conocer su modo de obrar. Aunqe algunos dicen qe la ipecuacana posee ademas de las propiedades eméticas, las excitantes i tónicas, él asegura qe nunca produce buen efecto en las disenterias agudas i flojísticas i qe debe preferirse para estos casos el mercurio, el nitrato de potasa, el fosfato de soda i los oleosos.

Aconseja sin embbargola ipecacuana en infusion acompañada de láudano para aniqilar su propiedad excitante, cuando la disenteria provenga de embarazo estomacal, o de una bilis deteriorada o extravasada, ya sea efecto de una gastromesenteria, ya sea qe esté solamente acompañada de ella. Asi se limpian las primeras vias i se aumenta el movimiento peristáltico intestinal.

En cuanto a las lavativas opina qe deben ocupar un lugar importante en la curacion de la disenteria, pues qe se contraen directamente a los órganos afectados. Los emolientes $i$ anodinos calman la excesiva irritabilidad, embotan la sensibilidad, disminuyen el tenesmo, cubriendo como con un barniz cierta porcion del intestino. Debiendo esperarse los mejores resultados de las lavativas, deben usarse en ellas las medicinas mas propias para la curacion del mal. Son pues importantes el opio, el alcanfor, la ipecacuana; i cuando ai ulceracion o principio de gangrena èl nitrato de plata $i$ otros anticépticos.

Concluye el autor de esta memoria diciendo qe el deseo de ver florecer en Chile el estudio de las ciencias médicas le a impelido a presentarla a la aprobacion de la universidad, aunqe con desconfianza, por no ser fruto de un talento superior i de una antigua $i$ aprovechada práctica. 
yobre la conveniencla 1 objetos de un congreso jeneral americano, lelda ante la facultad de lejes de la univermidad do Chille para obtener el grado de llcenclado, por J. B. Alberdl, abogado en la nepúbllea del Urugual.

Los congresos jenerales, a dicho el abate De-Pradt, son en materias políticas, lo qe las juntas de médicos en la curacion de las enfermedades. Sus dictámenes pueden carecer de eficacia i acierto; pero su reunion supone siempre la presencia de un mal.

Un mal estar social i político aflije efectivamente a los pueblos de Sud-América desde qe disuelto el antiguo edificio de su vida jeneral, trabajan i conspiran por el establecimiento del qe debe sucederle. Todos sienten qe las cosas no están como deb en estar: una necesidad vaga de mejor órden de cosas se ace esperimentar en todos los espíritus. Exuberantes de juventud i fuerzas de vitalidad, dutados de una compleccion sana i vigorosa, nuestros pueblos abrigan necesariamente la esperanza de su curacion en el mal de qe se sienten poseidos. E aqí, señores, la situacion i espíritu qe an excitado constantemente a los pueblos de Sud-América desde el principio de su emancipacion a ablar de la convocacion de un congreso jenteral o continental: $i$ a fé señores qe los pueblos de Sud-América no se eqivocan cuando llevan su vista a este médio curativo de sus padecimientos. Una enfermedad social los aflije. Este echo es real. Las naciones no están sujetas a esas dolencias nerviosas qe a veces acen sentir males qe no existen. Los pueblos ambicionan salir de este estado i a fé, señores, qe tienen razon. Ellos se fijan en la necesidad de una gran junta medical, de un congreso organizador continental, como en uno de los medios de arribar al fin deseado, i es mi creencia, señores, qe tampoco se eqivocan en este punto. Los Estados Americanos no piensan; ni an pensado jamas, qe la reunion de una asamblea seinejante pueda ser capaz de sacarlos por sus solos trabajos del estado en qe se encuentran: pero creen qe entre los muchos medios de susceptible aplicacion a la estirpacion de los males de carácter jeneral, uno de los mas eficaces puede ser la reunion de la América en un punto i en un momento dados para darse cuenta de su situacion jeneral, de sus dolencias i de los medios qe en la asociacion ide sis esfuerzos pudieran encontrarse para cambiarla en un sentido ventajoso. 
En otrá situacion, no ménos grav e qe la presente, en la qe el peligro venia de otra parte, un ombre de instinto superior, señores, el jeneral Bolivar fué asaltado de este grandiusu pensamiento, i el congreso de Panamá no demoró en verse instalado. El remedio abia sido excelente, pero su aplicacion vino extemporáneamente, porqe el mal se abia retirado por sí mismo. El mal de entónces fué la usurpacion americana ejecutada por la Europa. Desde qe vencida por nuestras armas, desistió serıamente del pensamiento de dominarnos, dejo de existir por ese mismo. echo el mal cuya probable repeticion abia dado oríjen a la convocacion del congreso de Panamá. El congreso se disulvió sin dejar resultados, por qe el gran resultado qe debia nacer de él, se obró espontáneamente. Bolivar, señores, no fué un simple poeta, ni un poeta cupista del poeta de Austerlitz, al pedir un congreso de todos los pueblus de América. En ello, por el contrario, se mustró ombre de Estado, i político orijinal: no siempre lo grandioso es del dominio de la utopia: nada mas grandioso qe la libertad, i ella entre tantu es un echo qe se realiza en muchas partes. Un filósolo, señores, un ombre qe piensa i qe no obra, qiero nombrar al abate de Saint Pierre, por ejemplo, puede ser un utopista; pero un ombre de espada, un ombre de accion, es lu qe puede aber mas positivo i práctico en la vida. De este jénero de ombres era el jeneral Bolivar: nadie ménos qe él pudo ser tratado de utopista; por la razon de qe es el ombre qe mas echos positivos nos a dejado en América. I el qe a vencido grandes resistencias es justamente, señores, el mas acreedor a ser considerado como conocedor de los medios $\mathbf{i}$ posibilidad de vencerlas. Ai utopistas negativos, señores, como los ai dogmáticos, i esos son los espíritus escépticos, o mejor diré los espíritus sin vista. Si ai visionarios qe ven lo qe no existe, los ai tambien qe no ven lo qe todo el mundo toca: i no es la ménos solemne de las utopias la qe afirma qe es imposible la realizacion de un echo considerado practicable por el jénio mismo de la accion i por el buen sentido de los pueblos. Bolivar fué tambien orijinal en su pensamiento, pues la América del Sud ofrece tal omojeneidad en sus elementos orgánicos $i$ tales medios para la ejecucion de un plan de política jeneral; de tal modo es adecuado para ella el pensamiento de un órden político continental, qe si no temiesemos violar la cronolojía de los grandes ombres, mas bien diriamos qe Bolivar fué copiado por Napoleon, Richelieu i Enriqe IV. E aqi, señores, los umbres qe como Bolivar an pensado i propendido a la centralizacion continental del movimiento político: todos ellos son ombres de accion, espíritus positivos, grandes consumadures de echos. Cumo ombres de tacto, nunca se infatuaron con la presuntuosa creencia de qe lleva- 
rian a cabo lo qe empezaban i concebian: ellos no prometian dar acabado el trabajo concebido. El gran ombre sabe qe los grandes echos se completan por los siglos: él emprende i lega a sus iguales la continuacion de la obra. Asi el pueblo americano, gran empirista, sino gran pensador, acepta el pensamiento de su asociacion continental, i convoca un congreso, no para qe lo organize de un golpe de mano, sino para qe al ménos dé un paso en la ejecucion de este gran trabajo, qe debe durar como la vida de sus graduales i lentos adelantos. La sínodo o carta orgánica qe salga de sus manos no será lei viva desde la ora de su promulgacion: pero será una carta náutica qe marqe el derrotero qe deba seguir la nave comun para surcar el mar grandioso del porvenir. La Asamblea jeneral i la Convencion francesas icieron constituciones: ¿Qé son oi dia esos trabajos? No son leyes vijentes, ciertamente: pero son tipos ideales de organismo social ácia cuya ejecucion marcha el pueblo a pasos lentos; son la luz qe alumbra a las oposiciones liberales, el término a qe se dirijen todos los conatos i anelos del pais: son esperanza de un bien qe el tiempo convertirá en realidad: ¿Se cree de buena fé qe nuestras constituciones republicanas promulgadas en América, sean en realidad ni puedan ser otra cosa por aora qe esperanzas $i$ promesas, de un órden qe solo tendrá fiel realidad en lo futuro? Pues tambien la América qiere tener escrito i consagrado el programa de su futura existencia continental. Aun cuando el deseado congreso no trajese otro resultado qe éste, él no abria sido infructuosamente convocado.

Este pensamiento tiene adversarios, $i$ los tiene entre ombres dignos i corazones onrrados. Los ai qe le combaten como un medio temible qe los gobiernos tiránicos pudieran emplear para afianzarse mutuamente, en perjuicio de los pueblos qe mandan. Estos ombres merecen aplauso por su nobilísimo celo a favor de la libertad. Pero si aceptásemos sus temores, seria necesario tenerlos tambien por todos los establecimientos de órden politico, desde luego qe no ai uno solo de ellos de qe no pueda acerse Juso funesto en perjuicio de los pueblos: las mismas cámaras lejislatiras, el jurado, serian en tal caso objetos de sospecha i temor, desde luego qe son susceptibles de convertirse en instrumentos de opresion i despotismo político, como vemos qe sucede en ciertos estados.

Otros combaten el Congreso continental suponiendo qe no podrá ser sino reproduccion literal del de Panamá. I a fé, señores, qe no se engañan si en efecto se a de reunir ese Congreso para pactar medios de resistir a una agresion externa, qe no viene ni vendrá para la América. Pero es posible asegurar qe el ve- 
nidero Congreso tendrá mui distintos fines qe el de Panamá,

Censuran otros con especialidad lo intempestivo qe fuera su convocatoria en la época presente, i yo estaria por este modo de ver, si se me designase cuál otro seria el momento mas oportuno de su reunion, i cuándo i con qé motivo deberá llegar ese instante.

Otros, en fin, le son adversarios, porqe no ven los objetos qe pudieran ser asunto de las deliberaciones de tal Congreso : $i$ ciertamente qe su disentimiento no puede ser mas excusable, pues ¿qién podria estar por la reunion de una asamblea qe no tuviese porqé ni para qé reunirse? Pero a mi ver, son estos justamente los qe mas se eqivocan en su oposicion, $i$ cuyo error merece ser contestado con anticipacion a los en qe incurren los otros opositores ; pues con solo dar a conocer los objetos de interés americano, qe pudieran ser justo motivo para la convocatoria de una asamblea continental, se consigue desvanecer en gran parte las objeciones de temor e incertidumbre qe se oponen a su realizacion.

En vista de esto, señores, yo me ocuparé sucesivamente: 1.॰ de numerar los objetos e intereses qe deberán ser materia de las decisiones del Congreso : 2.० De acer ver las conveniencias aceesorias qe una reunion semejante traeria a cada uno de los pueblos de América qe concurriesen a ella : i $3 .^{\circ}$ de refutar las objeciones qe se an echo sobre los peligros e inconvenientes, qe se seguirian de ella.

Colocaré a la cabeza de los objetos de deliberacion el arreglo de limites territoriales entre los nuevos Estados. Este asunto tiene mas importancia de la qe descubre a primera vista. Esta importancia no reside precisamente en la mayor o menor porcion de territorio qe deba adjudicarse a los estados qe contienden sobre esta materia. En este punto el paño es abundante en América, i la tijera del congreso puede retasear fragmentos mas grandes qe la Confederacion Helvética, sin temor de dejar estrecho el vestido qe debe llevar cada Estado. El terreno está demas entre nosotros, i la américa no podrá entablar contiendas por miramientos a él sin incurrir en el ridículo de esos dos locos, a qienes Montesquieu supone dueños solitarios del orbe, i disputando por límites. Sin embargo, no fuera difícil qe la preocupacion por el interés territorial, qe recibimos sin exámen del ejemplo de la política europea, trajese desavenencias con ocasion de los conflictos de límites oi pendientes entre la República del Plata i Bolivia, entre el Estado oriental i el Brasil, entre Bolivia i el Brasil i algunas otras de este mismo brden entre otros Estados. Seria oportuno qe el congreso se ocupase de dar a este respecto un corte capaz de prevenir las desavenencias, qe pudieran oriji- 
narse de la discusion directa $i$ parcial de los interesados. Pero este es a punto estrecho de la cuestion de límites. A mi ver esta cuestion es inmensa i abraza nada ménos qe la recomposicion de la América política. La América está mal echa, señores, si me es permitido emplear esta expresion. Es menester recomponer su carta jeográfico-política. Es un edificio viejo, construido segun un pensamiento qe a carucado : antes era una fábrica española, cuyos departamentos estaban consagrados a trabajos especiales, distribuidos segun el plan industrial i necesario del fabricante : oi cada uno de los departamentos es una nacion independiente, qe se ocupa de la universidad de los elementos sociales, i trabaja segun su inspiracion i para sí. En esta ocupacion nueva, en este nuevo réjimen de existencia, no siempre encuentra adecuado i cómodo el local de su domicilio para el desempeño de sus multiplicadas i varias funciones, i tendria necesidad de variar el plan de su edificio; pero tropieza en los límites qe estableció la Metrópoli monárqica, i qe a respetado la América Republicana. Tomo por ejemplo a los pueblos de Bolivia, qe bajo el réjimen colonial eran fábricas de fundiciunes i acuñamientos m€tálicos de propiedad española, i qe oi no pueden ser lo qe estan llamados a ser. Estados comerciales e industriales, porqe no tienen puertos de mar ni veículos de intelijencia marítima con el mundo exterior i europeo. Entre tanto es constante qe por medio de concesiones realizables de parte de otros Estados, Bolivia podria tener los medios qe oi le faltan para llenar su destino nacional. E aqí un jénero de intereses qe un congreso jeneral podia arreglar en beneficio de todos i cada uno de los actualmente perjudicados. Estos intereses afectan a una gran parte de la América mediterránea i central, qe no debe ser explotada por la América litoral i costanera : el centro vive de su márjen i vice versa.

Es cierto qe para la eje sucion de este designio seria preciso qe el congreso no fuese una simple junta de plenipotenciarios; sino tambien una especie de gran corte arbitral i judiciaria, qe como los congresos de Viena, Verona, Troppau, Laibach i Lóndres, pudiera adjudicar en calidad de árbitro supremo, costas, pu rtos, rios, porciónes elementales de terreno en fin, al pais qe tuviese absoluta necesidad de poseer alguno de estos beneficios para dar ensanche i progreso al movimiento de su vida moderna. El congreso debe tener todo este poder por delegacion expresa de cada Estado, i porqe él nace del interés jeneral i Americano qe es llamado a forn.ular en sus grandes decisiones.

Debe el congreso al delinear las nuevas fronteras no conponerlas de simples flas de fuertes militares $i$ oficinas de aduanas: 
sino qe, con un profundo conocimiento de la jeografía física de nuestro continente, debe establecer fronteras naturales, qe consistan en rius, montañas u otros accidentes notables del terreno. Este sistema tiene por objeto evitar e i empleo permanencia de fuerzas militares para custodia de límites i fronteras : uno de los medios de llenar otro gran interes del congreso i de la América, la abolicion del espiritu militar i el establecimiento de la paz por la ausencia de los medios de acer la guerra.

No se dirá qe esto es impracticable por la razon qe es grave, porqe esto seria suponer qe el congreso se reune para asuntos efimeros. Las divisiones de jeografía política no son cosas normales e inmutables como las qe son obra de la naturaleza : ellas son variables como la política qe las establezca. Echese una ojeada comparativa a las cartas jeográficas de distintas épocas : en ellas se verá qe a cada cambio notable operado en el mundo político, viene inerente otro análogo en las divisiones territoriales de las naciones. Ia Europa del siglo V. no es la Europa de Cárlo-Magno: las divisiones de Napoleon no son las divisiones de Viena. ¿Escaparémos nosotros exclusivamente a esta lei? Lígase mas bien qe la revolucion moderna no a llevado su mano a todas las reformas exijidas. Evidemment, dice un publicista frances ablando de las divisiones territoriales de Sud América, "évidemment rien de toutes ces divitions n'est definitif......L'A mérique est appelée du d'autres destinées.......) I en efeclo asta aqi no nos an faltado cambios : se a formado i disuelto la República de Colombia: se a creado la República Oriental: el Paraguai se a echo estado aparte. Bajo el antiguo réjimen no fueron ménos variables las fronteras: recuérdense los virreinatos del Perú $i$ de la Plata. ¿Porqé pues qedarian inalterables las demarcaciones existentes?

Será tambien el mas eficaz medio de establecer el eqilibrio continental qe debe ser base de nuestra política internacional ciril - privada. Enten lamos lo qe debe ser nuestro eqilibrio, como emos visto lo qe debe ser nuestro arreglo de límites. Mas qe de la ponderacion i balanza de nuestras fuerzas militares, él debe nacer del nivelamiento de nuestras ventajas de comercio, navegacion i tráfico, el nuevo i grande interes de la vida americana. En la santa guerra de industria i de comercio qe estos paises estan llamados a alimentar en lo venidero, nada mas qe por las armas de la industria i del comercio, debe establecerse en todo lo posible la mayor ignaldad de fuerzas i ventajas. Eqilibrada la rigeza es necesario eqilibrar tambien el territorio como parte de ella, no como medio de preponderancia militar : aqi repetiré la observacion qe ya ice de qe no valuo el precio del suelo por sus dimenciones, sinó por las ventajas de su situacion i conformacion jeo- 
gráfica. En América el vasto territorio es causa de desórdenes i atruso: él ace imposible la centralizacion del gobierno, i no ai estado ni nacion donde aya mas de un solo gobierno. El terreno es nuestra peste en América, como lo es en Europa su carencia: Chile el mas peqeño de los Estados de América es mas rico, nias fuerte i mas bien gobernado qe todos. Mas chico qe él es el Estado oriental del Úruguai, i resiste a la grande $i$ anarqisada República Arjentina.

Una cuestion concerniente al eqilibrio allará para tratar el congresu en la de la independencia del Paraguai. Será ese congreso el qe deba deducir si está en la conveniencia mercantil i militar de la América del sud, el qe el Paraguai, con sus rios qe dan desaugo a los tesoros de una mitad de nuestro continente, deba ser adjudicado integramente a la República Arjentina, qe solo necesita de esta agregacion para reportar una preponderancia.

Despues de los límites i el equlibrio viene el derecho marítino entre los objetos qe a de tratar el congreso. Nuestra navegacion se dividirá en oceánica, qe es base del comercio exterior, i mediterránea o riverana, qe es el alma del comercio interior para ciertos estados, j para otros de todo su comercio externo i central. Regalar la navegacion es facilitar el movimiento de nuestra riqeza, cuyo mas poderoso vé́culo de desaogo i circulacion es el agua. Se ábla mucho de caminos en este tiempo: no olvidemos qe los rios son caminos ge andan, como dice Pascal. Para acer transitables estos caminos caminantes, es preciso ponerlos bajo el amparo del derecho. Su propiedad aparece dudosa para ciertos estados, i su uso está sujeto a dificultades. Estos puntos exijen esclarecerse $i$ determinarse cuanto ántes; $i$ nadie mas competente qe un congreso jeneral para ejecutarlo. La navegacion de los rios de Sud-América, envuelve grandescuestiones de interes material, entre las Repúblicas de la América occidental i las qe ocupan su litoral del oriente. Aqellas se apoyan sobre las ramas superiores de nuestros grandes rios; las otras poseen sus embocaduras. Nueva Granada posee los rios Guaviare i Meta, tributarios del Orinoco, cuyas bocas pertenecen a Venezuela: el Negro, el Vaupes i el Caqeta, tributarios del Amazonas, cuya embocadura está en territorio Brasilero i Guayanes. El Ecruador tiene tambien los rios Tungurugai i Ucayale, qe vierten sus aguas en la caja del Amazonas. El Perú, es propietario de las altas vertientes del Ucayale, qe mas abajo se ace ecuatoriano i despues brasilero, i del Madeira, qe tambien derrama sus caudales en el Amazonas. Bolivia posee tambien conexiones idraúlicas con el Brasil, pues sus rios Mamore $i$ Branoo desaguan en el mismo Amazonas, i las tiene mas Intimas con la República Arjentina, 


\section{$-304-$}

por medio del Pilcoinayo i el Bermejo, qe atraviesan su territorin ántes de entrar al Rio Paraguai, sobre cuya parte mas alta reposa igualmente una porcion del territorio Boliviano. El Brasil a su turno, poseedor de las alturas del Paraná i el Paraguai, tributarios, del Plata tiene ácia Montevideo i Buenos-Aires sobre todo, la misma subordinacion en qe estan respecto de el los Estados de Nuera Granada, Ecuador, Perú i Bolivia.

La ciencia internacional enseña qe la Nacion propietaria de la parte superior de un rio navegable, tiene derecho a qe la nacion qe posee la parte inferior no le inpida su navegacion al mar, ni le moleste con reglamentos i gravámenes qe no sean necesarioz para su propia seguridad...... El congreso de Viena sentó esta doctrina por base de los reglamentos de navegacion del Rhin, el Neckar, el Mein, el Mosela, el Meusa i el Escalda: izo mas todavía, declaró enteramente libre la navegacion en todo el curso de estos rios (son lns palabras del Acta de Viena) desde el punto en ge empieza cada uno de ellos a ser navegable asta su embocadura.... “El Vistula, el Elva, el Po an sido sucesivamente sometidos, en el uso de sus aguas navegables, al mismo derecho marítimo, por actos firmados en 1815 i 1821. Puede pues sentarse qe la Europa a reconocido la libertad casi completa de sus rios navegables, La América del Norte consagró este mismo principio, a propósito de la navegacion del Misisipi, en la época en qe (1792) poseedores los Estados-Unidos de la parte superior de este rio i su orilla izqierda, la España era dueña de la boca i ámbas riveras inferiores. No abria razon pues, para qe la América del Sud, no consagre esta misma doctrina en sus leyes de navegacion mediterránea. Ella debe dar absoluto acceso al tráfico naval de sus rios, en favor de toda bandera Americana ; $i$ con cortas limitaciones, de cualesqiera otras banderas, sin exclusion. La frecuencia de la Europa en nuestras costas marítimas a sido benéfica para la prosperidad americana; por qe no lo seria tambien su internacion por el veículo de nuestros rios? Yo veo todavia en nuestros corazones fuertes reliqias de la aversion con qe nuestros dominadores pasados nos icieron ver el ingreso de la Europa en el seno de nuestro continente monopolizado por ellos: proibiciones odiosas establecıdas en oprobio nuestro i para provecho del tráfico peninsular, qeremos mantenerlas como leyes eternas de nuestro derecho de jentes privado. Con violacion de estas máximas el Paraguai a capturado en años anteriores una nave americana, qe, con procedencia del Berinejo, acia un viaje de exploracion científica por las aguas del Paraguai en qe desagua aqel rio. El congreso jeneral deberá decidir si actos de esta naturaleza ayan de repetirse impunemente en la navegacion futura de los rios americanos. 


\section{$-305-$}

En cuanto a la navegacion de los mares americanos, por las marinas de América, convendrá tambien qe se adupten mediuas de aplicacion continental, capaces de excitar la prosperidad i aumento de nuestra marina naval. Este punto conduce a otro de los sérios asuntos de qe deba ocuparse el congreso americano: el derecho internacional mercantil. $E$ aqi el grave interes qe debe absorver el presente i el porvenir de la América por largo tiempo: el comercio consigo mismo i con el mundo trasatlántico. A su proteccion, desarrollo i salvaguardia, es qe deben ceder las ligas, los congresos, las uniones americanas en lo futuro. Antes de $\mathbf{1 8 2 5}$ la causa aniericana estaba representada por el principio de su independencia territorial: conqistado ese echo, oi se representa por los intereses de su comercio i prosperidad material. La actual causa de América es la causa de su poblacion, de su riqeza, de su civilizacion i provision de rutas, de su marina, de su industria i comercio. Ya la Europa no piensa en conqistar nuestros territorios desiertos; lo qe qiere arrebatarnos es el comercio, la industria, para plantar en vez de ellos su comercio, su industria de ella: sus armas son sus fábricas, su marina, no los cañones: las nuestras deben ser las aduanas, las tarifas, no los soldados. Aliar. las tarifas, aliar las aduanas, e aqi el gran medio de resistencia americana. A la santa alianza de las monargias militares de la Europa, qizo Bolivar oponer la santa alianza de las Repúblicas americanas, i convocó a este fin el congreso de Panamá. Señores, las oposicion entre las dos alianzas santas a desaparecido. No es el programa de Panamá el qe debe ocupar el congreso; no es la liga militar de nuestro continente, no es la centralizacion de sus armas lo qe es llamado a organizar esta rez. Los intereses de América an cambiado: sus enemigos pollticos an desaparecido. No se trata de renovar puerilmente los yotos de nuestra primera época guerrera. La época política i militar an pasado: la an sucedido los tien.pos de las empresas materiales, del comercio, de la industria i riqezas. Se a convenido en qe es menester empezar por aql para concluir por la completa realizacion de las sublimes promesas de órgano político contenidas en los programas de la revolucion. El nuevo congreso, pues, no será político sino accesoriamente: su carácter distintivo será el de un congreso comercial i marítimo, como el celebrado modernamente en Viena,Stuttgart, con ocasion de la centralizacion aduanera de la Alemania. El mal qe la gran junta curativa es llamada a tomar bajo su tratamiento no es mal de opresion extranjera, sino mal de robreza, de despoblacion, de atrazo i miseria. Los actuales enenigos de la América están abrigados dentro de ella misma; son sus desiertos sin rutas, sus rios esclavizados i no explorados; sus 
costas despobladas por el veneno de las restricciones mezqinas, la anarqia de sus aduanas i tarifas; la ausencia del crédito, es decir, de la riqeza artificial i especulativa, como medio de producir la riqeza positiva i real. E aqí los grandes enemigos de la América, contra los qe el nuevo congreso tiene qe concertar medidas de combate i persecusion a muerte.

La union continental de comercio debe, pues, comprender la uniformidad aduanera, organizándose poco mas o menos sobre el pie de la qe a dado principio, despues de 1830, en Alemania i tiende a volverse a europea. En ella debe comprenderse la abolicion de las aduanas interiores, ya sean provinciales, ya nacionales, dejando solamente en pié la aduana marítima o exterior. Acer de estatuto americano i permanente, la uniformidad de monedas, de pesos i medidas qe emos eredado de la España. La Alemania está ufana de aber conseguido uniformar estos intereses, cuy a anarqía acia casi imposible el progreso de su comercio. Nosotros qe tenemos la dicha de poseerla en plata $i$ arraigada a nuestros antiguos usos, cuantos esfuerzos no deberemos acer para mantener perpétua e invariable su benéfica estabilidad.

Rejidos todos nuestros estados por un mismo derecho comercial, se allan en la posicion única i soberanamente feliz de mantener $i$ acer del todo extensivas al continente las formalidades de validez i ejecucion de las letras i vales de comercio. Estableciendo un timbre $i$ oficinas con rejistros continentales, las letras i vales vendrian a tener la importancia de un papel moneda americano i jeneral, i por este medio, se echaria cimientos a la creacion de un banco i de un crédito público continentales. La misma jeneralidad podia darse a la validez $i$ autetididad de los documentos i sentencias ejecutoriadas; a los instrumentos probatorios de 6 rden civil i penal, rejistrados en oficinas especialmente consagradas al otorgamiento de los actos de autenticidad continental.

Las formalidades preparatorias i de comprobacion exijidas para entrar en el ejercicio de las profesiones científicas e industriales, es otro de los objetos qe debe arreglar el congreso americano. ILa uniformidad de nuestra lengua, leyes, creencias i usos, ace qe la competencia para el ejercicio de ciertas ciencias i materias, sea de suyo americana. En casos semejantes no debe seguirse en nuestros estados la práctica adoptada por los pueblos de Europa distintos respectivamente en lengua, leyes, creencias relijiosas $i$ políticas, usos, etc. Será suficiente con qe se adopte el número de pruebas qe aga indispensable la necesidad de poseer aqella parte en qe la ciencia o profesion se aya localizado. Así la centralizacion universitaria en ciencias morales i filosóficas es un echo ge en América del Sud no presenta una ejecucion imposible; i es fá- 
cil ver de cuanto estímulo no serviria a los jóvenes enlas vocaciones científicas i profesionales, la idea de qe un grado expedido en cualqiera universidad de un estado americano, les acia profesor en diez repúblicas.

Los inventos científicos, la produccion literaria, las aplicaciones de industria importadas, recibirian un impulso grandioso, desde luego qe un congreso americano concediese garantías al autor de un invento, un escrito o publicacion útil del ejercicio exclusivo de su privilejio en todos los estados de Sud América, con tal qe a todos estendiese su práctica. No es este uno de los ménos importantes objetos qe el congreso jeneral tendria qe tratar.

La construccion de un vasto sistema de caminos internacionales a expensas recíprocas, qe trazados sobre datos modernos. concilien la econoniia, la prontitud $i$ todas las nuevas exijencias del réjimen de comunicacion i rose in terior: la posta exterior o de estado a estado, consecuencia precisa del establecimiento de nuevos vínculos e intereses jenerales, sometida a un impuesto único i continental: e aqi dos objetos mas dignos de particular atencion por parte del congreso.

La extradicion criminal civil : única extradicion admisible en virtud de la universalidad de la justicia i del crímen civiles. Qe el qe asesina en el Plata, sea aorcado en el Orinoco : nada mas bello qe este vasto reinado de la justi via criminal. Pero es necesurio abolir para siempre en nombre de la libertad política, la extradicion de los qe son acusados por el sofisma de partido civil político, comso culpables de delitos de lesa patria : por la inviolabilidad del asilo político, cada estado a de poder ser tribuna de oposicion i censura inviolables de los demas : esta censura mútua i normal, no podrá ménos qe utilizar a todos. Otro punto es éste, qe no debe ser olvidado.

Una de las grandes miras del congreso debe ser la consolidacion jeneral de la paz americana : serán medios para obtener este resultado, a mas de todos los arreglos propuestos la amortizacion del espíritu militar, aberracion impertinente qe ya no tiene objeto en América. La independencia americana, su dignidad i prerrogativas no descansan en las bayonetas de sus pueblos : el Océano $\mathrm{i}$ el desierto, son sus invencibles guardianes : ella no es débil, comparada con la Eurupa; en su territorio, es fuerte, como el mundo entero. Será otro medio preventivo de la guerra el no tener sóldados, por el principio de $\mathrm{qe}=$ donde ai soldados ai guerra. Se puede pactar el desarmamiento jeneral, concediendo a cada Estado el empleo de las fuerzas únicas qe ace indispensable el mantenimiento de su órden interior, i declarando ostil a la América, al qe mantega fuerzas qe no sean indispensablemente 
necesarias. La guardia nacional i no los ejércitos asalariados, deben ser la base lícita de los poderes fuertes de la América. Tuda república qe mantiene fuertes ejércitos atenta contra la santa lei de su comercio i prosperidad industrial con detrimento de la América ; i la América qe ama el órden i necesita de él debe desarmarla en nombre de la paz comun. Se deben tambien abrogar la paz i neutralidad armadas en América, como estériles, para reemplazarla por la paz $i$ neutralidad ocupalas $i$ mercantiles.= Para prevenir la guerra podria tambien, como en el foro civil, establecerse una judicatura de paz internacional, adonde acudiesen en conciliacion, ántes de ir a las armas los Estados dispuestos a ostilizarse : esta gran judicatura americana, para acerse efectiva en todo nuestro vasto continente, podria subdividirse en cortes parciales, correspondientes a tres o cuatro grandes secciones en qe la América Unida debe necesariamente dividir la administracion de aqellos intereses declarados continentales. El dietámen de la corte conciliadora importando tanto como la sancion moral de la América, pondria al desobediente fuera de la lei de la neutralidad ; i contra él podrian emplear los demas estados, sino las armas, al ménos todas las medidas de reprobacion i coaccion indirecta susceptibles de emplearse contra un pais qe incurre en nuestra malqerencia.

Este punto qe conduce al derecho i práctica de la intervencion, no puede ser abolido donde qiera qe ai mancomunidad de intereses. Acer comunes las cosas $i$ exijir la neutralidad de la indiferencia en su manejo es establecer cosas contradictorias. La América tendrá siempre derecho de intervenir en una parte de ella : el órgano está sujeto al cuerpo, la parte, al todo. La intervencion en América es tradicion de 1810. La revolucion se salvó por ella : la neutralidad la abria echo sucumbir. Buenos-Airos intervino en Chile: Chile i Colombia en el Perú, i la América se salvó por esos actos. En cualqiera época qe un mal semejante al de la esclavitud colonial se aga ver en América con tendencia a volverse jeneral, la América tendrá el indispensable derecho de intervenir para cortarle de raiz. Es justamente en punto a intervencion i neutralidad qe el derecho internacional americano debe ser especial i orijinal; en cualqier otro punto podrá ser fiel imitacion de la diplomacia europea, sin incurrir en insentatez : en éstos, no : la América, una e indivisible en los elementos políticos i sociales qe la forman, en los males qe la aflijen, en los medios qe puedan salvarla, será siempre un cuerpo ménos íntimo qe la union de Norte $\Lambda$ mérica si se qiere, pero mil veces mas estrecho i unido, qe lo formen los pueblos de la Europa : la neutralidad, pues, qe entre pueblos eterojéneos es indispensable, es de imposible prác- 
tica donde los pueblos abitan un suelo, fueron ayer un solo pueblo, i oi son una sola familia. Consideraciones son estas qe el congreso debe tener mui presente al poner los principios del derecho internacional Americano. Tocamos aqi otro de los grandes objetos del congreso jeneral : el establecimiento de un derecho de jentes para nuestro continente privativamente i para con la Europa. El nuestro privado se compondrá en gran parte de las decisiones recaidas subre los ubjetos qe dejamos indicados. Establecerá la igualdad de los poderes o Estados del Continente Americano, determinando con especialidad las circunstancias qe forman la individualidad nacional de cada uno, para dejar a salvo al sistema qe aya de emplearse para con las fracciones en qe se dividan las actuales Repúblicas. Sentará las formas de su diplomacia privada sobre principios consecuentes con los de igualdad, economía, sobriedad i llaneza democráticas. Este punto es grave i afecta al cuerpo mismo del congreso. Una diplomacia expeditiva i fácil, económica en formas, ceremonias i protocolos, aria realisables i eficaces de mas en mas las grandes asambleas diplomáticas a qe la América dichosamente comienza a cobrar aficion. Resolverá lo qe aya de acer la América Unida con los estados qe se subdividan; qe se liguen parcialmente; qe se consuliden en uno mismo ; qe cambien el principio de su policía fundamental; qe pacten alianzas de guerra con el europeo; qe violen el principio legal i establezcan la dictadura; véase por aqi si en casos semejantes será dable a la América permanecer neutral.

En cuanto a la política con la Europa ella debe ser franca, por qe no está en el caso de temer ; mas propia para atraerla qe para contenerla : paciente i blanda mas qe provocativa : modesta, como su edad: parlamentaria mas bien qe guerrera : la civilıacion $i$ no la gloria militar, es su gran necesidad, i en ello ganará con el roce inalterable de la Europa : no debe abusar de su derecho de excomunion, de su poder de resistencia negativa, ácia al europeo, qe el mismo europeo jenerosamente le a dado a conocer, pues en tales excomuniones ella no pierde ménos qe el excluido. Pero, como qiera qe sea, el sistema adoptado a de ser uniforme $i$ jeneral, a fin de qe por el poder de esta jeneralidad, los actos de sus estados tengan, ya qe no la sancion de la fuerza, por lo ménos la respetabilidad moral qe inviste lo qe es universal i comun.

Ará parte de esta rama la política para con Roma. Los inconrenientes de la influencia excesiva de Roma en nuestro continente serán ménos de temerse qe los qe pudiera ofrecer el influjo temporal del resto de la Europa. El mar Atlántico ace imposible en este continente lejano, el ejercicio de toda accion opresiva 
qe tenga orfjcn en el otro, sea qe se trate de cosas temporales, o meramente de dominio relijioso. Para con la metrópolı católica, la misma firmeza, dignidad, moderacion qe para con la madre España : sucede en lo tocante al culto lo ye con respecto al comercio i otros intereses, qe las conveniencias i desventajas asisten a una i otra parte, de suerte qe Roma no viene a perder ménus qe nosotros, por el entorpecimiento de nuestras relaciones mútuas. De todos modos i en todos los casos nuestra política para con ella debe ser invariablenıente la de no permitirla en estus paises el ejercicio de una autoridad qe no esté en armonfa con los principios de nuestra independencia i soberanía nacional, i del nuevo réjimen democrático adoptado por nuestros estados. Ermanar el espíritu católico con el de progreso i libertad en qe an entradu estas repúblicas, e aqi la sencilla i grande base de los concordatos americanos con Roma. Cuánta ventaja no reportaria en este sentido la América, si en las conferencias de un congreso comun adoptase una regla de conducta uniforme i jeneral.

Volviendo a los objetos de mero interes americano de qe el congreso deba ocuparse, no bastará prevenir la guerra, desterrarla en los posible; será necesario sujetarla a un derecho i a formas nuevas en los casos en qe fuere inevitable. Si es necesa rio qe por largo tiempo sea ella un rasgo característico de la vida americana, démosla a lo ménos una forma qe la aga ménos capaz de destruir el progreso del comercio i la riqeza de los Nuevos Estados ; agamos asta cierto punto conciliable su presencia, con la de la prosperidad mercantil o industrial, dando a estos intereses cierta neutralidad qe los substraiga a los malos efectos de la guerra. Uno de los medios de llegar a este fin en la guerra de mar, será la supresion del corso, declarado piratería con tanta razon por los poderes marítimos mas respetables. El comercio es el grande aliciente qe estos paises ofrecen al extranjero, i su mas grande instrumento de poblacion: agamos, pues, de modo qe él subsistia inviolable, como un medio reparador de las devastaciones operadas por la guerra.

Los pueblos de América abitamos un desierto inconmensurable. Es necesario escapar a la soledad, poblar nuestro mundo solitario. La colonizacion es un gran medio de llegar a este resultado ; pero un medio qe despierta recuerdos dolorosos. Sin embargo, como qiera qe aya sido el carácter del empleado por la Europa en los pasados siglos, a él le debemos nuestra existencia, i a él es posible qe deban su ser en lo futuro militares de pueblos americanos. No le excluyamos, pues, de nuestros medios de ciyilizacion i progreso. Si no le podemos emplear nosotros, dejémosle usar por los qe pueden acerlo. Propongamos modificaciones 
en su ejecucion; esto entra en nuestro derecho ; pero no la pongamos trabas absolutas, porqe esto sale de nuestro poder. Afortunadamente a envejecido ya en la consideracion de la Europa, el sistema de colonizacion empleado por ella en los siglos 16.17 i 18; i no fuera difícıl la adopcion de un sistema de colonizacion americana qe conciliase las ventajas de la Europa, con la independencia i personalidad política de este continente. Tengamos prudencia i tratemos de promuver lo qe talvez puede obrarse a nuestro despecho. El mundo social necesita espacio : nosotros le tenemos de sobra: ¿podremos reusárselo impunemente? Esta cuestion se liga especialmente a la suerte de la porcion mas meridional de América, qe solo es pertenecia nuestra en los mapas de los jeográfos, pero qe, en la realidad, es posesion inconqistada de los indrjenas. Aqi la obra española perınanece inacabada, i la barbarie se mantiene dueña del espacio qe podria utilizar la civilizacion: es, pues, necesario completar su conqista, pero por medios dignos de ella. El congreso jeneral podria ocuparse de este'asunto, qe importa a la suerte de toda América. A la ocupacion salvaje de la Patagonia i del Sud de Chile, se debe talvez el no uso de uno de los mas realizables veŕculos de intelijencia i tráfico mercantil entre las dos costas Oecidental i Oriental de la América. Se abla de la navegacion del Estrecho de Magallanes, situado en $53^{\circ}$ latitud; de la canalizacion de Panama, situado bajo un cielo pestífero ; i no se pensa en qe la América puede ser atravesada por una bella ruta, trazable en el punto en qe al Sud deja de ser continua la cadena de los Andes. La Europa misma i todas las potencias comerciales del mundo, no podrian ser invitadas por el congreso, a tomar parte en la ejecucion de este trabajo de universal conveniencia?

Asta aqí e pasado en revista los objetos de qe pudiera ocuparse un congreso Americano; no pretendo qe sean todos i los únicos. Tampoco creo qe un congreso determinado, deba tratar de todos ellos i organizarlos de una sola vez. Ellos serán la materia de muehos congresos, qe en distintos momentos del porvenir se irán reuniendo para ocuparse de aqellos intereses a los qe ubiere llegado su oportunidad. Para muchos de ellos, se necesita grandes trabajos preparatorios, qe solo el tiempo podrá llevar a cabo. La constitucion del continente, como la de cada uno de sus Estacios, será la obra de los tiempos, para la cual se sucederán los congresos a los congresos ; debiendo entre tanto dar principio alguna vez por uno de ellos. Yo aplaudiré tuda mi vida el sentimiento de aqellos Estados, qe sacan su vista del recinto estrecho de sus fronteras i la levantan asta la esfera de la vida jeneral i continental de la América. Es llevar la vista al buen camino. Eu 
un gran sistema político, las partes viven del todo $i$ el todo de las partes. La mano de la reforma debe ir alternativamente del trabajo constitucional, de la obra interior del edificio a la obra exterior. Lo demas es construir a medias i de un modo incompleto. Otros pueblos podrán tener en su seno los jérmenes de su prosperidad: los de América desgraciadamente los poseen fuera, $i$ de fuera deben entrar los manantiales de su vida. La Metrópoli no plantó en ella semillas de progreso , sino de estabilidad i obediencia. La vida exterior nos deje absurver en lo futuro. En ella somos incxpertos, porqe emos sido educados en la domesticidad colonial i para la vida privada i de familia. Dejemos qe nuestros fueblos empiezen su grande aprendizaje. La necesidad de esta nueva tendencia se revela por el movimiento normal de las cosas. I.a Imérica, de íntima i mediterránta qe ántes era, aora se ace esterna i litoral. $\mathbf{A}$ bia sido echa para vivir en reclusion i se la izo abitar lo mas central de nuestro suelo: desde su entrada en el mundo, a salido a las puertas para recibirle. Los pueblos mediterráncos si qieren prosperidad en adelante ge aguarden a los tiempos de los caminos de fierro: por aora, bienaventurados los qe abitan las orillas de los mares, porqe solo ellos pueden ver la cara del mundo, i recibir con su contacto el espíritu de su vida moderna. Veamos lo qe se pasa en Chile, lo qe se pasa en el Plata, Santiago, apénas se acrecienta en tanto qe Vatparaiso se duplica: Potosi, Córdova, se despueblan en tanto ge Montevideo se ace capital de Estado, i Buenos-Aires recibe de las aguas del Plata, barcadas de ombres qe cubren en el acto los claros qe ace el cañon de la guerra civil. A la vida exterior i jeneral, sí; qe el feudalismo, qe el espiritu de aldea nos aoga por todas partes! Qe la América se reuna en un punto, piense en su destino, se de cuenta de su situacion, able de sus medios, de sus dolores, de sus esperanzas. Allí, a la luz de tanta publicidad se verá qe valor tienen en la consideracion del juicio continental, ombres, cuestiones i cosasqe pretenden ser su expresion i simulacro. La América reunida en asamblea jeneral, se dará cuenta de sí misma i se ará conocer del mundo en su verdadera capacidad o incapacidad: este conocimiento no podrá ménos qe utilizar a todos, porqé de él saldrán principios de conducta práctica para todos. Estas asambleas continentales an tenido lugar en todos tiempos, i sus resultados, buenos o malos, an sido eficaces. En la edad media, los Concilios tuvieron en Europa, el rol qe oi se desempeña por los congresos; i la iglesia católica, este estado qe abraza todos los continentes, se a organizado por grandes asambleas, qe se reunian cada vez qe abia un asunto de interes universal qe tratar. In el pasado i presente siglo, la Europa se a reunido mas de una 
vez en congresos continentales, para reglar su forma o modo de existir jeneral, o bien para intervenir en el estado ge se separaba del movimiento comun, a fin de acerle tomar un réjimen interno conciliable con el interes europeo. ¿Estas santas intervenciones ejercidas por la iglesia i el monarqismo, deberán qedar abolidas tan luego cuando se trata de aplicar sus beneficios a la causa de la libertad americana? La Europa incoerente, eterojénea en poblacion en lenguas, en creencias, en leyes $\mathrm{i}$ costumbres, a podido tener intereses jenerales i congresos que los arreglen; i la Ámérica del Sud, pueblo único por la identidad de todos estos elementos, no a de poderse mirar en su grande i majestuosa personalidad, ni tener representantes jenerales, apesar de qe posee intereses comunes! La centralizacion americana, no será la obra del Congreso, rigorosamente ablando, porqe esta obra está ya echa, i su trabajo es debido a la grandeza del pueblo español qe se produjo él mismo, con todos sus atributos en cada uno $i$ todos los puntos de América meridional donde puso su planta.

«En la vida de los pueblos, dice Guizot, la unidad esterna, vi»sible, la unidad de nombre $i$ de gobierno, aunqe importante, no „es la principal, la mas real, la qe constituye verdaderamente nuna nacion. $\Lambda$ i una unidad mas profunda, mas poderosa: es la )qe resulta, no de la identidad de gobierno i destino, sino de la "similitud de instituciones, de costumbres, de ideas, de elementos »sociales, de sentimientos, de lenguas; la unidad qe reside en los nombres mismos qe la sociedad reune, de la similitud, i no en las "formas de su acercamiento; la unidad moral en fin, mui superior sa la unidad política, i la única qe es capaz de fundarlas. Pero esta grande i poderosa unidad moral envuelve en su seno a los Estados Americanos de orfjen español; i el congreso solo tendria qe formular ciertos resultados de la obra ya en planta.

La materia americana es susceptible de dividirse en tres categorías: asuntos peculiares esclusivamente a la América española emancipada: asuntos privativos de la América del Sud: asuntos de todo el continente americano. Estos ramos son susceptibles de cierto grado de independencia en sus relaciones de categoría a categoría; i se deberá tener presente esto ya sea para medir la estension qe deba darse a la convocatoria, ya para concebir el órden de los pactos i discusiones.

(Apesar de la frecuencia con qe me e valido de la palabra contínental en el curso de esta Memoria, soi uno de los qe piensan qe solo deben concurrir al congreso jeneral, las repúblicas americanas de orfjen español. Ménos qe en la comunidad de su suelo, yo veo los elementos de su amalgama i unidad en la identidad de los términos morales qe forman su sociabilidad. Si la unidad del 


\section{$-314-$}

suelo debiese acernos componer un sistema político jeneral, yo no veo porqe deba escluirse del Congreso Americano a la $R$ usia, qe posee en América tres veces mas territorio qe Chile; a la Inglaterra cuyas posesiones en América exceden en dimensiones a Jas de los Estados-Unidos; a la España, que posee dọs de las grandes Antillas, islas Americanas; a Dinamarca dueña de la Groenlandia, adyacencia americana; a la Francia en fin i a la Olanda, ge tambien tienen parte en las Antillas i bocas del Amazonas. Si se objetase a esto la diversidad de principio político, yo observaria qe esta diversidad no escluye la liga de los intereses qe no son políticos, justamente los mas primordiales de los qe deben ocupar al venidero Congreso. Se sabe qe las confederaciones $\mathrm{Hel-}$ vética i Jermánica, contienen en su seno respectivo, poderes aristocráticos, monárquicos i republicanos a la vez.-Observemos qe cuando la Europa se a reunido en Viena o Paris, no se a llevado de la regla de la unidad territorial, pues a llamado a la Inglaterra, qe no es poder continental, i no a llamado a la Asia i a la Africa, apesar de qe forman parte del antiguo continente. Considero frívolas nuestras pretensiones de acer fanilia comun con los ingleses republicanos de Norte América. Si su principio político es lo qe debe llamarnos a la comunidad, no veo porqe los Suizos, tambien republicanos i casi tan distantes como ellos, no deban hacer parte de nuestra familia. Yo apelo al buen sentido de los mismes norte-americanos, qe mas de una vez se an reido de sus cándidos parientes del Sud. Ciertamente qe nunca nos an reusado brindis i cumplimientos escritos; pero no recuerdo qe ayan tirado un cañonazo en nuestra defensan.

Se a contrariado la realizacion del nuevo Congreso Americano, con las razones de oposicion qe militaron contra el de Panamá. Esto es confundir épocas, i miras mui diferentes. Se a dicho qe no se trata ni debe tratarse de una reproduccion literal del congreso de Panamá. iA qé conduciria oi una liga militar contra la España? da qé la redaccion de un manifiesto de motivos justificativos, qe ya conoce $i$ aprueba el mundo?

Es inútil, pues, citar las razones alegadas por $A$ Jams, por $Z a-$ bala, por el autor de las meditaciones colombianas, en oposicion al Congreso de Panamá, para oponerse a la reunion de un Congreso qe no debe parecerse al de Panamá. Aqellas autoridades negaron la oportunidad he un Congreso dado, no la de todos los congresos posibles. El ministro $\mathbf{i}$ amigo de Bolivar $\mathbf{i}$ el presidente de los Estados-Unidos, se opusieron a la confederacion de la América como medio de defensa bélica contra la Europa; pero no a la alianza feliz de esfuerzos intelectuales, a una confederacion saludable de buenos oficios i trabajos útiles..... Estas son 
las palabras del ilustre Adams, comunicadas al ministro de Norte América euviado a Panamá. No pueden ser mas aplicables en apoyo de nuestra tésis, qe escluye igualmente la federacion militar de la América i está exclusivamente por la alianza moral i la union de esfuerzos útiles, en provecho de la prosperidad material e intelijente de la América.

Se a atacado tambien la idea de un congreso americano, comparándolo al Consejo Anfictionico, dieta federal qe conducia los negocios de la liga Anfictiónica, propuesto a los pueblos griegos, por un rei de Atenas. No, señores, el congreso americano no será la dieta Anfictiónica. La liga elénica, era un medio de defensa militar: la liga anericana será un medio de prosperidad material. La Grecia era peqeña: la América podria alojar cómodamente a toda la familia de Platou en una isla del Paraná o en el archipiélago de Chiloé: la Grecia era accesible al enemigo estranjero: la América solo pudo ser arrebatada por conqistadores extraños a los salvajes qe la poblaron primitivamente.

Se a recordado tambien para atacarle los inconvenientes qe a traido a la Europa el congreso de reyes, celebrado en Viena en 1815, por medio de plenipotencios: se a anunciado qe los gobiernos de América podrian reunirse, por sus representantes, para pactar una liga de apoyo mútuo $i$ de opresion de las libertades americanas. El aviso es de agradecerse, porqe la cosa no es insignificante. Pero si los gobiernos abrigan ciertamente la intencion de pactar en congreso jeneral la opresion de la América, se eqivocan terriblemente en la eleccion del medio adoptado para el ajuste de un pacto semejante. Un congreso de repúblicas no es congreso de reyes: el uno es responsable, el otro no lo es: el uno es institucion democrática, el otro es un cuerpo privado. Los reyes absolutos solo se deben cuenta asl mismos: los gobiernos republicanos la deben a los pueblos qe representan. Las cadenas de los pueblos no se remachan a la luz del dia. Los pactos feudales qe oi ofrecen ciertos estados oprimidos de América, se an forjado a la sombra de una diplomacia clandestina i reservada; no se an ajustado a la luz de los congresos representativos. Voila ce qùe sont et tout ce que peurent étre les congrès sous Tempire de la loi monarchique, dice un publicista francés ablando de los congresos de Viena i de Verona, i sus aciagos resultados. La democratie seiule, pourrait donner d de telles assemélés un caractère de justice et d'utilité générale.... Un congrés formé des deputés de nations en possession de leur souveraineté, serait pour toutes ce qu'un sénat est pour chacune d'elles.

¿Témese que los diputados concurrentes a la grande asamblea no sean espíritus bastante capaces de alzarse a la altura de su 
mision? Para eso son las instrucciones de qe irán provistos, i qe se redactarán por los primeros ministerios de América. Sobre este punto, seria probable qe en cada uno de los lados qe forman el triángulo de nuestro continente, ubiese un estado qe iciese prevalecer el testo i sentido de sus instrucciones. Pero felizmente los mas capaces de acer esto, son los que ménos recelos deben infundir de ambicion tiránica a los pueblos: en el Norte seria Venezuela; en la costa Atlántica seria el Brasil; en la del Pacífico seria Chile: los tres paises en qe justamente florece mas alagüeño el sistema representativo. Cuando ménos es de esperarse qe estos pueblos no serian arrastrados a una coalicion vergonzosa i traidora. I si de tal cosa fuesen capaces los mas de los gobiernos Sud-Americanos, reunidos en congreso, aun así mismo este acto seria benéfico en resultados; pues entónces podriamos decir lo qe el abate de Pradt, delante de los resultados del congreso de Curlsbad (Este congreso es uno de los mas grandes " acontecimientos de estos tiempos, porque a echo conocer el es》p pritu de los gobiernos i la tendencia qe prevalece entre ellos. ) Podria llamársele-el espíritu de los gabinetes de Alemania. Su》 cede en esto con los gobiernos lo qe con los ombres, qe impor" ta conocerles lo mejor posible. Establecido un juicio sobre el " particular, podreis guiaros por él para preveer lo qe arán ell " adelante. Se preguntaba desde largo tiempo cómo considera" ban los gabinetes el estado de la Europa. Carlsbad se a encar» gado de la respuesta... En vista de lo ge acaban de acer " se sabe lo qe arán por mucho tiempo. Se sabe entretanto, a qé 》 atenerse respecto a su espíritu, puez está declarado. Por lo me„ nos se a ganado esto con Curlsbad ". Desde qe concluyó la guerra de la independencia con la España, no sabemos lo qe pien sa la América de sI misma i de su destino: ocupada de trabajos i cuestiones de detalle, parece aber perdido de vista el punto comun de arribo qe se propuso alcanzar al romper las trabas de su antigua opresion. Los estados dif cuenta anualmente de su situacion parcial; i ¿porqé la América toda, de vez en cuando, no sc daria cuenta de su posicion jeneral? ¿No seria probable qe el exámen de los distintos actos qe componen nuestra vida pública, echo desde un punto de vista tan elevado, sirviese de un estímulo capaz de alejar a nuestros gobiernos de los intereses i pasiones qe no fuesen dignos de la estimacion americana? Así la Europa i el mundo nos conocerian mas a fondo, porqe tendrian opiniones competentes para tomar por bases de las suyas. I últimamente sabriamos nosotros mismos con certeza lo ge teniamos derecho a esperar de un movimiento cuyos frutos se nos preconizó tanto i cuyo acceso se nos presenta a ve- 
ces tan incierto i dudoso. Si la América oficial nos iciese conocer un desengaño, diriamos tambien nosotros: = « por lo ménos se a ganado esto con Lima.) ( suponiendo qe Lima debiese ser el asiento del congreso.)

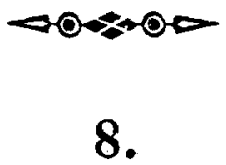

RESEÑA

wobre las diferentes constituelones politicas qe an rejldo a Chile dewde wu emancipacion de la metrópoll asta la fecha, 1 en especlal cobre la promulgada en 25 de majo de 1933.

Memoria presentada por el Bachiller D. Alejandro Reyes para - btener el grado de Licenciado en la Facultad de Leyes $i$ Ciencias Politicas de la Universidad de Chile.

Nínive i Persépolis, zanjando los primeros cimientos de la civilizacion futura de la umanidad, i Babilonia i Tiro, el pueblo Ebreo i Grecia, Aténas i Corinto, Espartai Argos, Efeso i Roma, continuando la obra asta el mayor perfeccionamiento qe aqellos tiempospermitian, an convertido en axioma el principio del incesante progreso umanitario. Durante aqella remota época, las artes i las ciencias tomaron un vuelo qe casi nos parece fabuloso; pero el astro qe guiaba a esos pueblos en su gloriosa carrera detuvo de repente su eurso, i los Hunnos i los Vándalos del Norte de la Europa los sumerjieron en las tinieblas delcaos de donde abian salido. No sucumbió, sin embargo, la luz de la razon, pues, aunqe opaca i sin brillo, lanzaba de cuando en cuando sus pálidos i lánguidos destellos para parecer despues mas radiante i pura qe lo qe se ostentó en la infancia del mundo. En medio de su agonía i del desórảen i trastorno completo ge orijinó la incursion de las órdas salvajes, aparece un rayo civilizador qe la da vida, qe la permite seguir su marchia, destrozando los bárbaros lazos qe la tenian sojuzgada. Renace el cristianismo de entre ese fárrago, ofreciéndose como el puerto de salvacion de la umanidad aflijida. El infunde esperanzas al oprimido, da mil consuelos al ombre esclavizado i muestra abiertas las puertas del cielo a todo el qe implora su divino ausi- 


\section{$-318-$}

lio. Morijera las costumbres, enaltece la filosofía i demas ciencias, reabilita a la especie umana i en su seno aparecen los Gregorios i los Crisóstomos. A esta época sucede la Edad media, i Carlo magno inmortaliza su nombre dando esplendor i fomento a las emanaciones de la intelijencia. El comercio i las Cruzadas estrechan despues a los miembros del jénero umano, ejercen un poderoso influjo en el desenvolvimiento de la industria, i estas últimas inspiran a los istoriadores i poetas. El espíritu de caballería, qe dió orijen a ideas tan elevadas, i el predominio del poder real sobre la nobleza, fueron, en fin, causas poderosas qe icieron qe la Europa, i en jeneral, el mundo, volviesen a su antiguo estado i se presentasen con mas fuerza i con mas vida. No reposando ya sus bases sobre la ferocidad ni el pillaje, ni sobre el despotismo i la esclavitud mas absoluta, sacudidas las cadenas con qe tanto tiempo tuvieron la tiranía i la supersticion aerrojada la mente umana, la marcha de la especie promete ser mas majestuosa, su cultura mas fecunda, su destino mas feliz. Enrriqecida con el trabajo de jeneraciones sucesivas, impregnada de ideas bebidas en tantas i tan diversas fuentes, descubrióse el nuevo veículo de qe tanta necesidad tenian para difundirse i para mejorar la intelijencia de las masas populares. Nace la imprenta, i abriendo una nueva era a las emanaciones de la razon, se muestra una potencia poderosa i formidable. Vulgar i de todo punto inútil creo detenerme a enumerar los beneficios qe la umanidad reportó de este inapreciable descubrimiento; por to qe, no interrumpiré mi narracion. Este prodijioso invento, unido a las causas arriba referidas, obró un trastorno completo en el estado del mundo conocido, de tal modo qe, no bastándole ya el terreno qe pisaba, se vió precisado a buscar otro a donde llevar el sobrante de su civilizacion i de su industria. Entónces fué cuando Colon, ge vivia oscurecido en la ciudad de Calvi, su patria, concibió la inaudita idea de la existencia de un continente qe, asta aqella época, nadie abia osado sospechar. Procede el ilustre navegante a la esploracion de los territorios qe abia soñado, i despues de mil fatigas e incertidumbres, llega, por fin, al suspirado puerto i regala un mundo a la corona de España. Los derechos adqiridos por este medio por los Monarcas de esta nacion fueron confirmados por el papa Alejandro VI en bula de 2 de Mayo de 1493, i desde entónces qedó irrevocablemente establecido el dominio de aqellos Monarcas en estas rejiones. Durante los tres siglos qe Jas tuvieron en su poder, poco o nada se obró qe interesase directamente a la civilizacion de la umanidad, pues qe solo vemos combates mas o ménos sangrientos e infructíferos, $i$ en jeneral, toda la istoria de las tres centurias solo se ocupa de luchas semejantes a las de Cortez i Mo* 
tezuma, Pizarro i Atahualpa, Valdivia iCaupolican, Qezada i Tizqesuca.

Pacificada la mayor parte del continente, los españoles depusieron las armas i solo pensaron en esplotar en su beneficio todas Jas riqezas materiales qe poseia, sin curarse mucho de la cultura de sus colonos a qienes consideraron por mucho tiempo como entes destinados por la naturaleza a ocupar en la jerarqía de los vivientes una escala inferior a la qe ocupa el ombre.

Largos años continuó este estado de cosas, i fué una consecuencia natural de él, el enbrutecimiento de los qe lo sufrian; pero apesar de cuạntos obstáculos pudo imajinar la metrópoli, la filosofía del siglo XVIIl surcó los mares i vino a jerminar en algunas cabezas, aciéndoles formar conciencia de lo qe en realidad eran i del futuro i brillante destino qe la naturaleza les deparaba. $\Lambda$ batidas aun, jemian en silencio sin osar manifestar sus ideas, asta qe se les ofreciéra una perspectiva mas alagüeña qe les permitiese llevar a efecto las bellas teorías con qe Rousseau i demas filósofos abian ilustrado su mente.

Pero en la isla de Córcega abia visto la luz un jenio; i este jenio, dejando atónita a la civilizada Europa, removió todos los tronos i aun qisiera acer bambolear el de los Czares. España fué tambien comprendida en la conflagracion jeneral, i poniendo el Corso su osada planta en la cima de los Pirineos, dirijió una mirada altiva a la Península i desparramó en ella sus jamas vencidas uestes. Le impuso su yugo $i$ el indomable pueblo español se llamó par un momento esclavo.

Entónces fué cuando los ijos de Colon oyeron sonar la ora de su destino i dijeron al mundo con voz firme:-LA AMErica SEA IIBRE-i la América lo fué. Su eco resonó al otro lado del Atlántico i vibró armonioso por do qiera qe llegó. Las provincias ántes españolas se apellidaron naciones; i como su situacion era ya mui diferente, trataron de constituirse i de compilar cuerpos de leyes jenerales qe iciesen efectiva su determinacion i deslindasen las atribuciones de las autoridades recientemente creadas. Su actual estado de civilizacion no les permitia tener ideas fijas sobre la nueva forma de gobierno qe deberian adoptar, i asi es qe sus primeros códigos constitucionales sont un laberinto en qe a una se allan mezcladas las prescripciones de su futuro sistema administrativo con los restos del qe los abia rejido asta entónces.

Permítaseme aora desviarme de la senda qe asta aqí e seguido, j concretarme a Chile para examinar a la lijera las diferentes Cartas que sus gobiernos an dictado desde el dia en qe lanzó en él su primer destello el sol de la libertad, dejando a otro la tarea de acer estensivas a toda la América ántes española las ob- 
servaciones qe aventuraré sobre mi pais. Pero para cumplir ml propósito, necesito ante todo patentizar en cuanto me sea posible el estado de cultura intelectual $i$ de adelanto naterial en qe este se encontraba en la época de su emancipacion política.

Colonia Chile, como toda la América, de una monarqla absoluta por exelencia, no estaba preparado para la reaccion democrática qe sufrió en 1810. Para cerciorarnos de lo incuestionable de este aserto, basta solo echar una lijera ojeada al cuadro triste qe en todos sentidos presentaba aun al observador ménos perspicaz. Las costumbres de sus abitantes eran las de una sociedad pasiva iociosa, su existencia era improductiva i la industria estaba circunscrita a la triste esfera del monopolio $i$ del privilejio. $\mathrm{Ni}$ aun se conocia la educacion industrial, ni el chileno tenia las disposiciones mas brillantes a ella. El mal venia de mui atras: de su orijen. Ijo de españal, en nada participaba de esa raza sajona, de esa raza activa e industriosa qe está en perpétua lucha con la tierra i con las aguas, con los muntes i con el aire, i qe parece dotada (c de esa audacia frenética qe Mahomet supo inspirar a sus Arabes en la conqista del imperio de Oriente.) Por el contrario, vejetaba en la inaccion, casi jamas pensó que algun dia seria miembro de una grán familia qe se titularia nacion, i sus miradas no penetraron mas allá del orizonte presente. Carecia nuestro suelo de vias de comunicacion qe son las fecundantes arterias qe an dado vida a los Americanos del Norte, i su falta no era tan sensible a causa de la estagnacion en qe estaba cuanto puede llaInarse industria. El comercio, ese ajente poderoso, ese precioso vínculo qe une a la especie umana i qe derrama a manos llenas la civilizacion en los pueblos donde tiene su asiento, estaba reducido a la nulidad o era propiedad esclusiva de unos cuantos qe una vez en cada año traian sus pacotillas a estos mares. La agricultura estaba en su infancia $i$ de tal modo grabada, qe apénas producia lo necesario a la subsistencia de los cultivadores i sus familias. La clase proletaria era victima de la opresion de los dueños de las fincas, i el premio de su constante trabajo era una racion de ambre, qe empleaban las mas veces en satisfacer torpes vicios. Nuestras costas estaban perpetuamente cerradas a la concurrencia estranjera, $i$ todo lo qe se divisaba en nuestro interior era pobre, ignorante $i$ atrazado en todos sentidos.

Pero si del estado material del pais ascendemos a su cultura intelectual, encontrarémós qe su desenvolvimiento era ninguno, porqe aqella no existia sino en un círculo mui estrecho. Estaban cegadas las fuentes qe la dan vida, i se consideraba contrabando acreedor a severas penas la introdnccion de libros de cualqier jénero qe fuesen, pues qe la metrópoli tenia un interes directo en 
mantener oscurecida la mente de nuestros antepasados a fin de qe jamas conociesen el lugar qe como ombres estaban llamados a ocupar en el mundo, ya individualmente o como miembros de una futura nacion. Casi por demas está decir qe la única universidad i los poqísimos colejios qe existian solo contenian un número mui reducido de jóvenes qe los frecuentasen con el objeto de estudiar el idioma latino, la filosofía escolástica, la teolojía dogmática i la instituta de Justiniano, qe era lo mas a qe podia aspirar la juventud de aqellos pasados tiempos. Las ciencias exactas, las naturales i físicas ni aun por sus nombres eran conocidas, siendo el título de abogado o de doctor la única aspiracion de los qe se dedicaban al estudio. Verdad es qe ubo en aqel tiempo profesores de derecho de no poca lucidez, pero no debe esto causar admiracion si se atiende a qe este ramo de los conocimientos umanos era qizá el único qe se cultivaba por los qe concurrian a las aulas. La educacion primaria, qe es uno de los medios mas eficaces para difundir la ilustracion en la masa de la sociedad, no producia ninguno de sus buenos resultados, por la escasez de establecimientos destinados a este objeto, porla imperfeccion de los métodos de enseñanza i por la ignorancia de los profesores encargados de ella, qienes escasamente sabian coordinar bien las palabras.

El incompleto cuadro qe acabo de trazar tan a la lijera de la situacion de nuestro pais a principios del siglo presente, dará con facilidad a conocer qe no se encontraba preparado para someterse a un nuevo órden de cosas enteramente opuesto al a qe estuvo so. metido por espacio de tres siglos i bajo el cual desenvolvió su existencia. La revolucion del año de 10 no fué, pues, el efecto del estado floreciente de nuestra civilizacion i de nuestras costumbres, puesto qe estábamos cducados para jamas sacudir el yugo de la servidumbre, i porqe nuestra existencia política era nula, dependiendo, como dependfamos, del monarca español i sus tenientes. Sin embargo, en medio de la jgnorancia jeneral, existian algunas intelijencias elevadas qe alcanzaron a conocer qe era ya llegado el caso de aprovecharse de las turbulencias en qe estaba envuelta la metrópoli $\mathrm{i}$ de ir preparando poco a poco la realizacion del grandioso plan qe abian combinado. Pero abria, sin duda, avortado su enıpresa, sino ubieran procurado acer caminar por grados al pueblo, cuyas tradiciones lo apegaban tanto al pasado qe desterraba la voz sola de innovacion. Ventaja mui importante fué para los patriarcas de nuestra emancipacion el ferreo gobierno qe rejía al pais en 1810 , el cual tenia exasperados los ánimos, i en una situacion tan violenta, qe permitia tomarmedidas qe en otras circunstancias abrian sido enérjicamente rechazadas. 
Dado el grito por lus qe encabezaban el movimiento, se reunió el pueblo, $i$ tomó por primera vez una resolucion como autoridad; destituyó a su jefe, i nombró por si' mismo un gobierno, bien qe respetando siempre i dejando ilesa la majestad angusta a qien creian aun su natural soberano. Sin qe el pueblo se apercibiese de la tendencia de los acontecimientos qe pasaban a su vista, las personas qe lo dirijian formaron un proyecto de una especie de constitucion política titulado: Reglamento constitucional provisorio del pueblo de Chile, qe fué publicado el año de 11 i sometido a la suscripcion de todos los pueblos de la república para darle toda la respetabilidad qe podia apetecerse. Ignoro si recibió su debida sancion i si se promulgó como la lei suprema del estado, aunqe ai motivos de presumir qe no. Pero, apesar de esto, es curioso examinar este documento salido a luz en una época en qe la mayoría de la nacion creia. mui de buena fé qe el nuevo órden de cosas solo era una continuacion del anterior, i qe el nombramiento qe abia echo del nuevo gobernador era efecto exclusivo de las convulsiones en qe la España estaba envuelta i de la autoridad exótica qe se abia colocado a la cabeza de los destinos de aqel reino. La forma de gobierno establecida en el código a qe acabo de acer referencia era, a la verdad, mui difícil de definircon precision. Se reconoce en él el principio base del sistema democrático: la soberanía del pueblo, i se deja al mismo tiempo subsistente la autoridad del absoluto monarca qe asta entónces abia rejido a la nacion. Mal puede, pues, concebirse la-supremacía de la voluntad jeneral de lus asociados unida a la supremacía de la voluntad de un solo ombre, cuyos dictados debian cumplirse por no estar sujetos a la residencia de autoridad alguna superior. Al someterse al soberano español, le declaraban tácitamente en el goce de todas sus inmunidades $i$ prerrogativas $i$ aceptaban sus mandatos; pero al mismo tiempo establecian un Senado en qien el pueblo delegaba las mas preciosas atribuciones inerentes a la soberania, como imponer contribuciones, declarar la gnerra i acer la paz, acuñar monedas i otras igualmente importantes. Fácil era, pues, qe llegasen a estar en conflicto estas dos autoridades soberanas, sin qe la constitucion determinará cual de las dos deberia ser respetada con preferencia. i fácil es tanbien comprender los embarazos qe tal monstruosidad traeria consigo. Esta consideracion me disi:ulpa de incubar mas sobre este punto. bastándome, por otra parte. lo dicho para dar a conocer el primer paso qe dió entre nosotros el derecho constitucional.

Pero ántes de pasar adelante, arè notar qe en esta constitucion se encuentra establecida la garantía mas inapreciable del sistema liberal, aqella qe ace casi imposible la existencia del poder ab- 
soluto i la qe sin duda preparó el campo para qe arribásemos a la realizacion del sistema democrático representativo tal cual existe oi entre nosotros. Qiero ablar de la libertad de imprenta, libertad extranjera en nuestro suelo, puesto qe ántes de la época a qe me refiero ni aun se conocia en Chile el arte qe ocupa el primer rango entre los benéficos a la umanidad. Detenerme en acer la apolojía de esta institucion seria fatigar del modo mas inútil la atencion de la Facultad qe me escucha.

La revolucion seguia su marcha envuelta en sus ajitaciones consiguientes $i$ en medio de ella iba adqiriendo mas vigor el principio democrático. El año de trece aparecieron sin embozo los planes de los patriotas qe la dirijian; i para probarlo, daré una idea de un proyecto de constitucion qe en ese año salió a luz, el cual, como el anterior, no recibió la sancion correspondiente. En él se establece un gobierno constitucional representativo, electivo, alternativo i responsable, cuya autoridad no se derivaba de otro orijen qe del pueblo. La masa del poder público estaba confiada a dos cuerpos llamados Juntas Ć́vicas qe se dividian en Gubernativas i Jenerales, correspondiendo a las primeras la resolucion de los negocios del Estado, i a las segundas el nombramiento de todos los funcionarios. Abia tambien un tercer cuerpo, llamado Censura, encargado de vijilar sobre la observancia de las leyes, dirijir la educacion i la moralidad públicas, velar sobre la conducta de los empleados, $i$, en jeneral, ejercer un poder tutelar sobre toda la República, teniendo un voto suspensivo sobre los actos de las juntas gubernativas cuando tenian fuerza de lei. Las garantías del ciudadano, como la seguridad, la libertad individual, la propiedad $i$ la igualdad, estaban bien aseguradas en este proyecto deconstitucion i en él se acian nulas las enajenaciones de personas $i$ se destruia la odiosa division de fueros, jérmen fecundo de funestos males.

No a dejado de llamar mi atencion el preámbulo qe encabeza el proyecto de qe me ocupo, pues qe en él se alla desenvuelta la idea de un Congreso Jeneral Americano qe tenia por objeto consolidar el sistema de gobierno qe las provincias ántes españolas acababan de adoptar, demarcar los límites de las nuevas naciones, promover su felicidad i asegurar su soberanía. No es mi ánimo analizar esta cuestion, sino poner de manifiesto los fines inmediatos ge los caudillos de nuestra revolucion pensaban obtener de la reunion de tal congreso.

En tal situacion estaban las cosas, cuando la lucha de la independencia fué adversa a la causa de la libertad chilena. En octubre de 1814, sufrimos un contratiempo, i este contratiempo produjo por resultado la retrogradacion al antiguo sistema colo- 
nial. El espacio ge medió entre aqella fecha i el 12 de febrero de 1817, ocupa una pájina negra en la istoria de nuestra rejeneracion, i qiero ocultarla a mis miradas. Por tanto, continuaré mi narracion desde qe se volvió a anudar la cadena de los acontecimientos qe an contribuido a la organizacion política del pais.

El 8 de Agosto de 1818 salió a la luz pública un tercer proyecto de constitucion, qe tampoco fué promulgado como lei. No me ocuparé, pues, de él, asl como de ninguno de los qe en diversas épocas aparecieron despues, $i$ solo me limitaré a los qe fueron revestidos de la sancion de autoridad lejitima.

$\Lambda$ sta el $\mathbf{3 0}$ de Octubre de 1822, no salió otro código constitucional, pero en este dia apareció la primera Constitucion Políti tica del Estado de Chile. Pacificada en su mayor parte la nacion, i en aptitud el gobierno de entregarse a su arreglo interior, creyó de su deber convocar una convencion, la cual presentó al Ejecutivo la carta a qe acabo de aludir. En ella se ven desenvueltas casi en toda su estencion las formas representativas; aunqe, en verdad, gedaba ilusorio el principio de la soberanía popular. Para cerciorarnos de esto, fijémonos únicamente en la distribucion de la masa del poder público. Estaba confiado a tres cuerpos: el Ejecutivo, el Lejislativo i el Judicial, aunqe en sustancia todos se refundian en el primero. Porqe, veamos de donde emanan todos ellos. El Ejecutivo se componia de una sola persona, titulada Director, elejible por seis años i reelejible por cuatro, i nombrada por el Congreso; este estaba dividido en dos Cámaras; una de Diputados i utra de Senadores, la primera de las cuales èra elejida por el pueble en votacion indirecta por medio de electores i la segunda, en su mayoría, lo era por el Director. Por manera qe las autoridades, o eran nombradas exclusivamente por este, o influia de un modo positivo i directo en su nombramiento. Abia tambien otra Cámara llamada Corte de Representantes compuesta de siete individuos nombrados por la Cámara de Diputados i de todos los ex-Directores, cuyas atrihuciones eran: cuidar del cumplimiento de las leyes, convocar al Congreso en casos extraordinarios i ejercer provisoriamente el Poder Lejislativo durante el receso de las Cámaras. El poder judicial residia en dos cortes, una Suprema i otra de Apelaciones, nombradas por el Ejecutivo.

Luego qe el jeneral Freire ocupó la silla directorial, convccó un congreso constituyente para qe redactase una constitucion, cuyos trabajos fueron sancionados por el Gobierno Supremo el 29 de Diciembre de 1823. Esta carta lundamental conferia la autoridad pública a un Director,cuyas funciones duraban por cuatro años, pudiendo ser reelejido por otros cuatro, a un Senado, a una 
Cámara Nacional, a una Corte Suprema de Justicia i a una Corte de Apelaciones. Las atribuciones del primero estaban circunscritas a mui estrcchos límites, pues, aunqe tenia exclusivamente cl derecho de iniciativa, para li: mayor parte de los casos necesitaba de la concurrencia del cuerpo lejislativo, i para otros, de la del poder judicial. El segunto era un cuerpo compuesto de nueve índividuos qe funcionaban seis años, pudiendo ser indefinidamente reelejidus. No tenia derecho de iniciativa sino en dos épocas del año qe ámbas duraban un mes, pero toda lei necesitaba su sancion, correspondiéndole ademas un veto suspensivo de los actos ejecutivos del Directorio qe creyese perjudiciales. Cada año debia visitar un Senador algunas de las provincias del Estado, de múdo qe en tres años debia estar todo recorrido. Este funcionario tenia facultad de examinar por sf mismo el estado de la administracion pública en todos sus ramos, dando cuenta a qien correspondia i pudiendo suspender a los empleados qe creyesen no cumplian con sus deberes, miéntras se les formaba el juicio qe él mismo debia iniciar. La tercera se componia de cincuenta Consultores Nacionales, cuyo número jamas podia pasar de doscientos, i cliyas funciones duraban ocho años, renovándose por octavas partes en cada año. Se reunia momentáneamente solo cuando se la convocaba en virtud del veto senatorio o para ejercer algunas de las poqísimas facultades qe la constitucion le conferia. Abia tambien otra autoridad qe residia en las Asambleas nacionales i provinciales, de las qe las primeras tenian facultad para censurar o suspender a todos los funcionarios de la Nacion, de cualqier órden o jerargía qe fuesen, para presentar obispos i arzobispos, i en jeneral, para ser el fiscal de la conducta oficial de todos los deligados del pueblo; $i$ las segundas ejercian iguales atribuciones dentro del territorio de las provincias qe representaban. La parte judicial de esta constitucion es lo mas completo qe en este ramo tenemos estatuido entre nosotros, i es la qe rije en la actualidad. Pero este código, valiéndome de la expresion de un escritor moderno, solo era a propósito para gobernar un pueblo compuesto de ánjeles; $i$ era por consiguiente, un bello ideal cuya realizacion casi no es dable en sociedades umanas.

Desde el año de 1823 asta el 28 rijí la constitucion de qe acabo de ablar. Pero ya en esta época, las ideas abian tomado otro rumbo, i estaban mas fijas en cuanto al perfeccionamiento democrático representativo. Como la perfectibilidad constitucional es casi imposible, aunge la constitucion de 28 estaba mui conforme con los principios de la ciencia social, no satisfacia, sin embargo, las exijencias de la sociedad para qe fué dictada. Los tres 
poderes qe rejian al Estado estaban perfectamente en eqilibrio, $\mathbf{i}$ el Ejecutivo no lo era todo, como en la del año 22, ni el Senado, como en la de 23. Era precisa la concurrencia de todos tres para la formacion de toda lei, $i$ pocas eran las atribuciones peculiares de cada uno de ellos, atribuciones qe, aunqe se ejercian individualrnente, no eran de tal naturaleza qe pudiesen trastornar el órden público, ni propender a la perjudicial preponderancia de la autoridad a qien estaban confiadas. Por dicha constitucion, se restrinjió a cinco años la duracion del período de la Presidencia, a dos años el de la Cámara de Diputados i a cuatro el del Senado, debiendo renovarse la mitad de este en cada bienio. Establecia tambien otro cuerpo, llamado Asamblea Provincial, nombrado directamente por el pueblo, qe estaba encargado de importantes atribuciones, como: nombrar lus Senadores, proponer para Intendentes, Vice-Intendentes $\mathrm{i}$ jueces letrados, establecer municipalidades, distribuir las contribuciones entre los pueblos de la proviusia, tener bajo su inmediata inspeccion los establecimientos públicos dc educacion, beneficencia, etc. El derecho electoral estaba mui estendido, i eran mui accesibles los asientos en cualqiera de ámbas Cámaras Lejislativas.

Una disposicion se encuentra en esta carta, i qe no e encontrado en ninguna otra de las promulgadas en Chile, disposicion altamente benéfica al engrandecimiento i desarrollo de la industria agrícola, i qe qitaba uno de aqellos lunares mas resaltantes de nuestra Lejislacion. Ablo de los mayorazgos. Impugnar esta institucion, seria un trabajo qe me distraeria del objeto qe me e propuesto en este escrito, $i$ estaria por demas a causa de las palpables ventajas qe trae consigo su abolicion.

Aunqe esta constitucion se acerca mas qe otra alguna al ideal republicano, no por eso era la mas a propósito para la época en qe fué dictada. Si la nacion abia concluido la lucha de la independencia, no abian concluido, sin embargo, las luchas intestinas indispensables a una sociedad naciente. No estaba tampoco mui establecido el respeto a la autoridad; i por tanto, el poder ejecutivo necesitaba de mas fuerza para vigorizar su accion qe la qe la misma constitucion le conferia. Los resultados corroboraron por desgracia este antecedente. Las conjuraciones se sucedian unas a otras, sin qe el gobierno tuviera el suficiente prestijio ni medios de sofocarlas. Varios caudillos se disputaban el poder apoyados en la fuerza de sus bayonetas, i mas de una vez corrió la sangre chilena en esa lucha fratricida qe concluyó el 17 de Abril de 1830 en las llanuras de Lirtai. El vencedor en esa sangrienta refriega ocupó el mando supremo; i a los principios de su gobierno, conrocó una convencion para reformar la constitucion del año 28 
cuyos trabajos fueron sancionados el 25 de Mayo de 1833. Esta constitucion es la qe actualmente rije al Estado, i me ocuparé de ella con alguna extension.

E examinado mui rápidamentc la série de constituciones qe los diferentes gobiernos qe a tenido la república an dictade desde nuestra emancipacion política. Casi todas ellas son cuerpos informes, o mas bien, ensayos del futuro derecho constitucional chileno. $E$ procurado dar una lijera tintura de la marcha de éste en cuanto a la organizacion política del pais, sin detenerme en los demas puntos qe abraza lo qe propiamente se llama derecho constitucional. Paso aora a acer un análisis, aunqe incompleto e inexacto qizá, de la parte dispositiva de nuestra actual constitucion, cuya reforma es talvez urjente i ya a sido pedido por varios b́rganos de la opinion pública. No participo de los deseos de aqellos qe qisieran darle desde luego un golpe fatal; por el contrario, veo en ella el sábio código, el mas sábio qe pudo dictarse en la época en qe salió a luz, época en qe Chile estaba en una completa desorganizacion, i donde era preciso elevar un coloso, un poder fuerte i provisto de recursos abundantes para enfrenar la anarqía i poner en su lugar los resortes dislocados de la máqina social. Sin él, aun estariamos envueltos en las escandalosas luchas qe le precedieron, i no se abria podido arribar a la consolidacion delórden, ni a infundir en el pueblo el respeto a la autoridad, sin el cual es imposible la existencia de una sociedad civilizada. Juzgada la constitucion actual segun las prescripciones de la ciencia política, merece sin duda severos reproches $i$ es en su mayor parte defectuosa. Pero no es bajo este aspecto como debe considerársela. Las teorias de la ciencia social deben siempre subordinarse a las peculiares circunstancias del pais a qe se aplican; la tendencia de las instituciones políticas debe ser la felicidad i el perfeccionamiento de la comunidad, i el lejislador debe combinar, en cuanto le sea posible, en una constitucion liberal, el interes democrático qe encuentra en los echos, con el elemento democrático qe encuentra en la ciencia. Nuestra sociedad, pues, puede considerarse en un estado mui diferente qe en el qe se encontraba en 1833; i esta diferencia de situacion, ace tambien indispensable la diferente aplicacion de los principios de la ciencia política. En algunos puntos, conviene ampliarlos mucho mas todavía $i$ en otros, circunscribirlos a una esfera mas estrecha.

Aunqe el derecho de sufrajio está en nuestra constitucion vijente mas restrinjido qe en todas las anteriores, creo qe seria conveniente reducirlo aun mas. La jeneralidad del pueblo chileno se alla envuelto en la mas absoluta ignorancia, tanto de sus derechos sociales como políticos: su sufrajio es, por consigu!ente, 
perjudicial a la marcha progresiva de la comunidad. Los publicistas modernos, i en especial Sismondi, reconocen corno una verdad inconcusa, ge el sufrajio no debe ser efecto de la voluntad de la mayoría de los asociados, sino de las emanaciones de la razon nacional. Aora pues, llegando a los echos, es indisputable, sin duda, qe el derecho electoral solo debe conferirse entre nosotros a las personas ilustradas, qe al ménos sepan leer $\mathrm{i}$ escribir, qe posean una propiedad mayor qe la qe exije la constitucion, i qe les obligue a poner todos los medios de su parte para la conservacion del órden i de las garantías individuales, por el interes directo qe en ello deben tener. En jeneral, el qe, conociendo sus derechos, tenga su conciencia fuera del alcance del coecho $i$ de las sujestiones de una persona extraña, i qe a mas de esto, tenga necesidad de conservar, en su propio beneficio, las autoridades qe con su voto contribuye a establecer, solo merece el título de ciudadano activo i la participacion de los derechos inerentes a la soberanía. Si en alguna parte pueden tener aplicacion directa estos principios, es en Chile, donde los proletarios componen la mayoría de los sufragantes, i donde éstos están sujetos a tantas influencias cuantos son los medios de vivir qe tienen. En Norte América, cada ciudadano es elector i elejible; pero alli, todo ombre nace productor. Desde qe sus facultades físicas le permiten trabajar, el americano trabaja, i está por consiguiente, interesado en la conservacion del órden i de la lei qe le garantize este trabajo. No sucede asi en Chile. Dotados sus abitantes de una naturaleza poco activa i ménos industriosa, vejetan en la inaccion o en un trabajo mui pasivo una buena parte de su vida, sin curarse mucho de cultivar su intelijencia, ni de la conservacion de los derechos sociales; $i$ bien puede decirse, sin temor de ser desmentido, qe las dos terceras partes de los sufragantes actuales en las elecciones populares ni aun conocen la mision qe en tales actos están llamados a desempeñar. De aqi resulta como consecuencia uecesaria qe las elecciones entre nosotros no solo no son efecto de la razon nacional, sino qe ni aun lo son de la voluntad nacional, porqe no puede darse este nombre a la qe no es espontánea, ni emana de la conciencia individual de cada uno. Estas consideraciones me inducen, pues, a opinar por una reforma de nuestra constitucion a este respecto.

La organizacion del poder lejislativo me parece la parte mas completa de este código, aunqe ai ciertas atribuciones qe, siendo naturalmente anejas a él, están vinculadas en el Ejecutivo. No debe olvidarse lo qe e dicho poco á: qe las reformas qe aora indico son resultados de la situacion en qe en este momento se encuentra el pais, situacion qe permite eqilibrar los tres poderes 
mucho mas qe lo qe pudo acerse en la época en qe esta constitucion fue dictada. Asi pues: en la furmacion de las leyes no encuentro esa igudldad qe deberia existir entre las autoridades qe deben contribuir a furmarlas. Al Presidente de la República corresponde por la constitucion un veto qe podria llegar a ser funesto. Ninguna de la cámaras puede jmpedir sin mil trabas la sancion de cualqier proyecto de lei, puesto qe si una de ellas lo desecha o lo adiciona o corrije, pasa a la de su orfjen, i si esta insiste en su aprobacion, vuelve otra vez a la revisora, i su negatira no podrá tener efecto sino concurre la difícil mayoría de las dos terceras partes de sus miembros presentes. Esta es la parte qe la constitucion da a las cámaras lejislativas en la formacion de las leyes. Veamos aora la qe da al Presidente de la República. Si este desecha un proyecto de lei aprobado ya por ámbas cámaras, se tendrá por no propuesto, ni se podrá proponer en la sesion de aqel año; i si solo lo corrije o adiciona, es preciso qe estas correcciones o adiciones sean aprobadas por las dos cámaras para qe pueda promulgarse como lei; pues qe on el caso contrario, se tiene por no propuesto ni se puede proponer otra vez en el mismo año. De manera 'qe el Presidente tiene facultad constitucional para acer ilusorio cualqier acto lejislativo. El Presidente debe, a mi juicio, concurrir a la formacion de las leyes, pero de modo qe no pueda dejar burlados los acuerdos de la autoridad en qien esencialmente reside la potestad lejislativa. En nuestro pais, en qe el ejecutivo es sino por lei, al ménos de echo, el árbitro de las elecciones populares, esta facultad es tanto mas peligrosa, cuanto qe podria servir para acer nulas las cámaras qe alguna vez pudieran ser efecto de la voluntad espontánea de la mayoría, siempre qe estas estuviesen en choqe con las ideas o pretensiones qizá injustas del poder ejecutivo. Por lo demas, la constitucion de nuestro poder lejislativo es, segun creo, la mejora aplicacion qe pudiera acerse de la teoría a las circunstancias peculiares de la República.

No sucede lo mismo en cuanto al Ejecutivo. El está revestido de facultades qe le allanan mucho el camino ácia el despotismo i qe pueden convertirse en perjuicio de las libertades públicas. Tal es, por ejemplo, la de nombrar por sí, con acuerdo del Consejo de Estado, los ministros de la Corte Suprema de Justicia. Este tribunal, por las altas funciones qe ejerce, debe estar fuera de toda influencia del Ejecutivo qe tiene tantos medios de acer entrar en sus miras a las personas de qe necesita valerse. La independencia judicial es, por otra parte, la garantía mas preciosa del onor, vida i fortuna de los ciudadanos, i la lei debe asegurarla poniendo trabas al nombramiento de los individuos qe occpan los asientos de la majistratura. A este respecto merece imitarse lo qe dispone 
Ja liberal constilucion de los Estados-Unidos de Norte-América. Filla confia el nombramiento de los majistrados del tribunal superior al ejecutivo en consorcio con la cámara del senado. Se me dirá qe el Presidente de Chile necesita tambien de la propuesta del Consejo de Estado. Pero, en primer lugar, este cuerpo se compone de miembros nombrados esclusivamente por el Presidente pudiendo ser removidos a su voluntad, circunstancias ámbas qe no inducen mucha presuncion en favor de su independencia; $i$ en segundo, la misma constitucion concede al Ejecutivo facultad para conformarse o no con tal propuesta, i no faltarán en lo sucesivo cjemplos en qe se ponga en ejercicio este derecho en menoscabo del servicio público. A mas de qe, el Senado deriva su autoridad del pucblo i es un cuerpo qe, por sus facultades constitucionales, puede reg:ılarizar algun tanto la marcha del ejecutivo, i por tanto, inspira mas garantías qe otro cualqiera para la acertada eleccion de los ministros del Tribunal Supremo. ¿Por qé, pues, no abria de adoptarse el mismo trámite qe la constitucion designa para el nombramiento de arzobispo u obispo, respecto del de los respetables funcionarios del primer tribunal de la nacion? Si aqellos ocupan un lugar prominente en la jerarqia de los elevados funcionarios i pueden influir poderosamente en el bienestar espiritual de los miembros de la sociedad, no ocupa tampoco un Jugar ménos elevado ni ejerce una influencia menor en la felicidad temporal de los mismos asociados el cuerpo encargado de velar sobre la vicia i onrra de ellos i dar a cada uno lo qe le corresponde en justicia.

Otra de las facultades qe la constitucion confiere al Presidente de la República es la de conceder indultos pariculares con acuerdo del Consejo de Estado. Esta facultad, entendida en su sentido Jato, puede tracr, como a traido, funestas consecuencias en cuanto a la represion de los delitos. Ella se dirije a enervar la accion de los tribunales de justicia i a dejar muchas veces casi impunes a los criminales qe mas perjutican a la sociedad. Cierto es qe lo defectuoso de nuestra lejislacion penal ace indispensable la existen. cia de una autoridad a donde ocurrir para miligar sus rigores; pero esto debe entenderse con mucha economía. Debe, pues, restrinjirse a ciertos casos esta autorizacion tan ilimitada qe la constitucion da al Presidente de la República i no presenciar por mas tiempo el escándalo qe a cada paso se ofrece a nuestra vista de tener una tercera instoncia, qe ya se a convertido en ordinaria, toda causa criminal. Porqe el echo es qe rarisfma sentencia pronunciada por la corte suprema en es'a clase de juicios se lleva a efecto en los mismos términos qe aqel tribunal la pronunció. Pero lo peor del caso es el pernicioso efecto moral qe esta práctica pro- 
duce. Por cste medio se an conferido al Poder Ejecutivo facultades qe son esclusivamente privativas del Supremo poder judicial, trastornando de este modo el órden constitucional. Estas poderosas consideraciones acen desear vivamente qe se circunscriba a mui estrechos límites i a determinados casos la atribucion de indultar otorgada por la Carta al Presidente de la República.

Donde resalta mas la necesidad de la reforma, es en la facultad qe este tiene para declarar uno a varios puntos de la nacion en estado de silio i de ser investido por el Congreso de facultades estraordinarias. Estando la República en estado de sitio, se suspende el ejercicio de la constitucion i de las leyes i el Ejecutivo es el árbitro i supremo lejislador de la nacion. Santa i justa era esta facultad cuando fue preciso formarlo todo i cuandu la autoridad, para acerse respetar, neces taba del poderoso ausilio de medios absolutos e ilimitados, sin qe nadie pudiera coartarlos. para conservar su existencia i no ser víctima de las oscilaciones i frecuentes revueltas políticas. Pero, pasada tiempo a esa época, sólidamente establecido el prestijio de la autoridad i la obediencia a la constitucion $i$ las leyes, $i$ morijeradas asta cierto punto las costumbres sociales de las masas, esta disposicion a l'egado a ser perjudicial. No concibo, pues, caso alguno probable en la actualidad i en lo sucesivo en qe sea preciso recurrir a estos arbitrios sin qe aya un inminente riesgo de desqiciar por su base la armonía social. Elevado al poder un caudillo ambicioso, uno de aqellos qe de cuando en cuando suelen aparecer en la escena política como azote de los pueblos qe tiene la desgracia de ser rejidos por ellos, puede, pues, decir constitucionalmente: calle la prensa, callen las leyes, solo mi volontad impere. I no nos alucinemos con la traba qe la misma constitucion pone al ejercicio de esta facultad de necesitar del acuerdo del consejo de estado, porqe este cuerpo, qe segun la misma constitucion debe ser echura suya, se compondrá entónccs de ombres qe no arán otra cosa qe segundar sus planes liberticidas i obedecer ciegamente sus caprichos. Encarecer la necesidad de abolir los artículos constitucionales qe se refieren a este punto, sobre ser una tarea inoficiosa, seria tambien acer una ofensa al buen sentido qe reclama urjentemente qe se qite de la carta fnndamental el lunar qe mas la afea. En su lugar, creo seria conveniente, autorizar al Gobierno para qe pueda declarar uno - mas puntos de la República en estado de sitio, pero suspenciiéndose la Constitucion i la Lei en lo qe sea preciso para conservar la tranqilidad pública. Esta moderada facultad satisfaria las exijencias de los qe,yisieran dar al Ejecutivo un brazo de ierro, i las de los qe se espantan con las sombras de las probabilidades de despotismo.

Paso aora a ocuparme de los Ministros del despacho. Estos fun- 
cionarios desempeñan un rol mui principal en la administracion i gobierıo de la República. Partes integrantes del Ejecutiro, es prec'so su concurrencia para qe este pueda existir i para qe el jefe de la Na ion dicte la providencia mas insignificante, puesto qe sin la firma de aqellos ninguna puede ser obedecida por individua ni autoridad alguna del Estado. Esta importante participacion qe ellos tienen del poder público los coloca en situacion de irrogar grandes males tanto a la comunidad como a personas determinadas, i por consiguiente, parece nalural qe estén sujetos a una fácil residencia por loz abusoz qe puedan cometer en el ejercicio de la autoridad qe les está confiada. Peru ai ciertos crímenes, cımo la traicion, malversacion de fondos púb icos, soborno, infraccion de Ia constitucion, u otros igualmente graves, qe deberian producir accion popular porqe atacan directamente a la sociedad en masa. Sin embargo, la constitucion ace casi imposib'e la efectividad de la responsabiiidad ministerial en estos casos, porqe so!o concede a la Cámara de Diputados la facultad de acusarlos cuando incurran en los delitos $q$ a acabo de mencionar. Bien se conocen los mil medios qe un ministro tiene para captarse la mayoría de una Cám 1ra, mucho mas cuando se trata de un asınto qe como este. influye tan personal i directamente en él. Pero aun ai mas; qizá podrá ser algun tanto disculpable esta facult id esclusiva conferida a la Cámara de Diputados; mas en tal caso deberia acerse fácil i espedita la tramitacion de la acusacion, pues de la manera qe está establecida, se ace punto ménos qe impcsible la represion de los mencionados delitos cuando son cometidos por un ministro. ¿A qé nombrar dos comisiones tan numerosas para qe informen una acerca de si á o no lugar a examinar la proposicion de acusacion i otra acerca de si debe o no acerse dicha acusacion? Pero aun e to seria poco. Manda tambien la constituc on qe declarando la Cámara de Diputados aber lugar a la acusacion, deben nombrarse tres individuss de su seno para qe la prosigan ante el Senado qien debe pronunciar su fallo discrecional absolviendo o condenando al acusado. ¿Para qé este tribunal de escepcion? No son suficientemente íntegros los qe juzgan a los demus ciudadanos? I si no lo son ¿por qé se les deja subsistentes? Son ménos importantes el onor $i$ vida de todos los demas altos funcionarios i de un m:embro cualqiera de la sociedad, qe el mismo onor i vida de un Ministro del Despacho, para qe se someta a estos a un tribunal qe la Constitucion supone mas recto i mas intachable qe los demas existentes? Esta complicacion de procedimientos no importa otra cosa qe acer ilusoria la residencia de los ministros cuando se trate de los graves delitos públicos de qe e echo arr.ba referenc a. ofor $^{\circ}$ qé, pues, rio se a de observar en rsta clase de delitos el mismo 
órden de proceder qe la constitucion establece para el caso en qe un individuo privado acuse a un ministro por razon dg los perjuicios qe este pueda aberle inferido injustamente por algun acto del ministerio? Qél ¿merece mas facilidades la acusacion i competente castigo de un crimen qe solo perjudica a un solo individuo, qe aqel qe ataca directamente a la sociedad, como la malversacion de caudales públicos? No puedo darme cuenta de tal aberracion, ni de la causa ostensible qe pudo servir de base a tal disposicion.

Concluiré este lijero análisis de nuestras constituciones políticas, diciendo dos palabras sobre la organizacion del poder municipal. Entiendo qe las municipalidades, segun están establecidas en la Constitucion, son unos cuerpos cuya benéfica influencia poco puede acerse sent $r$ en los departamentos qe representan, porqe no tienen libertad de accion, porqe no pueden llevar a efecto por sí solas ninguna de las reformas qe intenten de lo qe está establecido. La mayor parte de sus facultades están circunscritas a la inspeccion de establecimientos o trabajos públicos, i lo qe salga de esta esfera, necesita de la aprobacion del Presidente de la República. Jamas convendré, porqe no puede ser, en qe las municipalidades sean independientes del Poder Ejecutivo de qiea bon una ram', pero tambien creo qe deben ser una especie de cámaras provinciales a qe competan otras atribuciones mas latas qe las qe aora tienen i qe puedan proceder por sí entodo aqello qe no tenga una importancia vital para el depurtamento a qien representan, debiendo en este caso obtener sus deliberaciones la sancion ejecutiva.

Asta aqi e concluido mi propósito. Vasto es el campo qe ofrece el asunto qe e elejido para esta memoria, pero vastos son tambien los conocimieutos qe necesita el qe qiera ocuparse estensamente de él. Solo me e limitado a iniciar, dejando a otro la tarea de esplanar ilustradamente las pocas ideas qe e acumulado en este. escrito, o de notar cualesqiera otros defectos de qe sin duda adolecerá la constitucion qe nos rije i qe se an escapado a mi exámen. Pero la materia es mui delicada i reqiere un tacto mui fino para qe pueda tratársela como es debido i produzca un resultado farorable en vez de pernicioso. 
